This document was prepared in conjunction with work accomplished under Contract No. DE-AC09-96SR18500 with the U. S. Department of Energy.

\title{
DISCLAIMER
}

This report was prepared as an account of work sponsored by an agency of the United States Government. Neither the United States Government nor any agency thereof, nor any of their employees, nor any of their contractors, subcontractors or their employees, makes any warranty, express or implied, or assumes any legal liability or responsibility for the accuracy, completeness, or any third party's use or the results of such use of any information, apparatus, product, or process disclosed, or represents that its use would not infringe privately owned rights. Reference herein to any specific commercial product, process, or service by trade name, trademark, manufacturer, or otherwise, does not necessarily constitute or imply its endorsement, recommendation, or favoring by the United States Government or any agency thereof or its contractors or subcontractors. The views and opinions of authors expressed herein do not necessarily state or reflect those of the United States Government or any agency thereof. 
WSRC-TR-2003-00331

December 31, 2004

\section{MULTIPLE LINES OF EVIDENCE SUPPORTING NATURAL ATTENUATION: LINES OF INQUIRY SUPPORTING MONITORED NATURAL ATTENUATION AND ENHANCED ATTENUATION OF CHLORINATED SOLVENTS}

December 31, 2004

Westinghouse Savannah River Company

Savannah River Site

Aiken, SC 29808

Prepared for the United States Department of Energy under Contract No. DE-AC09-96-SR18500 
WSRC-TR-2003-00331

December 31, 2004

This report was prepared by Westinghouse Savannah River Company (WSRC) for the United States Department of Energy (DOE) under Contract No. DE-AC0996-SR18500 and is an account of work performed under that contract. Every effort was made by the authors to assure the accuracy of the contents and interpretation. However, neither the DOE, nor WSRC, nor any of their employees makes any warranty, express or implied, or assumes any legal liability or responsibility for the accuracy, completeness, or usefulness of any information, apparatus, or product, or process disclosed herein, or represents that its use will not infringe privately owned rights. Reference herein to any specific commercial product, process, or service by trademark, name, manufacturer, or otherwise does not necessarily constitute or imply endorsement, recommendation, or favoring of same by the United States Government or any agency thereof. The views and opinions of the authors expressed herein do not necessarily state or reflect those of the United States Government or any agency thereof. 
WSRC-TR-2003-00331

December 31, 2004

\title{
MULTIPLE LINES OF EVIDENCE SUPPORTING NATURAL ATTENUATION: LINES OF INQUIRY SUPPORTING MONITORED NATURAL ATTENUATION AND ENHANCED ATTENUATION OF CHLORINATED SOLVENTS
}

\author{
Lead Author \\ Todd H. Wiedemeier, P.G. \\ T.H. Wiedemeier \& Associates, LLC
}

Contributing Authors

Michael J. Barden and W. Zachary Dickson

T.H. Wiedemeier \& Associates, LLC

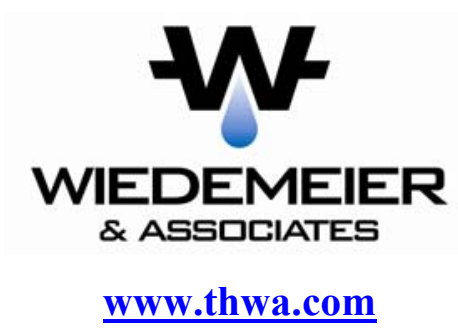

And

David Major, PhD., P.E.

GeoSyntec, Inc. 


\section{OVERVIEW}

The Department of Energy (DOE) is sponsoring an initiative to facilitate efficient, effective and responsible use of Monitored Natural Attenuation (MNA) and Enhanced Attenuation (EA) for chlorinated solvents. This Office of Environmental Management (EM) "Alternative Project," focuses on providing scientific and policy support for MNA/EA. A broadly representative working group of scientists supports the project along with partnerships with regulatory organizations such as the Interstate Technology Regulatory Council (ITRC) and the United States Environmental Protection Agency (USEPA). The initial product of the technical working group was a summary report that articulated the conceptual approach and central scientific tenants of the project, and that identified a prioritized listing of technical targets for field research. This report documented the process in which: 1) scientific ground rules were developed, 2) lines of inquiry were identified and then critically evaluated, 3) promising applied research topics were highlighted in the various lines of inquiry, and 4) these were discussed and prioritized. The summary report will serve as a resource to guide management and decision making throughout the period of the subject MNA/EA Alternative Project. To support and more fully document the information presented in the summary report, the DOE is publishing a series of supplemental documents that present the full texts from the technical analyses within the various lines of inquiry (see listing). The following report - documenting our evaluation of the state of the science for the lines of evidence for supporting decision-making for MNA-- is one of those supplemental documents.

\section{Summary Report:}

Natural and Passive Remediation of Chlorinated Solvents: Critical Evaluation of Science and Technology Targets, WSRC-TR-2003-00238

\section{Supplemental Documents:}

Baseline Natural Attenuation Processes: Lines of Inquiry Supporting Monitored Natural Attenuation of Chlorinated Solvents, WSRC-TR-2003-00329

Potential Enhancements to Natural Attenuation: Lines of Inquiry Supporting Enhanced Attenuation of Chlorinated Solvents, WSRC-TR-2003-00330

\section{Multiple Lines of Evidence Supporting Natural Attenuation: Lines of Inquiry Supporting Monitored Natural Attenuation and Enhanced Attenuation of Chlorinated Solvents, WSRC-TR-2003-00331}

Potential Enhancements to the Characterization and Monitoring of Natural Attenuation: Lines of Inquiry Supporting Monitored Natural Attenuation and Enhanced Attenuation of Chlorinated Solvents, WSRC-TR-2003-00332

Historical and Retrospective Survey of Monitored Natural Attenuation: A Line of Inquiry Supporting Monitored Natural Attenuation and Enhanced Attenuation of Chlorinated Solvents, WSRC-TR-2003-00333 
Historically, the recognition, evaluation and reliance on natural processes for remediation and final polishing of contaminated sites has been problematic. Over the past fifteen years, however, significant progress has been made due to the efforts of regulatory and federal agencies such as the United States Environmental Protection Agency (USEPA), the Department of Defense (DOD), and others. This progress has taken the form of regulatory protocols and case studies resulting from the evaluation of monitored natural attenuation (MNA) at multiple sites. One area being explored under this program is the concept of multiple lines of evidence. Possible enhancements and improvements to the existing guidance for collecting multiple lines of evidence to support decision-making for MNA will be explored and evaluated. Currently, direct measurement of attenuating processes is technically challenging which necessitates that a preponderance, or "quorum," of evidence be collected to evaluate the efficacy of MNA. The people that review and approve MNA must establish the definition of an acceptable quorum. During this project, the team will evaluate and, if deemed feasible, develop a paradigm that includes some of the spatial process mapping and other items highlighted in the National Academy of Science review (National Research Council, 2001) of the USEPA protocol (USEPA, 1998). The team will also evaluate the concept of a responsive characterization process based on conditional rules. For example, based on biogeochemical processes there is no need to measure reduced gases at aerobic sites.

Using the concept of natural attenuation capacity with its multiple processes, one must be able to evaluate which of these processes are occurring and to what extent. Because there are multiple processes that cause natural attenuation, it is important to identify the predominant processes occurring within the system. Then a "quorum of evidence" is assembled to understand the extent and rate at which these processes are occurring and if they are sustainable to handle the loading of contaminants into a given "treatment zone." If the processes are not sufficient or sustainable, then data needs to be collected to evaluate if there are ways to manipulate the system to make them sustainable. The difficulty lies in the ability to measure these processes. To measure these processes, indirect methods are typically employed. The data collected through the multiple lines of evidence approach allows the technical person to evaluate the relative importance of each attenuation mechanism and to identify the predominant attenuation mechanism, as necessary. The concept of multiple lines of evidence compliments the process of determining the sustainability of MNA followed up by identification of EA techniques when the system is not self-sustaining, or when MNA alone is not acceptable to the public or the appropriate regulatory agencies.

The use of multiple lines of evidence has been documented by the USEPA in both the Office of Solid Waste and Emergency Response (OSWER) Directive 9200.4-17 (USEPA, 1999) and the Technical Protocol for Evaluating Natural Attenuation of Chlorinated Solvents in Groundwater (USEPA, 1998). Multiple distinct but converging lines of evidence, in various forms have been used in recent years to evaluate natural attenuation (National Research Council, 1993; Wiedemeier et al. 1995, 1996a, and 1999, USEPA, 1998 and 1999, and American Society for Testing and Materials [ASTM], 1998). The USEPA identified three lines of evidence to evaluate natural attenuation. These are: 1) historical groundwater/soil chemistry data to evaluate contaminant mass loss over time (flux), 2) hydrogeologic and geochemical data to evaluate the 


\section{WSRC-TR-2003-00331}

December 31, 2004

type and rate of degradation processes occurring at the site that may reduce contaminant concentrations, and 3) field or microcosm studies which directly demonstrate the occurrence of a specific biological attenuation process. The guidance in the OSWER Directive is intended to build a preponderance of evidence starting with the first line of evidence and progressing through the third line of evidence as needed to provide adequate and conclusive evidence that natural attenuation is occurring at a rate sufficient that is protective of human health and the environment. The guidance in the USEPA technical protocol provides detailed guidance for implementing the OSWER Directive, specifically for evaluation of biological degradation of chlorinated solvents, including a comprehensive list of analytes for analysis.

The most promising enhancements to the current "lines of evidence" concept, as identified by USEPA, are:

- inclusion of analyses to evaluate abiotic degradation as a process causing the natural attenuation of chlorinated solvents;

- inclusion of volatile fatty acid (VFA) analyses to show that compounds capable of fermenting to hydrogen are available for reductive dechlorination;

- inclusion of the molecular tools for bioassessment into the degradation processes analyses; and

- inclusion of additional logic to help organize and select among the analyses identified by the USEPA in the Technical Protocol document (USEPA, 1998).

Recent advances in the understanding of the degradation of chlorinated solvents show that abiotic reactions can be important in some systems. Thus, inclusion of the analyses that lead to a determination of whether abiotic processes have a prominent role in natural attenuation is warranted. New molecular tools, as discussed in the molecular tool section of this document, have added greater capabilities for the analyses of microbes associated with natural biodegradation processes. These are discussed and included as tools for use in developing the lines of evidence. Please note that these analyses are not required, nor are they recommended, for every site where MNA is being evaluated. The additional analyses proposed in this document are intended to be used only at those sites where the dominant attenuation mechanism cannot be ascertained using the analytes described in the USEPA technical protocol for evaluating the natural attenuation of chlorinated solvents (USEPA, 1998).

The third enhancement of adding logic to analyses for determining degradation processes associated with natural attenuation will help the technical person proceed with the characterization of natural attenuation processes in a systematic manner. Because direct measurements are often not available to define the operative attenuation processes, it is not intuitive how the long list of analyses identified in available protocols is to be used and interpreted. "Why are the data being collected?" "How should the data be interpreted?" "What of the optional parameters should be collected?" The purpose of creating the logic is to help the technical person to evaluate the data that is collected and determine how to proceed. This is an area not discussed within. It is an area warranting additional work. 


\section{WSRC-TR-2003-00331}

December 31, 2004

\section{REFERENCES}

American Society of Testing and Materials (ASTM), 1998, Guide for Remediation by Natural Attenuation at Petroleum Release Sites: ASTM Philadelphia, PA.

National Research Council, 1993, In Situ Bioremediation, When Does it Work?: National Academy Press, Washington, D.C., 207 p.

National Reseach Council, 2001, Natural Attenuation for Groundwater Remediation, National Research Council, Committee on Intrinsic Remediation: National Academy Press, Washington, D.C.

US Environmental Protection Agency (USEPA), 1998, Technical protocol for evaluating natural attenuation of chlorinated solvents in ground water, EPA/600/R-98/128: Office of Research and Development, U.S. Environmental Protection Agency, Washington, D.C., p. 232.

US Environmental Protection Agency (USEPA), 1999, Use of Monitored Natural Attenuation at Superfund, RCRA Corrective Action, and Underground Storage Tank Sites, Final: Office of Solid Waste and Emergency Response. April 21. Directive Number 9200.4-17P.

Wiedemeier, T.H., Wilson, J.T., Kampbell, D.H., Miller, R.N., and Hansen, J.E., 1995, Technical protocol for implementing intrinsic remediation with long-term monitoring for natural attenuation of fuel contamination dissolved in groundwater: US Air Force Center for Environmental Excellence, San Antonio, Texas.

Wiedemeier, T.H., Swanson, M.A., Moutoux, D.E., Wilson, J.T., Kampbell, D.H., Hansen, J.E., and Haas, P., 1996a, Overview of the Technical Protocol for Natural Attenuation of Chlorinated Aliphatic Hydrocarbons under Development for the U.S. Air Force Center for Environmental Excellence: EPA/540/R-96/509, p. 35-59.

Wiedemeier, T.H., Rifai, H.S., Newell, C.J., and Wilson, J.T., 1999, Natural Attenuation of Fuel Hydrocarbons and Chlorinated Solvents, John Wiley and Sons, New York, New York. 
WSRC-TR-2003-00331

December 31, 2004

\section{Multiple Lines of Evidence Used to Evaluate Natural Attenuation and Enhanced Remediation of Chlorinated Solvents}

Prepared by:

Todd H. Wiedemeier, P.G., Michael J. Barden, and W. Zachary Dickson

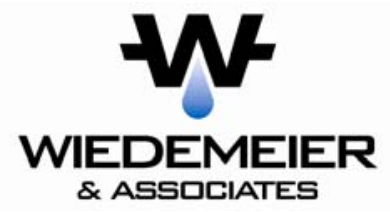

www.thwa.com

Contibuting Author:

Dave Major, P.E., GeoSyntec, Inc. 
WSRC-TR-2003-00331

December 31, 2004

This report is a work prepared for Westinghouse Savannah River Company and the United States Department of Energy by T.H. Wiedemeier \& Associates, LLC. In no event shall either Westinghouse Savannah River Company, the United States Government, or T.H. Wiedemeier \& Associates, LLC have any responsibility or liability for any consequences of any use, misuse, inability to use, or reliance upon the information contained herein, nor do any of these parties warrant or otherwise represent in any way the accuracy, adequacy, efficacy, or applicability of the contents hereof. 
WSRC-TR-2003-00331

December 31, 2004

\section{TABLE OF CONTENTS}

Page

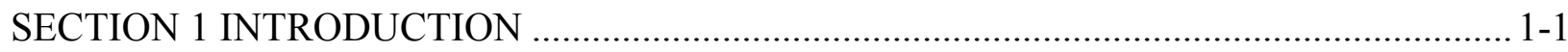

1.1 Lines of Evidence Used to Evaluate Natural Attenuation .............................................. 1-1

1.2 Data Required to Evaluate Natural Attenuation …….............................................. 1-4

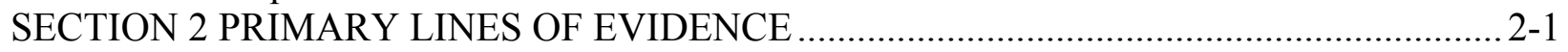

2.1 Contaminant Concentration Data......................................................................... 2 -

2.1.1 Graphical Evaluation of Plume Behavior ..................................................2-2

2.1.2 Statistical Methods for Evaluating Plume Behavior ...................................... 2-6

2.1.2.1 Nature of Groundwater Concentration Data and Appropriate Statistical Methods .................................................................... 2-8

2.1.2.2 Tests for Trend .................................................................... 2-9

2.1.2.3 Tests for Differences Between Groups of Data ......................... 2-17

2.1.2.4 Using Statistical Results ……………………..........................2-19

2.2 Contaminant/Daughter Product and Geochemical Data ............................................. 2-24

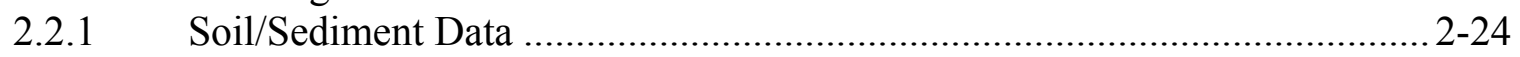

2.2.1.1 Total Organic Carbon ………………………........................ 2-25

2.2.1.2 Field Observation of Iron Minerals............................................ 2-25

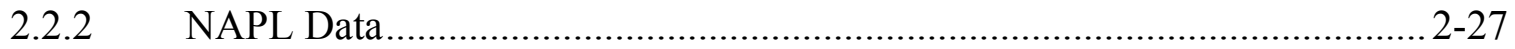

2.2.3 Groundwater Analytical Data ……………............................................2-2 2-27

2.2.3.1 Daughter Products.................................................................... 2-27

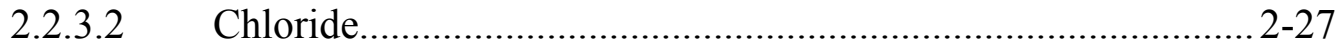

2.2.3.3 Dissolved Oxygen ............................................................. 2-28

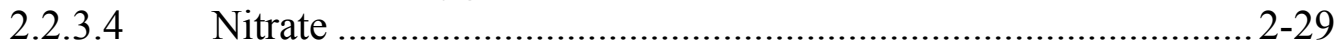

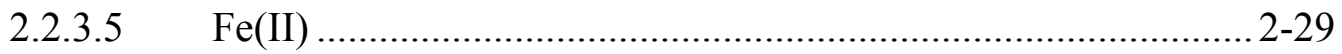

2.2.3.6 Sulfate and Sulfide............................................................... 2-29

2.2.3.7 Methane ........................................................................... 2-30

2.2.3.8 Ethene/Ethane ................................................................ 2-30

2.2.3.9 Acetylene .......................................................................... 2-30

2.2.3.10 Oxidation-Reduction Potential.................................................2-30

SECTION 3 SUPPLEMENTAL LINES OF EVIDENCE …….............................................. 3-1

3.1 Supplemental Groundwater Geochemical Data ....................................................... 3-1

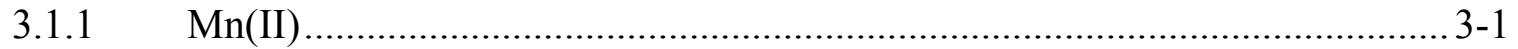

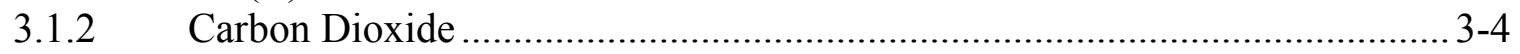

3.1.3 Alkalinity ........................................................................................

3.1.4 Dissolved Inorganic Carbon..................................................................... 3-4

3.1.5 Major and Minor Ions .......................................................................... 3-5

3.1.6 Dissolved Hydrogen........................................................................ 3-5

3.1.7 Dissolved Organic Carbon ....................................................................... 3-7

3.1.8 Volatile Fatty Acids (VFAs) ..................................................................... 3-8 
WSRC-TR-2003-00331

December 31, 2004

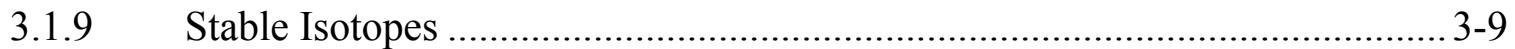

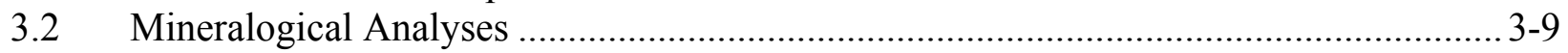

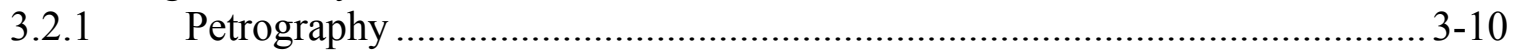

3.2.2 Wet Chemistry Techniques .................................................................... 3-12

3.2.3 X-Ray Diffraction ...............................................................................

3.2.4 X-Ray Fluorescence......................................................................... 3-14

3.2.5 Electron Microprobe Analysis …………............................................... 3-14

3.2.6 Mass Magnetic Susceptibility Analysis ………......................................... 3-15

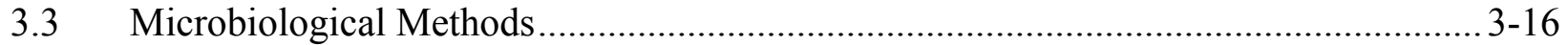

3.3.1 Microcosm Studies........................................................................... 3-16

3.3.2 Phospholipid Fatty Acids (PLFA) ......................................................... 3-16

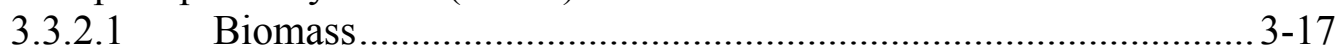

3.3.2.2 Community Structure ........................................................... 3-17

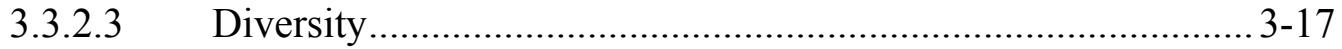

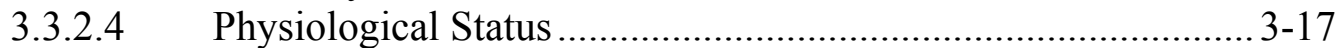

3.3.2.5 Example PLFA Analysis.......................................................3-19

3.3.3 Denaturing Gradient Gel Electrophoresis .....................................................3-23

SECTION 4 DEDUCING GEOCHEMICAL ENVIRONMENTS AND DEGRADATION

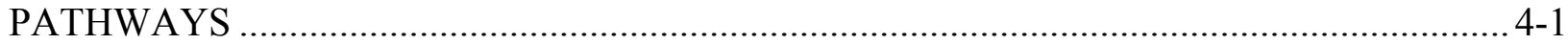

4.1 Type 1 Environment: Systems that are Anaerobic Due to Anthropogenic Carbon......... 4-2

4.2 Type 2 Environment: Systems that are Anaerobic Due to Naturally-Occurring

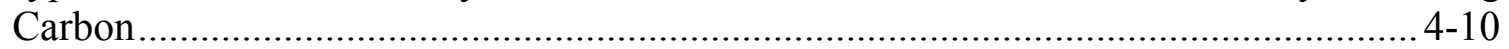

4.3 Type 3 Environment: Aerobic Systems Due to Lack of Fermentation Substrates ....... 4-10

4.4 Mixed Environments......................................................................................... 4-11

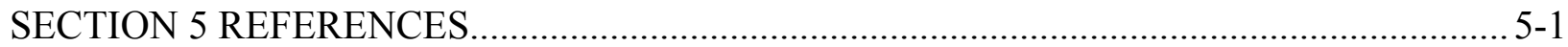


WSRC-TR-2003-00331

December 31, 2004

\section{LIST OF TABLES}

Table 1.1 Summary of the Lines of Evidence Used to Evaluate Natural Attenuation and Enhanced Remediation

Table 1.2 Aquifer and Soil/Sediment Data Required to Evaluate Natural Attenuation and Enhanced Remediation.

Table 1.3 Groundwater Data Required to Evaluate Natural Attenuation and Enhanced Remediation

Table 2.1 Example Calculation of the Mann-Kendall Statistic for TCE Concentrations in a Monitoring Well with Ten Sampling Events.

Table 2.2 Table of Null Probabilities for the Mann-Kendall Statistic, $\mathrm{n}=4$ through 20 ......... 2-12

Table 2.3 Example Calculations for the Wilcoxon Signed-Rank Test Comparing Groups of Paired Data for A) Quarterly Concentration Data in a Single Monitoring Well for Two Years $(\mu \mathrm{g} / \mathrm{L})$, and B) Concentrations in Several Monitoring Wells for Two Years $(\mu \mathrm{g} / \mathrm{L})$

Table 2.4 Critical Test Statistic Values for the Signed-Rank Statistic W', $\mathrm{n}=4$ through 20

Table 3.1 Supplemental Groundwater Data for Evaluating Natural Attenuation and Enhanced Remediation

Table 3.2 Range of Hydrogen Concentrations for a Given Terminal Electron-Accepting Process

Table 3.3 Supplemental Soil/Sediment Data for Evaluating Natural Attenuation and Enhanced

Remediation

Table 3.4 Description of PLFA Structural Groups .....

Table 3.5 Viable Microbial Biomass Expressed as Picomoles of PLFA per mL of Sample and as Cells per $\mathrm{mL}$ of Sample, Fatty Acid Structural Groups as Percent of Total PFLA, and Physiological Status Biomarkers as Mole Ratio

Table 4.1 General Characteristics of the "Type" Geochemical Environments

Table 4.2 Matrix Showing Some of the Potential Geochemical Environments Encountered in the Terrestrial Subsurface and the Impact of These Environments on the Fate of Chlorinated Ethenes..... 
WSRC-TR-2003-00331

December 31, 2004

\section{LIST OF FIGURES}

Figure 2.1 Isopleth Maps of Total VOC Concentrations in Groundwater at the Depth of Highest Contaminant Concentration...................................................................... 2-3

Figure 2.2 Sampling Locations for the Plots of Contaminant Concentration versus Time and Distance Downgradient Presented in Figure 2.3 ………….............................. 2-4

Figure 2.3 Plots of Contaminant Concentration versus Time and Distance Downgradient ................................................................................................ 2-5

Figure 2.4 Solute Plume Behavior Illustrated by Concentration Trends over Time for Monitoring Points in the Vicinity of the Source, Mid-Plume, and the Distal Portion of the Plume.

Figure 2.5 Photograph of Reduced and Oxidized Iron Minerals ............................................ 2-26

Figure 3.1 Biomass Content Presented as Total PLFAs ........................................................ 3-20

Figure 3.2 Relative Percentages of PLFA Structural Groups. Table 3.4 Describes the Various Structural Groups............................................................................. 3-21

Figure 3.3 Microbial Physiological Stress Markers............................................................. 3-24

Figure 4.1 Conceptual Model of Type 1 Environment for Chlorinated Solvent Plumes Due to a PCE and TCE Release............................................................................... 4-8

Figure 4.2 Conceptual Model of Type 3 Environment for Chlorinated Solvent Plume Due to a PCE and TCE Release.

Figure 4.3 Conceptual Model of Type 3 Environment for Chlorinated Solvent Plume with VC and 1,2-DCA.

Figure 4.4 Conceptual Model of Mixed Environments with Type 1 Environment in the Source Zone and Type 3 Environment in the Downgradient Portion of the Plume

Figure 4.5 Conceptual Site Model of Mixed Type 3/Type 1/Type 3 Environments ................. 4-15

Figure 4.6 Conceptual Model of a Plume Discharging to Surface Water ................................ 4-16

Figure 4.7 Example of a Plume that Grades from a Type 1 Environment with Dehalorespiration into a Type 1 Environment with Abiotic Degradation into a Type 3 Environment 
WSRC-TR-2003-00331

December 31, 2004

\section{SECTION 1}

\section{INTRODUCTION}

Multiple distinct and converging lines of evidence, in various forms have been used in recent years to evaluate natural attenuation and bioremediation (e.g., National Research Council [NRC], 1993; Wiedemeier et al. 1995, 1996a, and 1999; United States Environmental Protection Agency [USEPA], 1998 and 1999; and American Society for Testing and Materials [ASTM], 1998). By extension, many of these lines of evidence are useful for evaluating the effectiveness of enhanced remediation. The focus of this document is on the meaning and use of the lines of evidence for determining the efficacy of natural attenuation and enhanced remediation of chlorinated solvents.

\subsection{LINES OF EVIDENCE USED TO EVALUATE NATURAL ATTENUATION}

The "lines of evidence" used to evaluate natural attenuation are the different types of data that provide evidence for contaminant degradation and allow for quantification of the processes of natural attenuation. The most common lines of evidence include historical trends in contaminant data showing plume behavior and/or loss of contaminant mass over time, analytical data showing that geochemical conditions are suitable for degradation of the constituents of concern, and data that support the occurrence of biological or abiotic degradation. The use of these different types of data provide a weight of evidence for the actual or potential efficacy of natural attenuation. The three lines of evidence commonly used to evaluate natural attenuation are:

1) Contaminant concentration data demonstrating a reduction in concentration and/or loss of mass at the field scale;

2) Geochemical data providing an indication of whether conditions are favorable for contaminant degradation (biological or abiotic) and a signature of those process; and

3) Laboratory data providing evidence of degradation.

Each of these lines of evidence include a variety of different parameters that will vary depending upon the specific contaminants involved and the natural attenuation processes that are important for those contaminants. Additionally, the "weight of evidence" needed to evaluate natural attenuation at any given site typically will depend upon the site-specific understanding of the behavior of the contaminants involved.

In the case of chlorinated solvents, the geochemical environment is fundamentally important for controlling the biological and abiotic transformation and degradation processes that can

occur. Therefore, in this document the lines of evidence are grouped into "primary" and 
"supplemental" categories that are summarized in Table 1.1. The primary lines of evidence are essential to the evaluation of natural attenuation of chlorinated solvents. These include the contaminant concentration data and the critical geochemical parameters in the first and second lines of evidence that are needed to evaluate solute plume behavior and geochemical conditions. The supplemental lines of evidence include additional geochemical parameters and microbiological data in the second and third lines of evidence that can better elucidate transformation and degradation processes.

The primary lines of evidence are used to evaluate if natural attenuation is occurring at a rate sufficient to meet remedial objectives and to help determine which mechanisms of natural attenuation dominate. The data included in the supplemental lines of evidence can be useful for refining the understanding of a system. If the evaluation of natural attenuation shows that monitored natural attenuation (MNA) will not be protective, the data collected for the evaluation also can be used to evaluate and design alternate remedial measures. The actual combination of lines of evidence used to evaluate a site should be determined on a site-specific basis but, at a minimum, the data for the primary lines of evidence should be collected and analyzed to help estimate the natural attenuation capacity of the system. As a site becomes better characterized, the specific parameters needed to evaluate the efficacy of continuing natural attenuation or enhanced remediation will likely change. In many cases a subset of the data required to evaluate the primary lines of evidence may be sufficient to ensure that the chosen remedial approach remains effective.

The primary lines of evidence include the minimum data that must be collected to evaluate MNA. Section 2 describes the primary lines of evidence in more detail. Evaluation of these lines of evidence includes an assessment of plume behavior and an evaluation of plume geochemistry. One of the primary lines of evidence involves using historical contaminant data to evaluate if the contaminant plume is shrinking, stable, or growing. Although this line of evidence can be used to show that a contaminant plume is being attenuated, it does not necessarily show that contaminant mass is being destroyed. If the solute plume is adequately defined in three dimensions and a statistically sufficient historical data set is available, this line of evidence may be all that is required to show that natural attenuation is protective of human health and the environment, regardless of the operant mechanism(s). However, because of their complexity, and because almost every solute plume of chlorinated compounds behaves differently, it is usually necessary to determine the dominant mechanisms working to effect natural attenuation. This is the purpose of collecting daughter product and geochemical data which is useful for determining the relative importance of attenuation mechanisms and to determine whether or not contaminant mass is being destroyed. Based on what is learned from the primary lines of evidence it may be necessary to collect some of the data listed under the supplemental lines of evidence. 
WSRC-TR-2003-00331

December 31, 2004

Table 1.1

\section{Summary of the Lines of Evidence Used to Evaluate Natural Attenuation} and Enhanced Remediation

\begin{tabular}{|c|c|c|c|}
\hline Category & Line of Evidence & Data Requirements & Applicability/Comments \\
\hline \multirow[t]{2}{*}{ Primary } & $\begin{array}{l}\text { Contaminant } \\
\text { concentration data }\end{array}$ & $\begin{array}{l}\text { Historical contaminant data } \\
\text { from groundwater } \\
\text { monitoring }\end{array}$ & $\begin{array}{l}\text { Older sites with good historical data. } \\
\text { Should begin building historical } \\
\text { database for newer sites. } \\
\text { Used to evaluate solute plume } \\
\text { behavior and/or loss of contaminant } \\
\text { mass over time }\end{array}$ \\
\hline & $\begin{array}{l}\text { Contaminant/daughter } \\
\text { product and geochemical } \\
\text { analytical data }\end{array}$ & $\begin{array}{l}\begin{array}{l}\text { Aquifer and groundwater } \\
\text { data }\end{array} \\
\text { See Tables } 1.2 \text { and } 1.3\end{array}$ & $\begin{array}{l}\text { Used to evaluate the geochemical } \\
\text { environment, determine if biological } \\
\text { and/or abiotc degradation is } \\
\text { occurring, and to estimate natural } \\
\text { attenuation capacity. } \\
\text { Use to evaluate the relative } \\
\text { importance of natural attenuation } \\
\text { mechanisms (e.g., sorption, } \\
\text { dispersion, degradation, etc). } \\
\text { Determine relative importance of } \\
\text { biological versus abiotic degradation } \\
\text { mechanisms. }\end{array}$ \\
\hline Supplemental & $\begin{array}{l}\text { Geochemical and } \\
\text { microbiological data that } \\
\text { allow a refined } \\
\text { interpretation of the } \\
\text { distribution of biological } \\
\text { or abiotic degradation } \\
\text { mechanisms }\end{array}$ & $\begin{array}{l}\text { Additional groundwater } \\
\text { geochemical parameters, } \\
\text { mineralogical analyses, } \\
\text { microcosm studies, } \\
\text { microbiological data, stable } \\
\text { isotope data, etc. } \\
\text { See Tables } 3.1 \text { and } 3.3\end{array}$ & $\begin{array}{l}\text { Should be used only when the } \\
\text { additional data will provide useful } \\
\text { information, such as at sites where } \\
\text { the predominant degradation } \\
\text { mechanism(s) is (are) not readily } \\
\text { apparent. }\end{array}$ \\
\hline
\end{tabular}


WSRC-TR-2003-00331

December 31, 2004

At more complicated sites, select supplemental lines of evidence may be used to better elucidate mechanisms of natural attenuation. At sites where enhanced remediation is required, some combination of the primary lines of evidence and the data listed under the supplemental lines of evidence may be useful for determining the most efficient pathway(s) to remediation. Section 3 describes the supplemental lines of evidence in more detail.

\subsection{DATA REQUIRED TO EVALUATE NATURAL ATTENUATION}

Tables 1.2 and 1.3 summarize the data required to evaluate the primary lines of evidence used to evaluate natural attenuation of chlorinated solvents. The interpretation of these data is discussed in Section 2. Additional data for the supplemental lines of evidence that can be useful for evaluating MNA, and the interpretation of these data, are discussed in Section 3.

One of the overarching considerations when evaluating MNA is how well the site is characterized. Evaluation of the lines of evidence is entirely contingent upon the quality of the available site characterization data and the understanding of the hydrogeologic and groundwater chemistry relationships at the site. Also, the interpretation of data from the lines of evidence requires an understanding of what is being sampled and the reason for the sampling. The degree of characterization required will be site specific and will depend upon, among other things, the velocity and direction of groundwater flow, the complexity of the hydrogeologic system, and the distance to potential receptors.

Development of a good conceptual site model (CSM) is fundamental to the evaluation of natural attenuation. Development of the CSM should include an evaluation of:

- The nature, extent, and magnitude of contamination, including:

$>$ The nature and history of the contaminant release;

--Catastrophic or gradual release of non-aqueous phase liquid (NAPL)?

--More than one source area possible or present?

--Divergent or coalescing plumes?

$>$ The three-dimensional distribution of mobile and residual NAPL and dissolved contaminants. The distribution of mobile and residual NAPL is used to define the dissolved plume source area;

$>$ Groundwater and soil/sediment chemical data;

> Historical water quality data showing variations in contaminant concentrations;

Chemical and physical characteristics of the contaminants; and

$>$ Potential for degradation of the contaminants. 
Table 1.2

Aquifer and Soil/Sediment Data Required to Evaluate Natural Attenuation and Enhanced Remediation

\begin{tabular}{|c|c|c|c|}
\hline Analysis & Method & Data Use & Comments \\
\hline $\begin{array}{l}\text { Contaminants of } \\
\text { Concern/Daughter } \\
\text { Products }\end{array}$ & $8260 \mathrm{~B}$ & $\begin{array}{l}\text { Used to determine presence of parent } \\
\text { and daughter compounds and rates of } \\
\text { attenuation. }\end{array}$ & $\begin{array}{l}\text { Decreasing source concentrations are important } \\
\text { for natural attenuation and daughter products are } \\
\text { a good indicator of contaminant degradation. }\end{array}$ \\
\hline $\begin{array}{l}\text { Total Organic } \\
\text { Carbon }\end{array}$ & $\begin{array}{l}\text { SW9060 modified } \\
\text { for soil samples. }\end{array}$ & Sorption/solute retardation calculations. & $\begin{array}{l}\text { Procedure must be accurate over the range of } \\
0.1-5 \text { percent TOC. }\end{array}$ \\
\hline Bulk Density & $\begin{array}{l}\text { Geotechnical } \\
\text { Laboratory } \\
\text { Procedure. }\end{array}$ & Sorption/solute retardation calculations. & May be estimated from literature values. \\
\hline Hydraulic Gradient & $\begin{array}{l}\text { Determined from } \\
\text { site potentiometric } \\
\text { surface maps. }\end{array}$ & $\begin{array}{l}\text { Estimation of seepage velocity. } \\
\text { Required for groundwater flow and } \\
\text { solute transport models. }\end{array}$ & At least three measurement points required. \\
\hline $\begin{array}{l}\text { Hydraulic } \\
\text { Conductivity }\end{array}$ & $\begin{array}{l}\text { Determined from } \\
\text { slug tests or } \\
\text { pumping tests. }\end{array}$ & $\begin{array}{l}\text { Estimation of seepage velocity. } \\
\text { Required for groundwater flow and } \\
\text { solute transport models. }\end{array}$ & $\begin{array}{l}\text { Critical parameter with the potential for the most } \\
\text { measurement error. Sensitivity analyses on this } \\
\text { parameter may be useful when estimating } \\
\text { seepage velocity. }\end{array}$ \\
\hline $\begin{array}{l}\text { Total and Effective } \\
\text { Porosity }\end{array}$ & $\begin{array}{l}\text { Determined from } \\
\text { tracer tests or } \\
\text { estimates from } \\
\text { literature values. }\end{array}$ & $\begin{array}{l}\text { Estimation of seepage velocity. } \\
\text { Required for groundwater flow and } \\
\text { solute transport models. }\end{array}$ & Literature values typically are used. \\
\hline $\begin{array}{l}\text { Field observation } \\
\text { of reduced iron } \\
\text { minerals }\end{array}$ & Visual observation. & $\begin{array}{l}\text { Estimation of the potential for abiotic } \\
\text { degradation through reaction with } \\
\text { reduced iron minerals. }\end{array}$ & $\begin{array}{l}\text { Oxidized iron minerals typically impart some } \\
\text { shade of rust color to the soil ranging from rusty } \\
\text { brown, to yellow or orange, to red or maroon. } \\
\text { Reduced iron minerals typically cause the soil to } \\
\text { be gray to black in color. }\end{array}$ \\
\hline
\end{tabular}


Table 1.3

Groundwater Data Required to Evaluate Natural Attenuation and Enhanced Remediation*

\begin{tabular}{|c|c|c|c|c|c|}
\hline Analysis & Method/Reference & Comments & Data Use & \begin{tabular}{|c|} 
Sample Volume, Sample Container, \\
Sample Preservation
\end{tabular} & $\begin{array}{l}\text { Field or } \\
\text { Laboratory }\end{array}$ \\
\hline $\begin{array}{l}\text { Chemicals of } \\
\text { Concern }\end{array}$ & SW8260B & $\begin{array}{l}\text { EPA Handbook } \\
\text { method. }\end{array}$ & $\begin{array}{l}\text { Used to determine presence of parent and } \\
\text { daughter compounds and rates of attenuation. }\end{array}$ & $\begin{array}{l}\text { Collect } 3 \times 40 \mathrm{~mL} \text { VOA vials, preserve } \\
\text { with HCL and cool to } 4^{\circ} \mathrm{C} \text {. } \\
\end{array}$ & $\begin{array}{l}\text { Fixed-base } \\
\text { laboratory }\end{array}$ \\
\hline Chloride & IC method E300 ${ }^{\mathrm{a} /}$ & $\begin{array}{l}\text { Method SW9050 } \\
\text { may also be used. }\end{array}$ & $\begin{array}{l}\text { Final product of chlorinated solvent reduction. } \\
\text { Can be used as a tracer. }\end{array}$ & $\begin{array}{l}\text { Collect } 1 \times 1 \text { Liter poly container and } \\
\text { cool to }=4{ }^{\circ} \mathrm{C} \text {. }\end{array}$ & $\begin{array}{l}\text { Fixed-base } \\
\text { laboratory }\end{array}$ \\
\hline $\begin{array}{l}\text { Dissolved } \\
\text { Oxygen }\end{array}$ & $\begin{array}{l}\text { E360.1- Dissolved } \\
\text { oxygen membrane } \\
\text { electrode. }\end{array}$ & $\begin{array}{l}\text { Avoid exposure to } \\
\text { atmospheric oxygen. }\end{array}$ & $\begin{array}{l}\text { Concentrations less than about } 0.5 \mathrm{mg} / \mathrm{L} \\
\text { generally indicate an anaerobic pathway - use } \\
\text { in conjunction with other geochemical data. }\end{array}$ & $\begin{array}{l}\text { Measure dissolved oxygen onsite } \\
\text { using a flow-through cell. }\end{array}$ & Field \\
\hline Nitrate & IC method E300 & $\begin{array}{l}\text { Method E300 is a } \\
\text { Handbook method. }\end{array}$ & $\begin{array}{l}\text { Substrate for microbial respiration if oxygen is } \\
\text { depleted. Absence is required for Fe(III) } \\
\text { reduction to occur. }\end{array}$ & $\begin{array}{l}\text { Collect } 1 \text { Liter poly container and cool } \\
\text { to } 4{ }^{\circ} \mathrm{C} \text {. }\end{array}$ & $\begin{array}{l}\text { Fixed-base } \\
\text { laboratory }\end{array}$ \\
\hline Iron (II) $\left(\mathrm{Fe}^{2+}\right)$ & $\begin{array}{l}\text { Colorimetric } \\
\text { Hach Method }\end{array}$ & $\begin{array}{l}\text { Filter with } 0.45 \\
\text { micron inline filter. }\end{array}$ & $\begin{array}{l}\text { Indicates an anaerobic degradation process due } \\
\text { to depletion of oxygen, nitrate, and } \\
\text { manganese. Required for abiotic reductive } \\
\text { dechlorination. }\end{array}$ & $\begin{array}{l}\text { Collect } 100 \mathrm{~mL} \text { of water in a } \\
\text { headspace-free container to eliminate } \\
\text { introduction of oxygen and analyze as } \\
\text { soon as possible. }\end{array}$ & Field \\
\hline Sulfate $\left(\mathrm{SO}_{4}{ }^{2-}\right)$ & IC method E300 ${ }^{a}$ & $\begin{array}{l}\text { Method E300 is a } \\
\text { Handbook method. }\end{array}$ & Substrate for anaerobic microbial respiration. & $\begin{array}{l}\text { Collect } 1 \text { Liter poly container and cool } \\
\text { to } 4{ }^{\circ} \mathrm{C} \text {. }\end{array}$ & $\begin{array}{l}\text { Fixed-base } \\
\text { laboratory }\end{array}$ \\
\hline Sulfide & E376.1 & Handbook method. & Required for abiotic reductive dechlorination. & $\begin{array}{l}\text { Collect } 500 \mathrm{~mL} \text { in plastic or glass } \\
\text { container, preserve with } \mathrm{NaOH} \text { to } \mathrm{pH} \\
<9 \text {, cool to } 4{ }^{\circ} \mathrm{C} \text {, no headspace. }\end{array}$ & $\begin{array}{l}\text { Fixed-base } \\
\text { laboratory }\end{array}$ \\
\hline $\begin{array}{l}\text { Oxidation- } \\
\text { Reduction } \\
\text { Potential (ORP) }\end{array}$ & Direct-Reading Probe & $\begin{array}{l}\text { Avoid introduction } \\
\text { of oxygen during } \\
\text { sampling. }\end{array}$ & $\begin{array}{l}\text { The ORP of groundwater influences and is } \\
\text { influenced by the nature of biologically } \\
\text { mediated reactions. }\end{array}$ & $\begin{array}{l}\text { Measure ORP onsite using a flow- } \\
\text { through cell. }\end{array}$ & Field \\
\hline $\begin{array}{l}\text { Methane, Ethane, } \\
\text { and Ethene }\end{array}$ & RSK-175 & $\begin{array}{l}\text { Method published by } \\
\text { researchers at the US } \\
\text { EPA. }\end{array}$ & $\begin{array}{l}\text { Presence of methane suggests biodegradation } \\
\text { via methanogenesis. Ethane and ethene are } \\
\text { daughter products of complete dechlorination. }\end{array}$ & $\begin{array}{l}\text { Collect } 6 \times 40 \mathrm{~mL} \text { VOA vials, preserve } \\
\text { with HCL, and cool to cool to } 4{ }^{\circ} \mathrm{C} \text {. }\end{array}$ & $\begin{array}{l}\text { Fixed-base } \\
\text { laboratory }\end{array}$ \\
\hline $\mathrm{pH}$ & $\begin{array}{l}\text { E150.1 - Field probe } \\
\text { with direct reading } \\
\text { meter. }\end{array}$ & Field. & $\begin{array}{l}\text { Fundamental measurement which is critical for } \\
\text { interpretation of carbonate data. Used as a } \\
\text { well stabilization criterion. }\end{array}$ & $\begin{array}{l}\text { Measure in flow-through cell during } \\
\text { well purging. }\end{array}$ & Field \\
\hline Temperature & $\begin{array}{l}170.1 \text { - Field probe with } \\
\text { direct reading meter. }\end{array}$ & Field only. & $\begin{array}{l}\text { Fundamental measurement required in all } \\
\text { thermodynamic calculations. }\end{array}$ & $\begin{array}{l}\text { Measure in flow-through cell during } \\
\text { well purging. }\end{array}$ & Field \\
\hline Conductivity & $\begin{array}{l}\text { E120.1/SW9050, direct } \\
\text { reading meter }\end{array}$ & $\begin{array}{l}\text { Protocols/Handbook } \\
\text { methods. }\end{array}$ & $\begin{array}{l}\text { General water quality parameter that is } \\
\text { proportional to dissolved ions in solution. }\end{array}$ & $\begin{array}{l}\text { Measure in flow-through cell during } \\
\text { well purging. }\end{array}$ & Field \\
\hline Acetylene & $\begin{array}{l}\text { Under } \\
\text { Development } \backslash \text { Not } \\
\text { available }\end{array}$ & GC-FID method. & $\begin{array}{l}\text { Product of abiotic reductive dechlorination by } \\
\text { iron sulfide minerals. }\end{array}$ & $\begin{array}{l}\text { Preservation techniques under } \\
\text { development. }\end{array}$ & $\begin{array}{l}\text { Fixed-base } \\
\text { laboratory }\end{array}$ \\
\hline
\end{tabular}

*Not all analytes will be required for every site or every sampling event. a/ Ion Chromatography 
WSRC-TR-2003-00331

December 31, 2004

- Geologic and hydrogeologic data (in three dimensions, if feasible):

$>$ Lithologic and stratigraphic relationships (e.g., well boring logs, geologic crosssections, etc);

$>$ Grain size distribution (sand vs. silt vs. clay);

$>$ Aquifer hydraulic conductivity;

$>$ Groundwater flow gradients and potentiometric or water table surface maps (over several seasons, if possible);

> Preferential flow paths (geologic features, utility conduits, abandoned wells, etc); and

$>$ Interactions between groundwater and surface water and rates of infiltration/recharge.

- Locations of potential receptor exposure points:

$>$ Groundwater production wells; and

Downgradient and cross-gradient groundwater discharge points.

The CSM is a representation of release mechanisms, the NAPL source, groundwater flow and solute transport, including transport pathways, exposure points, and receptors, and should be based on available geological, biological, geochemical, hydrological, climatological, analytical data, and current and future uses for the site. After development, the CSM can be used to help determine optimal placement of additional monitoring points, as necessary, to aid in the natural attenuation investigation and to develop a solute fate and transport model, if required. Contracting and management controls must be flexible enough to allow for the potential for revisions to the CSM and thus the data collection effort. Successful CSM development involves:

- Definition of the problem to be solved (generally the nature, magnitude, and extent of existing and future contamination).

- Integration and presentation of available data, including:

$>$ local geologic and topographic maps;

$>$ geologic data;

$>$ hydraulic data;

$>$ geochemical data;

$>$ current and future land use; and

$>$ contaminant concentration and distribution data. 
WSRC-TR-2003-00331

December 31, 2004

- Determination of additional data requirements, including:

$>$ borehole locations and monitoring well spacing;

$>$ quality assurance project plan (QAPP);

$>$ sampling and analysis plan (SAP); and

$>$ any data requirements that have not been adequately addressed.

In some cases, available site-specific data are limited. If this is the case, future site characterization activities should include collecting the data necessary to evaluate natural attenuation at the site. Regardless of whether natural attenuation is selected as a sole remedial strategy or in conjunction with an engineered remediation system, the additional costs incurred by such data collection will likely be outweighed by the cost savings that will be realized. Much of the data collected to evaluate natural attenuation also can be used to design and evaluate other remedial measures. 
WSRC-TR-2003-00331

December 31, 2004

\section{SECTION 2}

\section{PRIMARY LINES OF EVIDENCE}

The primary lines of evidence used to evaluate MNA include: 1) an evaluation of plume behavior using temporal and spatial contaminant data; and 2) field and laboratory data for evaluating the relative importance of natural attenuation mechanisms. This section describes the primary lines of evidence and their use.

\subsection{CONTAMINANT CONCENTRATION DATA}

A statistically significant historical database of contaminant concentration data showing plume stabilization and/or loss of contaminant mass over time is used to demonstrate that natural attenuation is occurring at a site. This is perhaps the fundamental line of evidence for evaluating monitored natural attenuation as a remedial approach. In fact, historical data are important for evaluating any remediation technique. It is important to note that plume stabilization can occur with or without destructive attenuation mechanisms. In some cases, nondestructive mechanisms of natural attenuation such as dispersion, sorption, and volatilization may be sufficient to cause the solute plume to reach steady-state equilibrium, or even recede if the strength of the NAPL source is decreasing due to natural weathering or engineered remediation. In addition, the data to support this line of evidence must be collected to help evaluate the effectiveness of enhanced remediation. The aquifer and soil/sediment data described in Section 2.2 are used to help separate the components of natural attenuation and to help quantify the natural attenuation capacity of the system.

Both graphical and statistical methods can be used to evaluate plume behavior, and ultimately some combination of graphical representations and statistical techniques likely will be used to evaluate plume behavior at most sites. It is important when evaluating the behavior of a contaminant plume that the historical data demonstrate a clear and meaningful pattern in contaminant mass and/or concentration over time at appropriate monitoring or sampling points. Methods to accomplish this are discussed in USEPA (1992) and Helsel and Hirsch (2002). Useful graphical approaches to evaluate solute plume behavior are briefly described in Section 2.1.1. Statistical approaches to evaluate plume behavior are presented in Section 2.1.2. 
WSRC-TR-2003-00331

December 31, 2004

\subsubsection{Graphical Evaluation of Plume Behavior}

There are several ways to present data showing changes in contaminant concentrations and plume configuration over time. One method consists of preparing isopleth maps of contaminant concentration over time. Figure 2.1 shows isopleth maps of volatile organic compound (VOC) concentrations in groundwater where there is a NAPL source. The VOC concentrations shown on this figure were mapped at the depth of highest concentration. Note that VOC data were collected during the same season (the season with the highest VOC concentrations). This is important because seasonal variations in recharge can cause significant changes in contaminant concentrations and groundwater geochemistry and an apparent reduction in plume size and/or contaminant concentrations could simply be the result of seasonal variation.

Another method that can be used to present data showing changes in contaminant concentrations and plume configuration over time is to plot contaminant concentrations versus time for individual monitoring wells, or to plot contaminant concentrations versus distance downgradient for several wells along the groundwater flow path for several sampling events. It is important when plotting data in this manner that at least one data point is located a short distance downgradient of the solute plume in the groundwater flow path. This ensures that contaminants are not migrating downgradient of the observation wells. To ensure that contaminants are not migrating, it is important that downgradient wells are located in the path of contaminated groundwater flow. Geochemical data can be used to confirm that downgradient wells are sampling groundwater that was once contaminated with organic compounds, as discussed in Wiedemeier and Haas (2002).

Visual inspection of plotted data for concentration versus time and/or distance can yield qualitative information on the presence of trends that are indicative of solute plume behavior. While such plots are recommended for most plume stability analyses, visually discerning trends in the plotted data is a subjective process, particularly if the data does not display a relatively obvious uniform trend and shows some variability over time. For data that shows considerable variation in concentrations, such as is common for concentration versus distance plots, the use of semi-logarithmic plots can be useful. Plotting the concentration data on a logarithmic scale against time on an arithmetic (linear) scale can counter the relatively large changes in concentration (e.g., a concentration reduction from $1 \mathrm{mg} / \mathrm{L}$ to $1 \mathrm{ug} / \mathrm{L}$ represents a 1,000 -fold reduction) and effectively "linearize" the data.

As an example, Figure 2.2 shows sampling locations for the plots of contaminant concentration versus time and distance downgradient which are presented in Figure 2.3. Based on the geochemical data presented in Figure 2.2 it can be concluded with reasonable certainty that well $\mathrm{H}$ is in the plume's flow path, therefore if the plume were migrating downgradient it should be detected. Wells $\mathrm{F}$ and $\mathrm{H}$ are spaced 100 feet apart, and the groundwater seepage velocity is 150 feet per year; with 8 years of sampling data from the same season it can probably be concluded with reasonable certainty that the plume is not migrating downgradient. 
September 1993

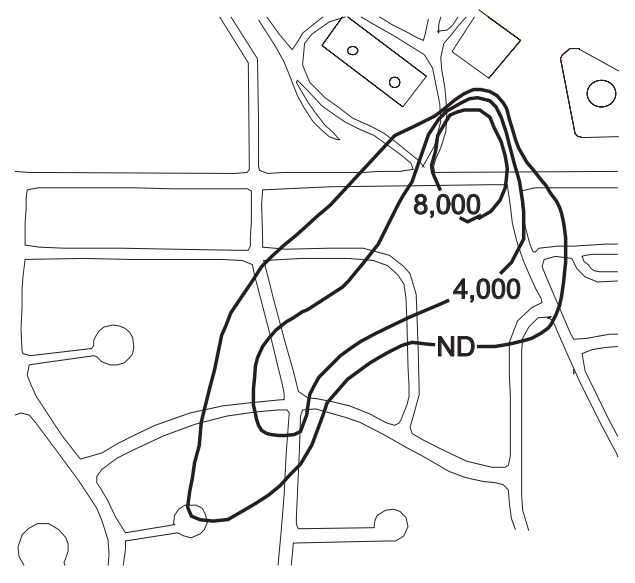

September 1995

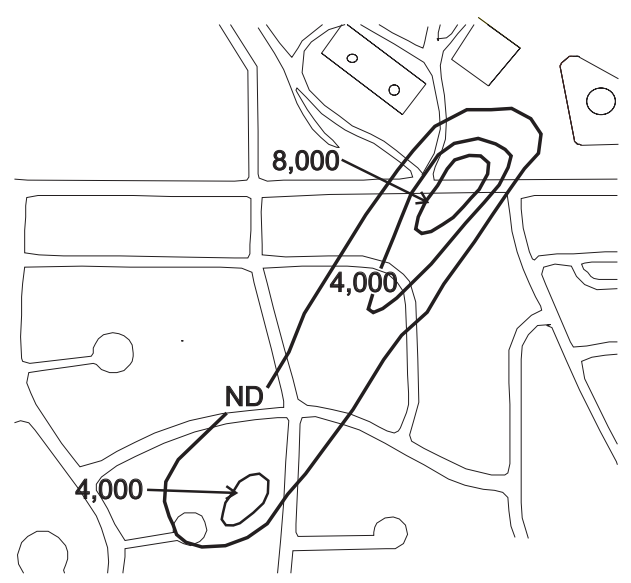

September 1994
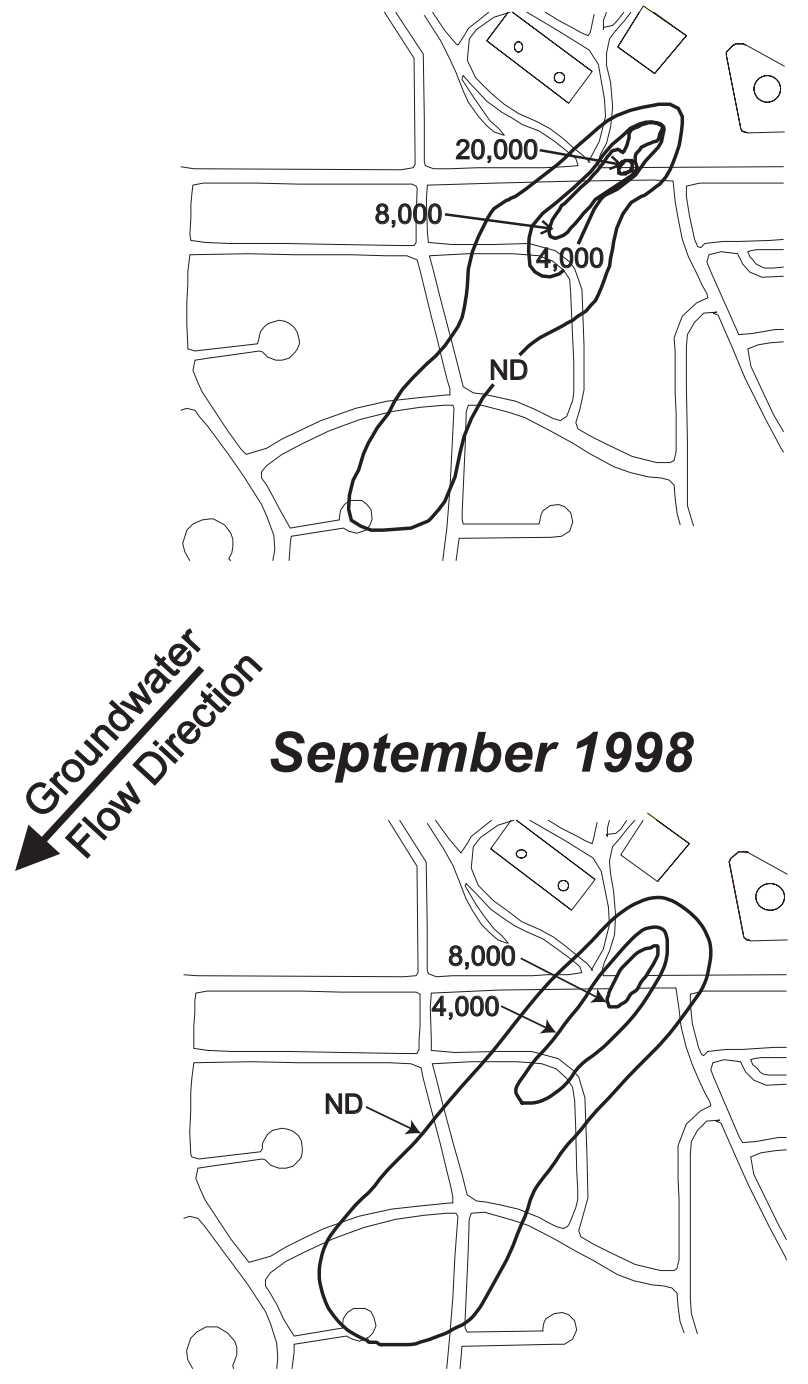

Line of Equal Total

VOC Concentration ( $\mu \mathrm{g} / \mathrm{L})$

Groundwater Flow

Velocity $\sim 1,600$ feet per year

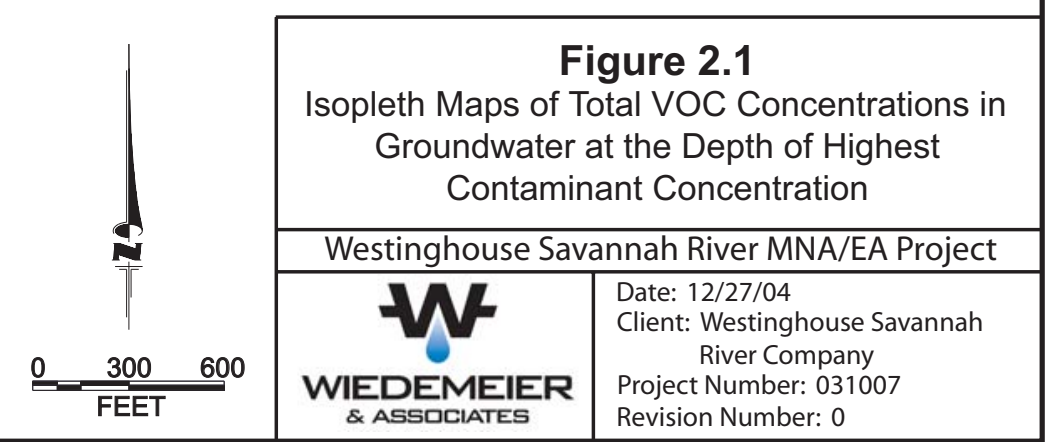




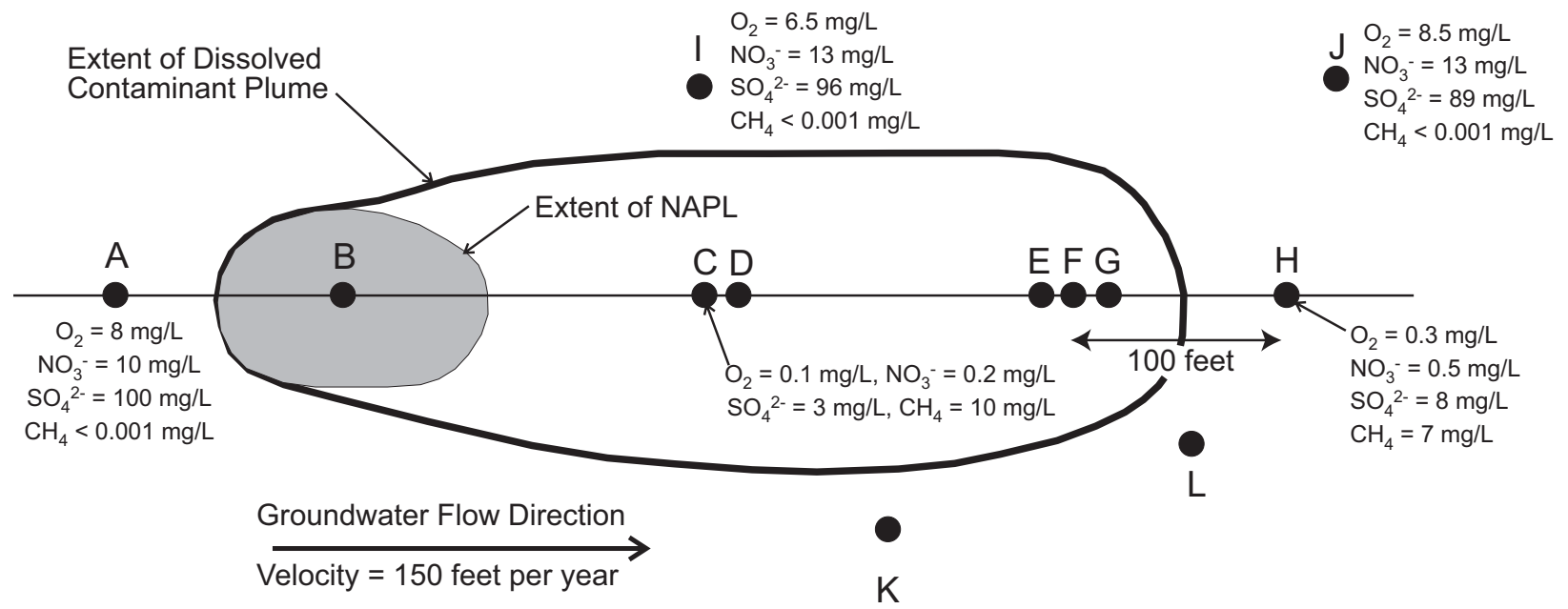

West

East

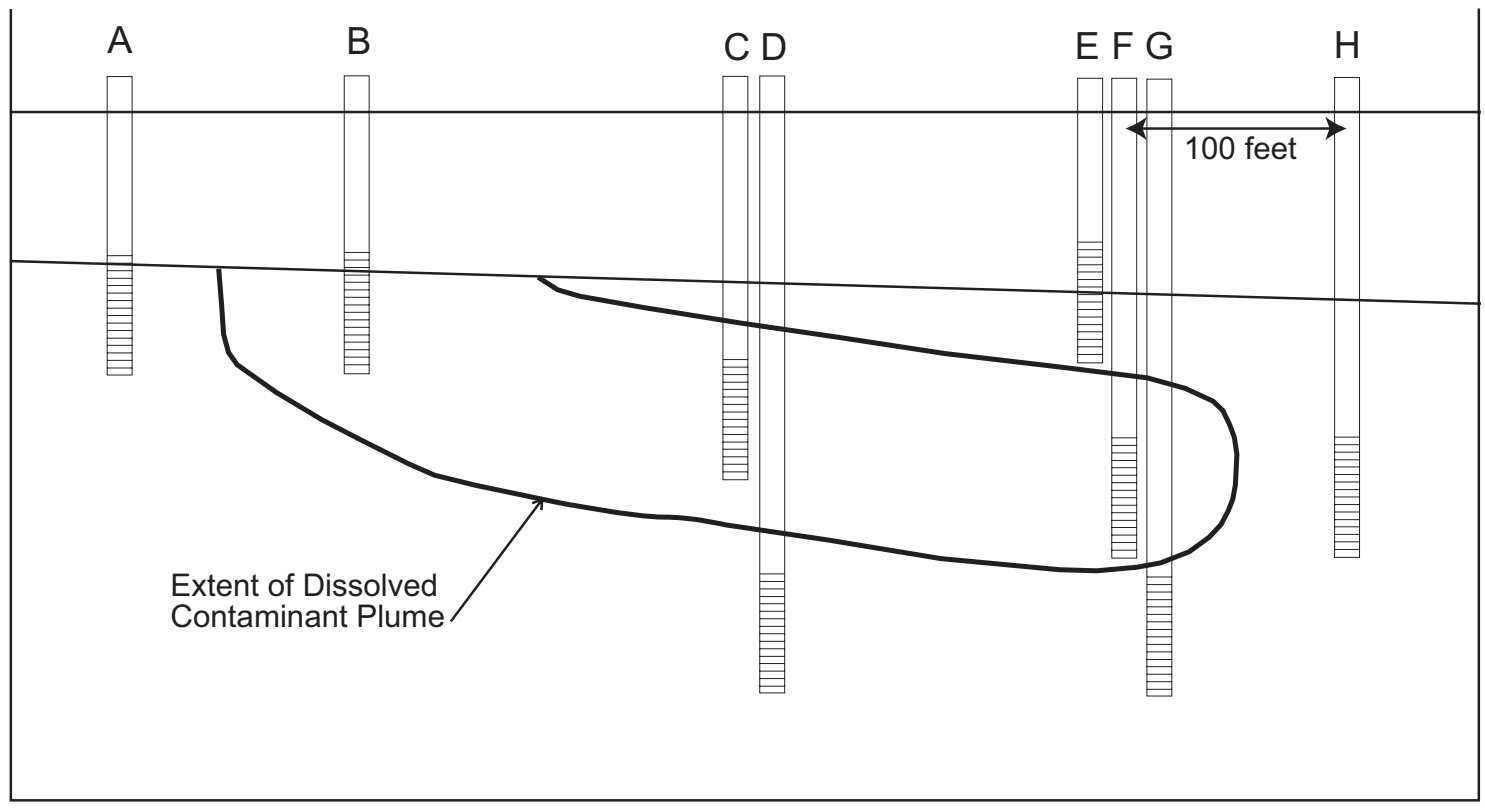

Figure 2.2

Sampling Locations for the Plots of Contamination versus Time and Distance

Downgradient Presented in Figure 2.3

Westinghouse Savannah River MNA/EA Project

\begin{tabular}{|c|c|}
\hline WIED & $\begin{array}{c}\text { Date: } 12 / 12 / 04 \\
\text { Client: Westinghouse Savannah } \\
\text { River Company } \\
\text { Project Number: } 031007\end{array}$ \\
\hline & Revision Number: 0 \\
\hline
\end{tabular}



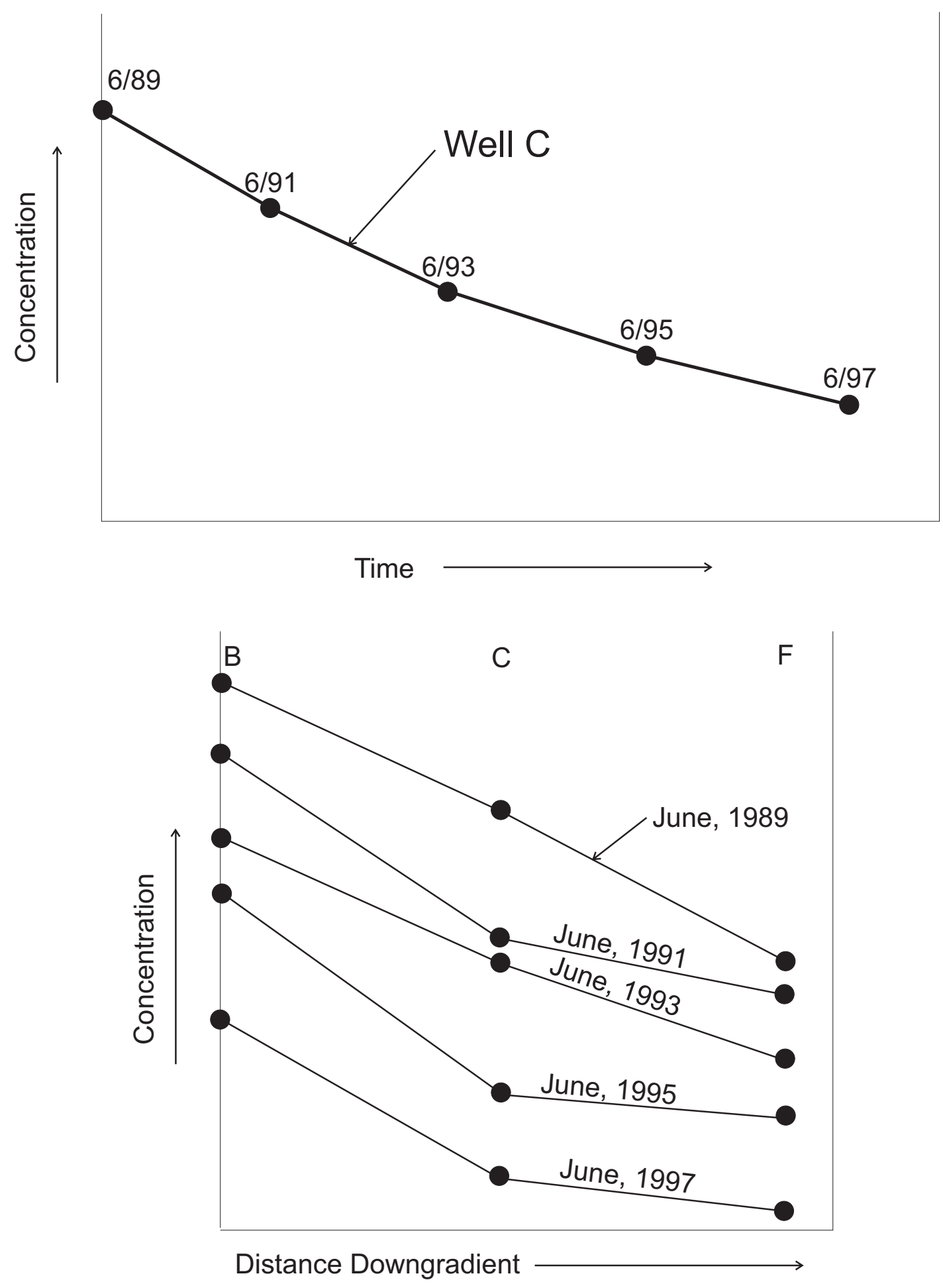

Figure 2.3

Plots of Contaminant Concentration versus Time and Distance Downgradient

Westinghouse Savannah River MNA/EA Project

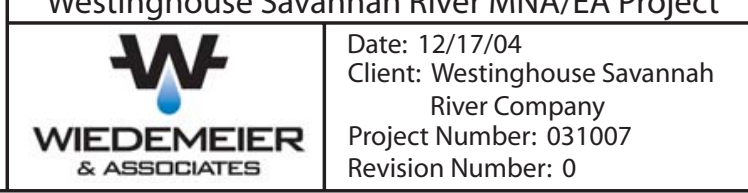


WSRC-TR-2003-00331

December 31, 2004

The combination of decreasing contaminant concentrations shown by the plots in Figure 2.3, and the lack of contaminant migration provide reasonable evidence for natural attenuation and contaminant mass destruction. The chemical and geochemical data discussed in Section 2.2 can be used to show that this loss of contaminant mass is the result of destructive attenuation mechanisms.

\subsubsection{Statistical Methods for Evaluating Plume Behavior}

Statistical methods are powerful tools for identifying significant changes and trends in groundwater concentration data. They provide for an objective evaluation of the data and allow statements to be made about the confidence in results. This provides a quantitative indication of the likelihood that conclusions drawn from the data are correct. In evaluating natural attenuation, statistical methods are used to assess groundwater monitoring data for the presence of significant trends or changes in concentrations over time that can provide insight into solute plume behavior. Once again, it is paramount to verify the monitoring events and data subject to statistical analyses are comparable. If high water levels correlate with higher contaminant concentrations, then data from high and low water table events may not be comparable. If sampling was conducted during an extreme weather event (e.g. 100-year flood), then it may not be comparable to previous events. A more detailed discussion of the concept of comparibility is found in Gilbert (1987).

The application of statistics requires an understanding of the underlying assumptions of the tests and nature of the data since these determine the selection of appropriate methods and interpretation of the results. While a detailed review of the statistical analysis of concentration data and its application are beyond the scope of this document, a brief discussion of the significant factors and some methods that are applicable in the majority of situations is provided. More detailed discussion is available in several statistics texts (e.g., Gilbert, 1987; Gibbons, 1994; USEPA, 2000; Helsel and Hirsch, 2002). This is not a theoretical discussion; rather, it provides practical considerations where statistical results are used in decision-making.

Statistical tests are a form of hypothesis testing and their basis is the comparison of what statisticians call the "null hypothesis" $\left(\mathrm{H}_{0}\right)$ to an alternative hypothesis $\left(\mathrm{H}_{1}\right)$. The null hypothesis is the statistical hypothesis being tested; generally that the test results are merely a product of chance factors. For example, to test for a trend in a concentration time series, $\mathrm{H}_{0}$ would be that there is no change in concentration over time, and $\mathrm{H}_{1}$ would be that the concentration is either increasing or decreasing with time. The two hypotheses are compared using a test statistic that is calculated from the data series being tested.

Most statistical tests are intended to detect a significant difference between a group of samples or from a predefined condition. This is determined by comparing the value for the test statistic calculated from the data set to the probability of obtaining that value purely due to chance. The probability values are determined from the "null" distribution for the test statistic that is the distribution of values for the test statistic under the null hypothesis $\left(\mathrm{H}_{0}\right)$. The

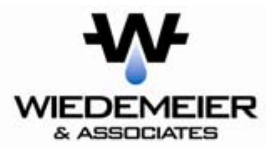


WSRC-TR-2003-00331

December 31, 2004

significance level is a means of determining whether the test statistic is "significantly" different from values that would typically occur under $\mathrm{H}_{0}$. If the probability for the test statistic value calculated from the data set is less than the level of significance, the null hypothesis $\left(\mathrm{H}_{0}\right)$ can be rejected in favor of the alternative hypothesis $\left(\mathrm{H}_{1}\right)$.

There are two possible types of decision errors associated with statistical hypothesis testing. A Type I error is when $\mathrm{H}_{0}$ is incorrectly rejected. A Type II error is when $\mathrm{H}_{0}$ is accepted when $\mathrm{H}_{1}$ is true. Both types of decision errors have implications for the conclusions drawn from results of statistical tests.

A Type I error is rejecting the null hypothesis $\left(\mathrm{H}_{0}\right)$ when it is in fact true. This is essentially equivalent to a "false positive" result, such as concluding that there is an increasing or decreasing trend in concentration over time when no trend is actually present. The probability of incorrectly rejecting $\mathrm{H}_{0}$ is the "significance level" $(\alpha)$ of the test. Type I errors are controlled by selecting an appropriate $\alpha$-value to reduce the likelihood of drawing an incorrect conclusion from the test.

The inability to reject the null hypothesis (failure to accept the alternative hypothesis) at some level of significance does not imply that the null hypothesis is true. A Type II error is failing to reject (accepting) the null hypothesis $\left(\mathrm{H}_{0}\right)$ when it is false and the alternative hypothesis $\left(\mathrm{H}_{1}\right)$ is true. This is essentially equivalent to a "false negative" result, such as concluding that there is no trend in concentration over time when an increasing or decreasing trend is actually present. The probability of this occurring is $\beta$ and the power of a statistical test to detect a significant difference is $1-\beta$. The statistical power of a test is related to both the $\alpha$-value selected and the sample size $(n)$.

Ideally, we would like to minimize both Type I and Type II errors in using statistical tests, but this is difficult in practice. The importance of either type of decision error should be evaluated in terms of the ultimate use of the results of the statistical test. A pragmatic approach is to specify an acceptable value for $\alpha$ and concurrently reduce $\beta$ by 1 ) increasing the sample size and/or 2) using a statistical test with the greatest power for the type of data being evaluated (Helsel and Hirsch, 2002).

Statistical tests are described as one-sided or two-sided depending upon the specific alternative hypothesis involved. A two-sided test is used when a difference in either direction from $\mathrm{H}_{0}$ would cause $\mathrm{H}_{0}$ to be to be rejected, such as a test for detecting the presence of a trend/change in concentration. For example, if there is no reason to assume that concentrations are not stable or that departures from $\mathrm{H}_{0}$ in only one direction are of interest, a two-sided test is appropriate. A one-sided test is used when a change in only one direction from $\mathrm{H}_{0}$ would cause $\mathrm{H}_{0}$ to be to be rejected, such as a test for detecting an increase (or decrease) in concentration over time. For example, if only evidence that concentration is increasing (or decreasing) over time is considered important, $\mathrm{H}_{0}$ would be stated as "the change in concentration over time is less (or greater) than or equal to zero (0)," and $\mathrm{H}_{1}$ would be "the change in concentration over time is greater (less) than zero (0)." 
WSRC-TR-2003-00331

December 31, 2004

The null distributions for most test statistics are symmetrical and the probability values for only one "tail" of the distribution are given. For detecting an increase (or decrease), only the difference in one direction is important and the critical test statistic value at $\alpha$ is used (one-sided tail). For detecting the presence of a trend/change in concentration, both a positive or negative difference is important and the critical test statistic value at $\alpha / 2$ is used (two-sided tail).

The issue of confidence levels, or significance levels, is important when applying statistics. The practical implication of the confidence level is that there is error associated with the decision to reject the null hypothesis. If the calculated value of the test statistic leads you to reject the null hypothesis, it does not mean that the value for the test statistic you obtained could not have occurred by chance. It means that the probability of obtaining that value by chance alone is sufficiently small that it is reasonable to conclude that the result is not due to chance and that the decision to reject the null hypothesis is correct. The confidence level simply quantifies the likelihood that rejecting the null hypothesis is appropriate.

The confidence level for a statistical test is related to the significance level $(\alpha)$ and is simply described by the value 1- $\alpha$, typically expressed as a percentage. The significance level $(\alpha)$ is specified in advance of the test and defines the "acceptable" level of Type 1 error that the user is willing to tolerate in deciding to reject the null hypothesis. For example, if the desired confidence level for a statistical test is $95 \%$ (0.95), the significance level would be specified as 0.05 and the null hypothesis would be rejected if the calculated test statistic value has a probability $\leq 0.05$. This means that the likelihood of making an incorrect decision to reject the null hypothesis is 5 in 100 ( 1 in 20) and, conversely, the likelihood that the decision to reject the null hypothesis is correct is 95 in 100 (19 in 20).

The confidence level simply quantifies the "confidence" associated with obtaining a "significant" result for a statistical test, such as concluding that there is a trend in concentration over time or a difference in concentrations. There is no magic to defining the appropriate confidence level and adjusting the confidence level simply changes the tolerance for Type I error in decision-making. In most scientific applications, a 95\% confidence level is used since there is general concurrence that the associated error (5\%) is sufficiently small. Decreasing the confidence level for a statistical test will increase the likelihood of obtaining a "significant" result, but will also increase the chances that the null hypothesis will be incorrectly rejected. The specified confidence level is simply a reflection of the user's willingness to accept a mistaken conclusion for a statistical test.

\subsubsection{Nature of Groundwater Concentration Data and Appropriate Statistical Methods}

Issues involved with the statistical analysis of groundwater concentration data are myriad, but most commonly involve missing values, non-detect (censored) values, small number of data points, and the lack of certain knowledge of the underlying distribution. All of these complicate the application of statistical methods and either require significant data manipulation or the use of methods that are little affected by these data characteristics. Trend analysis, in particular, is

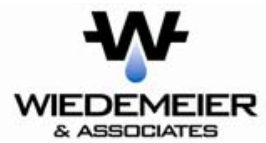


WSRC-TR-2003-00331

December 31, 2004

sensitive to these issues, as well as to changes in sampling and analytical procedures, seasonal or other cyclic variation in the data, and correlated data (Gilbert, 1987).

Statistical approaches can be separated into parametric and non-parametric methods. The familiar parametric statistics, such as regression analysis, rely on data conforming to an underlying distribution, such as normal (Gaussian) or log-normal. Parametric statistics are sensitive to missing data points and outliers, how non-detect values are handled, and departures from the assumed distribution. Non-parametric statistical methods do not depend on assumptions regarding the underlying data distribution and are also known as "distribution-free" methods. They can accommodate missing data points and non-detect values that are common in groundwater concentration data sets. These methods rely on the ranks or relative magnitudes of the data rather than the actual values and are fairly straightforward to use. In many situations, particularly those involving small data sets, non-parametric methods perform as well or better than parametric methods (Helsel and Hirsch, 2002).

The selection of statistical methods is frequently limited by the availability of sufficient data. Aside from the issues mentioned previously, parametric methods are sensitive to sample size and their power is reduced for small data sets. This is a common problem for groundwater concentration data. Non-parametric methods typically are equally or more powerful for discerning trends and changes for small data sets.

Because of the issues associated with most groundwater concentration data, the use of nonparametric techniques are generally preferred for environmental concentration data (Gilbert, 1987; Gibbons, 1994) and some commonly used methods are described briefly below. Additional information on these non-parametric methods is provided in Hollander and Wolfe (1999), Conover (1999), and Helsel and Hirsch (2002).

\subsubsection{Tests for Trend}

The Mann-Kendall test for trend (Mann, 1945; Kendall, 1975) is used to determine the presence or absence of a trend in concentration over time for individual monitoring points. It is a test for zero slope of time-ordered data that is based on a non-parametric analog of linear regression. The basic methodology and its variants (such as the Seasonal Mann-Kendall test) are described in Gilbert (1987) and Helsel and Hirsch (2002) and four or more independent sampling events are required. The results of the Mann-Kendall test indicate the presence or absence of a statistically significant increasing or decreasing trend in concentrations over time at a monitoring point. These results can be used to help evaluate whether the solute plume is receding, expanding, or stable.

The Mann-Kendall test for 4-40 comparable data points is very straightforward to apply and an example calculation is provided in Table 2.1. Concentration data are ordered sequentially over time and a matrix is constructed comparing each data value to subsequent values. 
WSRC-TR-2003-00331

December 31, 2004

Table 2.1

Example Calculation of the Mann-Kendall Statistic for TCE Concentrations in a Monitoring Well with Ten Sampling Events.

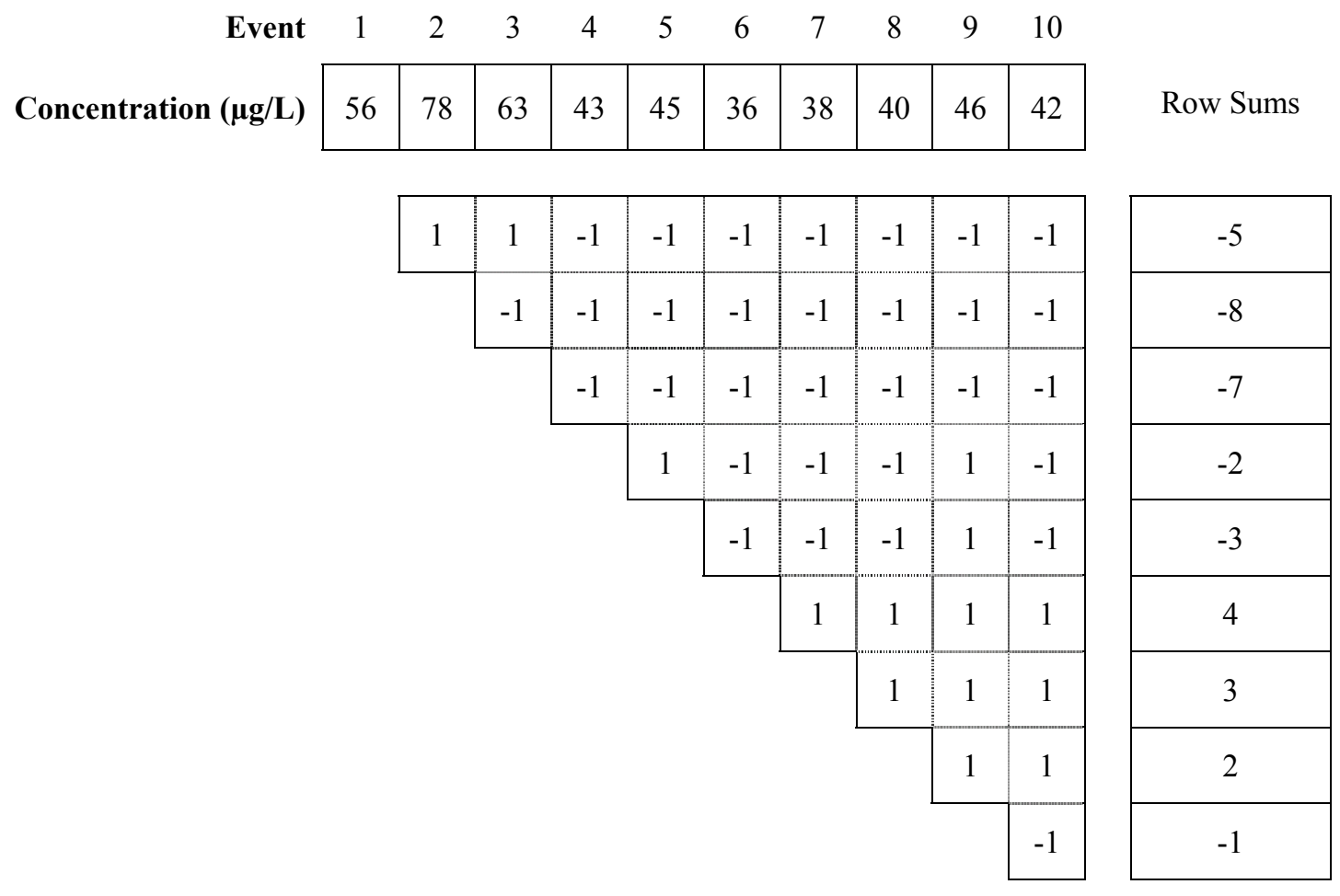


WSRC-TR-2003-00331

December 31, 2004

Starting with the earliest data point, each subsequent data point is compared and a value entered into the matrix: +1 if the later value is greater, -1 if the later value is less, and 0 if the later value is equal to the earliest data point. The process is repeated for the next data point in the sequence, comparing its value to subsequent ones, until all data points in the sequence have been compared and appropriate values entered into the matrix. The values in each row in the matrix are then summed and the row sums are then summed to generate the Mann-Kendall statistic $(S)$.

Once the $S$-statistic has been calculated, it is compared to the table of null probability values for $S$ for the number of data points $(n)$ in the series (Table 2.2). If the probability value for the calculated $S$-statistic and the number of data points $(n)$ is less than the specified significance level for the test ( $\alpha$ for one-sided; $\alpha / 2$ for two-sided), the result is significant at the $1-\alpha$ confidence level and a trend is present. The calculated $S$-statistic $(-17)$ and $n(10)$ for the example calculation in Table 2.1 correspond to a probability of 0.078 in Table 2.2. For a onesided test, this result is less than the $\alpha$ for the $90 \%$ confidence level $(\alpha=0.1)$ indicating a significant result, but is greater than the $\alpha$ for the $95 \%$ confidence level $(\alpha=0.05)$ indicating that the result is not significant at this level of confidence. Because the $S$ value is negative, it is concluded that a decreasing trend in concentration is present at the $90 \%$ confidence level. Whether this result is "significant" depends upon the significance level $(\alpha)$ specified for the test.

The Mann-Kendall test is robust to missing data points and non-detect values. Missing data points are simply ignored since they don't influence the test result. Non-detect values are replaced with a common value less than the smallest concentration value in the data series. If multiple detection limits are involved, the data must be further censored at the highest detection limit (Helsel and Hirsch, 2002). This decreases the power of the test to detect trends due to the increased number of tied values, but the impact in most situations involving small data sets is not significant. If the number of tied values is a significant proportion of the data series, the tie correction for the large-sample approximation described below can be used.

If more than 40 data points are available, a modification of the Mann-Kendall test based on the normal approximation can be used. This version of the Mann-Kendall test uses "Z" as the test statistic. The test is performed by calculating the $S$-statistic for the data set as described previously. The variance of the $S$-statistic is then calculated as:

$$
\operatorname{VAR}(S)=\frac{1}{18}\left[n(n-1)(2 n+5)-\sum_{p=1}^{q} t_{p}\left(t_{p}-1\right)\left(2 t_{p}+5\right)\right]
$$

where $n$ is the number of data points in the data set, $q$ is the number of groups of tied values, and $t_{p}$ is the number of data points in $p$ th group of tied values. If the calculated $S$ is 0 , the $Z$-statistic is also 0 . Otherwise, the $Z$-statistic is then calculated as follows:

$$
\begin{aligned}
Z & =\frac{S-1}{\sqrt{\operatorname{VAR}(S)}} & & \text { if } S>0 \\
& =\frac{S+1}{\sqrt{\operatorname{VAR}(S)}} & & \text { if } S<0
\end{aligned}
$$


WSRC-TR-2003-00331

December 31, 2004

Table 2.2

Table of Null Probabilities for the Mann-Kendall Statistic, $n=4$ through 20

\begin{tabular}{|c|c|c|c|c|c|c|c|c|c|c|c|c|c|c|c|c|c|}
\hline \multirow{2}{*}{$S$} & \multicolumn{17}{|c|}{ Number of data points $(n)$} \\
\hline & 4 & 5 & 6 & 7 & 8 & 9 & 10 & 11 & 12 & 13 & 14 & 15 & 16 & 17 & 18 & 19 & 20 \\
\hline 0 & 0.625 & 0.592 & & & 0.548 & 0.540 & & & 0.527 & 0.524 & & & 0.518 & 0.516 & & & 0.513 \\
\hline \pm 1 & & & 0.500 & 0.500 & & & 0.500 & 0.500 & & & 0.500 & 0.500 & & & 0.500 & 0.500 & \\
\hline \pm 2 & 0.375 & 0.408 & & & 0.452 & 0.460 & & & 0.473 & 0.476 & & & 0.482 & 0.484 & & & 0.487 \\
\hline \pm 3 & & & 0.360 & 0.386 & & & 0.431 & 0.440 & & & 0.457 & 0.461 & & & 0.470 & 0.473 & \\
\hline \pm 4 & 0.167 & 0.242 & & & 0.360 & 0.381 & & & 0.420 & 0.429 & & & 0.447 & 0.452 & & & 0.462 \\
\hline \pm 5 & & & 0.235 & 0.281 & & & 0.364 & 0.381 & & & 0.415 & 0.423 & & & 0.441 & 0.445 & \\
\hline \pm 6 & 0.042 & 0.117 & & & 0.274 & 0.306 & & & 0.369 & 0.383 & & & 0.412 & 0.420 & & & 0.436 \\
\hline \pm 7 & & & 0.136 & 0.191 & & & 0.300 & 0.324 & & & 0.374 & 0.385 & & & 0.411 & 0.418 & \\
\hline \pm 8 & & 0.042 & & & 0.199 & 0.238 & & & 0.319 & 0.338 & & & 0.378 & 0.388 & & & 0.411 \\
\hline \pm 9 & & & 0.068 & 0.119 & & & 0.242 & 0.271 & & & 0.334 & 0.349 & & & 0.383 & 0.391 & \\
\hline \pm 10 & & 0.008 & & & 0.138 & 0.179 & & & 0.273 & 0.295 & & & 0.345 & 0.358 & & & 0.387 \\
\hline \pm 11 & & & 0.028 & 0.068 & & & 0.190 & 0.223 & & & 0.295 & 0.313 & & & 0.354 & 0.365 & \\
\hline \pm 12 & & & & & 0.089 & 0.130 & & & 0.230 & 0.255 & & & 0.313 & 0.328 & & & 0.362 \\
\hline \pm 13 & & & 0.008 & 0.035 & & & 0.146 & 0.179 & & & 0.259 & 0.279 & & & 0.327 & 0.339 & \\
\hline \pm 14 & & & & & 0.054 & 0.090 & & & 0.190 & 0.218 & & & 0.282 & 0.299 & & & 0.339 \\
\hline \pm 15 & & & 0.001 & 0.015 & & & 0.108 & 0.141 & & & 0.225 & 0.248 & & & 0.300 & 0.314 & \\
\hline \pm 16 & & & & & 0.031 & 0.060 & & & 0.155 & 0.184 & & & 0.253 & 0.271 & & & 0.315 \\
\hline \pm 17 & & & & 0.005 & & & 0.078 & 0.109 & & & 0.194 & 0.218 & & & 0.275 & 0.290 & \\
\hline \pm 18 & & & & & 0.016 & 0.038 & & & 0.125 & 0.153 & & & 0.225 & 0.245 & & & 0.293 \\
\hline \pm 19 & & & & 0.001 & & & 0.054 & 0.082 & & & 0.165 & 0.190 & & & 0.250 & 0.267 & \\
\hline \pm 20 & & & & & 0.007 & 0.022 & & & 0.098 & 0.126 & & & 0.199 & 0.220 & & & 0.271 \\
\hline \pm 21 & & & & 0.000 & & & 0.036 & 0.060 & & & 0.140 & 0.164 & & & 0.227 & 0.245 & \\
\hline \pm 22 & & & & & 0.002 & 0.012 & & & 0.076 & 0.102 & & & 0.175 & 0.196 & & & 0.250 \\
\hline \pm 23 & & & & & & & 0.023 & 0.043 & & & 0.117 & 0.141 & & & 0.205 & 0.223 & \\
\hline \pm 24 & & & & & 0.001 & 0.006 & & & 0.058 & 0.082 & & & 0.153 & 0.174 & & & 0.230 \\
\hline \pm 25 & & & & & & & 0.014 & 0.030 & & & 0.096 & 0.120 & & & 0.184 & 0.203 & \\
\hline \pm 26 & & & & & 0.000 & 0.003 & & & 0.043 & 0.064 & & & 0.133 & 0.154 & & & 0.211 \\
\hline \pm 27 & & & & & & & 0.008 & 0.020 & & & 0.079 & 0.101 & & & 0.165 & 0.184 & \\
\hline \pm 28 & & & & & & 0.001 & & & 0.031 & 0.050 & & & 0.114 & 0.135 & & & 0.193 \\
\hline
\end{tabular}


WSRC-TR-2003-00331

December 31, 2004

Table 2.2 - Continued

Table of Null Probabilities for the Mann-Kendall Statistic, $n=4$ through 20

\begin{tabular}{|c|c|c|c|c|c|c|c|c|c|c|c|c|c|c|c|c|c|}
\hline \multirow{2}{*}{$S$} & \multicolumn{17}{|c|}{ Number of Data Points ( $n$ ) } \\
\hline & 4 & 5 & 6 & 7 & 8 & 9 & 10 & 11 & 12 & 13 & 14 & 15 & 16 & 17 & 18 & 19 & 20 \\
\hline \pm 29 & & & & & & & 0.005 & 0.013 & & & 0.063 & 0.084 & & & 0.147 & 0.166 & \\
\hline \pm 30 & & & & & & 0.000 & & & 0.022 & 0.038 & & & 0.097 & 0.118 & & & 0.176 \\
\hline \pm 31 & & & & & & & 0.002 & 0.008 & & & 0.050 & 0.070 & & & 0.130 & 0.149 & \\
\hline \pm 32 & & & & & & & & & 0.016 & 0.029 & & & 0.083 & 0.102 & & & 0.159 \\
\hline \pm 33 & & & & & & & 0.001 & 0.005 & & & 0.040 & 0.057 & & & 0.115 & 0.133 & \\
\hline \pm 34 & & & & & & & & & 0.010 & 0.021 & & & 0.070 & 0.088 & & & 0.144 \\
\hline \pm 35 & & & & & & & 0.000 & 0.003 & & & 0.031 & 0.046 & & & 0.100 & 0.119 & \\
\hline \pm 36 & & & & & & & & & 0.007 & 0.015 & & & 0.058 & 0.076 & & & 0.130 \\
\hline \pm 37 & & & & & & & & 0.002 & & & 0.024 & 0.037 & & & 0.088 & 0.105 & \\
\hline \pm 38 & & & & & & & & & 0.004 & 0.011 & & & 0.048 & 0.064 & & & 0.117 \\
\hline \pm 39 & & & & & & & & 0.001 & & & 0.018 & 0.029 & & & 0.076 & 0.093 & \\
\hline \pm 40 & & & & & & & & & 0.003 & 0.007 & & & 0.039 & 0.054 & & & 0.104 \\
\hline \pm 41 & & & & & & & & 0.000 & & & 0.013 & 0.023 & & & 0.066 & 0.082 & \\
\hline \pm 42 & & & & & & & & & 0.002 & 0.005 & & & 0.032 & 0.046 & & & 0.093 \\
\hline \pm 43 & & & & & & & & & & & 0.010 & 0.018 & & & 0.056 & 0.072 & \\
\hline \pm 44 & & & & & & & & & 0.001 & 0.003 & & & 0.026 & 0.038 & & & 0.082 \\
\hline \pm 45 & & & & & & & & & & & 0.007 & 0.014 & & & 0.048 & 0.062 & \\
\hline \pm 46 & & & & & & & & & 0.000 & 0.002 & & & 0.021 & 0.032 & & & 0.073 \\
\hline \pm 47 & & & & & & & & & & & 0.005 & 0.010 & & & 0.041 & 0.054 & \\
\hline \pm 48 & & & & & & & & & & 0.001 & & & 0.016 & 0.026 & & & 0.064 \\
\hline \pm 49 & & & & & & & & & & & 0.003 & 0.008 & & & 0.034 & 0.047 & \\
\hline \pm 50 & & & & & & & & & & 0.001 & & & 0.013 & 0.021 & & & 0.056 \\
\hline \pm 51 & & & & & & & & & & & 0.002 & 0.006 & & & 0.029 & 0.040 & \\
\hline \pm 52 & & & & & & & & & & 0.000 & & & 0.010 & 0.017 & & & 0.049 \\
\hline \pm 53 & & & & & & & & & & & 0.002 & 0.004 & & & 0.024 & 0.034 & \\
\hline \pm 54 & & & & & & & & & & & & & 0.008 & 0.014 & & & 0.043 \\
\hline \pm 55 & & & & & & & & & & & 0.001 & 0.003 & & & 0.020 & 0.029 & \\
\hline \pm 56 & & & & & & & & & & & & & 0.006 & 0.011 & & & 0.037 \\
\hline
\end{tabular}


WSRC-TR-2003-00331

December 31, 2004

Table 2.2 - Continued

Table of Null Probabilities for the Mann-Kendall Statistic, $n=4$ through 20

\begin{tabular}{|c|c|c|c|c|c|c|c|c|c|c|c|c|c|c|c|c|c|}
\hline \multirow{2}{*}{$S$} & \multicolumn{17}{|c|}{ Number of Data Points (n) } \\
\hline & 4 & 5 & 6 & 7 & 8 & 9 & 10 & 11 & 12 & 13 & 14 & 15 & 16 & 17 & 18 & 19 & 20 \\
\hline \pm 57 & & & & & & & & & & & 0.001 & 0.002 & & & 0.016 & 0.025 & \\
\hline \pm 58 & & & & & & & & & & & & & 0.004 & 0.009 & & & 0.032 \\
\hline \pm 59 & & & & & & & & & & & 0.000 & 0.001 & & & 0.013 & 0.021 & \\
\hline \pm 60 & & & & & & & & & & & & & 0.003 & 0.007 & & & 0.027 \\
\hline \pm 61 & & & & & & & & & & & & 0.001 & & & 0.011 & 0.017 & \\
\hline \pm 62 & & & & & & & & & & & & & 0.002 & 0.005 & & & 0.023 \\
\hline \pm 63 & & & & & & & & & & & & 0.001 & & & 0.009 & 0.014 & \\
\hline \pm 64 & & & & & & & & & & & & & 0.002 & 0.004 & & & 0.020 \\
\hline \pm 65 & & & & & & & & & & & & 0.000 & & & 0.007 & 0.012 & \\
\hline \pm 66 & & & & & & & & & & & & & 0.001 & 0.003 & & & 0.017 \\
\hline \pm 67 & & & & & & & & & & & & & & & 0.005 & 0.010 & \\
\hline \pm 68 & & & & & & & & & & & & & 0.001 & 0.002 & & & 0.014 \\
\hline \pm 69 & & & & & & & & & & & & & & & 0.004 & 0.008 & \\
\hline \pm 70 & & & & & & & & & & & & & 0.001 & 0.002 & & & 0.012 \\
\hline \pm 71 & & & & & & & & & & & & & & & 0.003 & 0.006 & \\
\hline \pm 72 & & & & & & & & & & & & & 0.000 & 0.001 & & & 0.010 \\
\hline \pm 73 & & & & & & & & & & & & & & & 0.003 & 0.005 & \\
\hline \pm 74 & & & & & & & & & & & & & & 0.001 & & & 0.008 \\
\hline \pm 75 & & & & & & & & & & & & & & & 0.002 & 0.004 & \\
\hline \pm 76 & & & & & & & & & & & & & & 0.001 & & & 0.007 \\
\hline \pm 77 & & & & & & & & & & & & & & & 0.001 & 0.003 & \\
\hline \pm 78 & & & & & & & & & & & & & & 0.000 & & & 0.006 \\
\hline \pm 79 & & & & & & & & & & & & & & & 0.001 & 0.003 & \\
\hline \pm 80 & & & & & & & & & & & & & & & & & 0.005 \\
\hline \pm 81 & & & & & & & & & & & & & & & 0.001 & 0.002 & \\
\hline \pm 82 & & & & & & & & & & & & & & & & & 0.004 \\
\hline \pm 83 & & & & & & & & & & & & & & & 0.001 & 0.002 & \\
\hline
\end{tabular}


WSRC-TR-2003-00331

December 31, 2004

Table 2.2 - Concluded

Table of Null Probabilities for the Mann-Kendall Statistic, $n=4$ through 20

\begin{tabular}{|c|c|c|c|c|c|c|c|c|c|c|c|c|c|c|c|c|c|}
\hline \multirow{2}{*}{$S$} & \multicolumn{17}{|c|}{ Number of Data Points (n) } \\
\hline & 4 & 5 & 6 & 7 & 8 & 9 & 10 & 11 & 12 & 13 & 14 & 15 & 16 & 17 & 18 & 19 & 20 \\
\hline \pm 84 & & & & & & & & & & & & & & & & & 0.003 \\
\hline \pm 85 & & & & & & & & & & & & & & & 0.000 & 0.001 & \\
\hline \pm 86 & & & & & & & & & & & & & & & & & 0.002 \\
\hline \pm 87 & & & & & & & & & & & & & & & & 0.001 & \\
\hline \pm 88 & & & & & & & & & & & & & & & & & 0.002 \\
\hline \pm 89 & & & & & & & & & & & & & & & & 0.001 & \\
\hline \pm 90 & & & & & & & & & & & & & & & & & 0.002 \\
\hline \pm 91 & & & & & & & & & & & & & & & & 0.001 & \\
\hline \pm 92 & & & & & & & & & & & & & & & & & 0.001 \\
\hline \pm 93 & & & & & & & & & & & & & & & & 0.000 & \\
\hline \pm 94 & & & & & & & & & & & & & & & & & 0.001 \\
\hline \pm 95 & & & & & & & & & & & & & & & & & \\
\hline \pm 96 & & & & & & & & & & & & & & & & & 0.001 \\
\hline \pm 97 & & & & & & & & & & & & & & & & & \\
\hline \pm 98 & & & & & & & & & & & & & & & & & 0.001 \\
\hline \pm 99 & & & & & & & & & & & & & & & & & \\
\hline \pm 100 & & & & & & & & & & & & & & & & & 0.000 \\
\hline
\end{tabular}


WSRC-TR-2003-00331

December 31, 2004

The sign of the calculated $Z$ indicates whether a trend is increasing (positive) or decreasing (negative). Once the $Z$-statistic has been calculated, it is compared to the table of null probability values for $Z$ that can be found in most statistics texts. Critical values for the $Z$-statistic at probabilities for the commonly used significance levels for one-sided $(\mathrm{p}=\alpha)$ and two-sided $(\mathrm{p}=\alpha / 2)$ tests are $1.29(\mathrm{p}=0.1), 1.64(\mathrm{p}=0.05)$, and $1.96(\mathrm{p}=0.025)$.

A general consideration for using the Mann-Kendall test is that a non-significant result does not demonstrate stability since the result could be due to concentrations at the monitoring point actually being at steady state (stable) or to the data set being inadequate to provide a statistically significant result (Barden, 2003). Failing to reject $\mathrm{H}_{0}$ does not mean that it was "proven" that there is no trend. Rather, it is a statement that the evidence available is not sufficient to conclude that there is a trend at the specified confidence level.

A suggested approach to dealing with the issue of a non-significant result for the MannKendall test is to use the coefficient of variation as an indication, or "test," of stability (Wiedemeier et al., 1999; GSI, 1998; Ling et al., 2003). The coefficient of variation (CV) measures the spread of a set of data as a proportion of its mean and the suggested approach concludes that a Mann-Kendall test that is not significant at the $90 \%$ confidence level where $C V<1$ indicates stability. However, the coefficient of variation is a relative measure of variation described by the ratio of the sample standard deviation to the sample mean. Thus, it depends upon both values and has no implicit meaning. If the mean value is large, even a small $C V$ can include significant variation. Data series with "low" values for $C V$ certainly show less scatter in the data, but there is no objective basis for using a particular value of $C V$ to determine "stability."

A useful variation on the Mann-Kendall test is a test for "homogeneity of stations" (Gilbert, 1987; Helsel and Hirsch, 2002). This test essentially pools the results for Mann-Kendall tests at individual monitoring points and allows statements to be made about consistency of trends throughout the plume or portions of the plume (e.g., whether the trends at all monitoring points are in the same direction - all increasing or all decreasing). Such a general statement about the presence or absence of monotonic trends is useful for making interpretations of the overall behavior of the entire plume or specific portions of the plume. For chlorinated solvent solute plumes, these results can be used in combination with geochemical data to discern different types of environments.

The presence of seasonal variability in groundwater concentration time series data can make discerning trends difficult brcause it contributes short-term variation, caused by water level fluctuations and other seasonal effects, that appear as background noise in a Mann-Kendall test for the whole time series. If the source of the seasonal effect can be identified, one way to "remove" the effect is to normalize the concentration data to the source variable. For example, if groundwater concentrations are shown to be correlated with water levels in monitoring wells, they could be "normalized" by dividing concentrations by water levels. This is a simplistic 
WSRC-TR-2003-00331

December 31, 2004

approach and more sophisticated data normalization techniques can be used (Helsel and Hirsch, 2002).

The "Seasonal Kendall test" (Hirsch et al.,1982; Hirsch and Slack, 1984) is a modification of the Mann-Kendall test that addresses this short-term variability due to seasonality and allows evaluation of overall trends in the time series. In a seasonal Kendall test, the Mann-Kendall test is applied to each season (e.g., quarter) separately and then the results are combined for an overall test (Hirsch et al., 1982). Each season by itself may show a positive trend, none of which is significant, but the overall seasonal Kendall statistic can be quite significant. The test has all the advantages of the Mann-Kendall test, but is more robust because it removes short-term variability caused by seasonality. When successive seasons are correlated, a correction must be used based on the covariance among seasons (Hirsch and Slack, 1984).

The seasonal Kendall test consists of calculating the Mann-Kendall statistic, $S$, and its variance, $\operatorname{VAR}(S)$, for the data from each season collected over a period of years. These "seasonal" statistics are then summed and the test statistic $Z$ is calculated as previously described using the summed values. As with the normal approximation, the sign of the calculated $Z$ indicates whether a trend is increasing (positive) or decreasing (negative). The calculated $Z$ statistic then is compared to the table of null probability values for $Z$ that can be found in most statistics texts. There is some question regarding the direct application of the standard $Z$ table values for a small number of "seasons" and few years of sampling data (Gilbert, 1987). However, the exact distribution for the test statistic can be determined using the technique described in Hirsch et al. (1982).

A practical limitation on the use of the seasonal Kendall test for evaluating groundwater data in long-term monitoring of natural attenuation is that seasonal (e.g., quarterly) data must be available. If the monitoring frequency is changed to annual or semi-annual basis, this seasonal data may be lost. If seasonal effects are identified during site characterization, or in the early stages of the long-term monitoring program, continued quarterly monitoring may be warranted to adequately define the impact of seasonal effects on trend results and to determine the appropriate frequency for later monitoring. Additionally, the number of data points for each season and the number of seasons considered can impact the results of the seasonal Kendall test. Generally, at least three years of monitoring data should be included in the analysis.

\subsubsection{Tests for Differences Between Groups of Data}

Another type of statistical test that is commonly suggested for evaluating groundwater concentration data for natural attenuation is a test for significant differences between groups of data. Several non-parametric methods are available for performing such comparisons and the appropriate method depends upon the number of groups to be compared and whether the data is paired (Gilbert, 1987; Helsel and Hirsch, 2002). All of these methods are non-parametric analogs of the Student's $t$-test. These methods test whether measurements from one data set are 
WSRC-TR-2003-00331

December 31, 2004

consistently larger or smaller than those from another data set, either using relative ranks of the data or the differences.

Two-sample tests are typically used for comparing earlier data sets to those from later time periods. These can include comparing concentrations in several monitoring points at two time points or comparing concentrations from an individual monitoring point for one time period to those for another time period (e.g., quarterly monitoring results for one year to those for another year). Such a comparison can essentially identify the presence or absence of a step trend in concentrations over time. Two-sample procedures should only be used when the data set(s) being analyzed can be naturally broken into two distinct time periods or when a known event has occurred that is likely to have resulted in a significant change in concentrations (Helsel and Hirsch, 2002). In general, the monotonic trend methods discussed previously are more appropriate.

The Mann-Whitney $U$ test (Mann and Whitney, 1947), also called the Wilcoxon rank sum test, is commonly suggested for the purpose of identifying step trends and has been specified in some States' regulations (e.g., New Jersey; Wisconsin). The typical application of this test is to compare concentrations from individual monitoring points for one time period to those for another time period (e.g., quarterly monitoring results for one year to those for another year). The Mann-Whitney $U$ test is based on the assumption that the two data sets are independent, meaning that there is no natural way to pair the data. However, in the typical use of this test for evaluating natural attenuation, the data for the two groups can be considered paired by "seasons" and are not really independent. Use of the Mann-Whitney $U$ test should be limited to the situations noted previously and where data set independence can be assured.

Data is considered paired when there is a natural way to spatially or temporally associate data values in each group. In many cases, the data involved in evaluating natural attenuation will be paired by location or by season (e.g., quarterly data). In such situations, a paired-sample test, such as the "sign test" or the "Wilcoxon signed rank test" (not to be confused with the Wilcoxon rank sum test), is more appropriate (Gilbert, 1987).

The sign test is more versatile than the Wilcoxon signed rank test since it has no distributional assumptions and can accommodate a few non-detect values. However, it has less ability to detect differences between populations. The test statistic is the number of data pairs where $x_{1 i}<$ $x_{2 i}$; the number of positive differences. At small sample sizes the sign test has limited utility. The Wilcoxon signed rank test is a more powerful alternative to the sign test that is more likely to detect significant differences between data sets. However, it does require that the underlying distribution is symmetrical. In some cases where the differences are not symmetric in the original units, but a logarithmic transformation of the two data sets produces symmetric differences, the Wilcoxon signed rank test is also appropriate (Helsel and Hirsch, 2002).

The Wilcoxon signed rank test involves calculating and ranking the differences $\left(D_{i}\right)$ of the data pairs. The $\mathrm{H}_{0}$ for the test is the median of the differences is zero (0). Example calculations

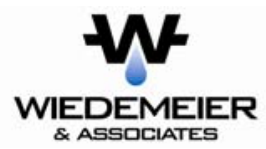


WSRC-TR-2003-00331

December 31, 2004

are shown in Table 2.3a for quarterly concentration data in a monitoring well from two years, and in Table 2.3b for concentration data from multiple monitoring wells for two years. The difference between each pair of values $\left(\mathrm{x}_{\mathrm{i}}-\mathrm{y}_{\mathrm{i}}\right)$ in the two data sets are calculated and the absolute value of the differences $\left(\left|D_{i}\right|\right)$ are then ranked from smallest to largest. The test uses only nonzero differences, so tied values $\left(x_{i}-y_{i}=0\right)$ are deleted and the sample size is reduced by the number of tied values. When two non-zero differences are tied, the average of the ranks involved is assigned to the tied values.

The signed rank $\left(R_{i}\right)$ for each pair is determined by the sign of the difference for each pair $\left(\mathrm{x}_{\mathrm{i}}-\right.$ $\mathrm{y}_{\mathrm{i}}$ ); “+” for a positive difference and "_-" for a negative difference. The test statistic $\mathrm{W}^{+}$is then calculated as the sum of the positive ranks. The $\mathrm{W}^{+}$statistic is compared to a table of critical values for $\mathrm{W}^{+}$quantiles (Table 2.4). For the appropriate sample size in Table 2.4, the critical values $\left(x\right.$ and $\left.x^{\prime}\right)$ are obtained for the significance level of the test. For a two-sided test $(p=\alpha / 2)$, the null hypothesis is rejected if $\mathrm{W}^{+} \geq \mathrm{x}$ or $\mathrm{W}^{+} \leq \mathrm{x}^{\prime}$ ( $x$ tends to be larger or smaller than $y$ ). For a one-sided test $(\mathrm{p}=\alpha)$, the null hypothesis is rejected if either $\mathrm{W}^{+} \geq \mathrm{x}(x$ tends to be larger than $y$; concentrations decrease) or $\mathrm{W}^{+} \leq \mathrm{x}^{\prime}$ ( $x$ tends to be smaller than $y$; concentrations increase).

The calculated $\mathrm{W}^{+}$statistic (9) and $n$ (4) for the example shown in Table 2.3a correspond to a probability of 0.125 in Table 2.4. For a one-sided test, the $\mathrm{W}^{+}$statistic (9) is not greater than the critical value for a significant decrease $(\mathrm{x}=10)$ or less than the critical value for a significant increase $\left(\mathrm{x}^{\prime}=0\right)$ at the $90 \%$ confidence level $(\alpha=0.1)$ indicating a non-significant result so the null hypothesis of no increase, or decrease, of concentration in this monitoring well is accepted. For the sample size in this example, the $95 \%$ confidence level for a one-sided test cannot be resolved and neither the $90 \%$ or $95 \%$ confidence levels can be resolved for a two-sided test. This illustrates the limitation of small sample sizes for such tests.

In the example shown in Table 2.3b, the symmetry of the differences for the data pairs is questionable. Recalculating the differences using the logarithms of the data values, $\log \left(\mathrm{x}_{\mathrm{i}}\right)-$ $\log \left(\mathrm{y}_{\mathrm{i}}\right)$, gives a distribution of differences that is more symmetrical. These differences are then ranked as described previously and the $\mathrm{W}^{+}$statistic is calculated. The calculated $\mathrm{W}^{+}$statistic (24) for the example shown in Table $2.3 \mathrm{~b}$ is less than the critical values for $\mathrm{x}$ and greater than the critical values for $\mathrm{x}^{\prime}$ at the $90 \%(\alpha=0.1)$ and $95 \%(\alpha=0.05)$ confidence levels for the sample size, $n(8)$. This indicates a non-significant result for either a one-sided or two-sided test at these confidence levels so the null hypotheses would be accepted and no significant change in overall concentrations for these monitoring well is indicated.

\subsubsection{Using Statistical Results}

The use of results from statistical tests in evaluating the first line of evidence for natural attenuation allows quantifiable patterns in contaminant concentrations over time to be determined. These can provide insight into solute plume behavior and changes over time in different parts of 
WSRC-TR-2003-00331

December 31, 2004

Table 2.3

Example Calculations for the Wilcoxon Signed-Rank Test Comparing Groups of Paired Data for A) Quarterly Concentration Data in a Single Monitoring Well for Two Years ( $\mu \mathrm{g} / \mathrm{L})$, and B) Concentrations in Several Monitoring Wells for Two Years $(\mu \mathrm{g} / \mathrm{L})$.

A
\begin{tabular}{|c|c|c|c|c|}
\hline Quarter & Year 1 & Year 2 & Difference & Rank \\
\hline $1^{\text {st }}$ & 32 & 27 & 5 & 4 \\
\hline $2^{\text {nd }}$ & 46 & 42 & 4 & 2.5 \\
\hline $3^{\text {rd }}$ & 28 & 30 & -2 & -1 \\
\hline $4^{\text {th }}$ & 30 & 26 & 4 & 2.5 \\
\hline \multicolumn{5}{|c}{$\mathbf{W}^{+}=$} \\
\hline
\end{tabular}

B
\begin{tabular}{|c|c|c|c|c|c|c|}
\hline Well & Year 1 & Year 2 & \multicolumn{2}{|c|}{ Raw Values } & \multicolumn{2}{c|}{ Log of Values } \\
\cline { 5 - 8 } & $(\mathbf{x})$ & $(\mathbf{y})$ & Difference & Rank & Difference & Rank \\
\hline MW-1 & 1045 & 890 & 155 & 8 & 0.070 & 5 \\
\hline MW-2 & 352 & 241 & 111 & 7 & 0.165 & 8 \\
\hline MW-3 & 256 & 287 & -31 & -6 & -0.050 & -3 \\
\hline MW-4 & 132 & 128 & 4 & 2.5 & 0.013 & 1 \\
\hline MW-5 & 46 & 40 & 6 & 5 & 0.061 & 4 \\
\hline MW-6 & 28 & 30 & -2 & -1 & -0.030 & -2 \\
\hline MW-7 & 30 & 25 & 5 & 4 & 0.079 & 6 \\
\hline MW-8 & 10 & 14 & -4 & -2.5 & -0.146 & -7 \\
\hline
\end{tabular}


WSRC-TR-2003-00331

December 31, 2004

Table 2.4

Critical Test Statistic Values for the Signed-Rank Statistic $W^{+}, n=4$ through 20 [ reject H0: at one-sided $\alpha$ when [ reject H0: at one-sided $\alpha$ when $\mathrm{W}^{+} \leq \mathrm{x}$ (table entry) (small W) ] $\mathrm{W}^{+} \geq \mathrm{x}^{\prime}$ (table entry) (large $\left.\left.\mathrm{W}\right)\right]$

\begin{tabular}{|c|c|c|c|c|c|c|c|}
\hline \multirow[b]{2}{*}{$\mathrm{n}$} & \multicolumn{3}{|c|}{$\alpha$-level } & \multirow[b]{2}{*}{$\mathrm{n}$} & \multicolumn{3}{|c|}{$\alpha$-level } \\
\hline & 0.025 & 0.05 & 0.1 & & 0.025 & 0.05 & 0.1 \\
\hline 4 & & & 0 & 4 & & & 10 \\
\hline 5 & & 0 & 2 & 5 & & 15 & 13 \\
\hline 6 & 0 & 2 & 3 & 6 & 21 & 19 & 18 \\
\hline 7 & 2 & 3 & 5 & 7 & 26 & 25 & 23 \\
\hline 8 & 3 & 5 & 8 & 8 & 33 & 31 & 28 \\
\hline 9 & 5 & 8 & 10 & 9 & 40 & 37 & 35 \\
\hline 10 & 8 & 10 & 14 & 10 & 47 & 45 & 41 \\
\hline 11 & 10 & 13 & 17 & 11 & 56 & 53 & 49 \\
\hline 12 & 13 & 17 & 21 & 12 & 65 & 61 & 57 \\
\hline 13 & 17 & 21 & 26 & 13 & 74 & 70 & 65 \\
\hline 14 & 21 & 25 & 31 & 14 & 84 & 80 & 74 \\
\hline 15 & 25 & 30 & 36 & 15 & 95 & 90 & 84 \\
\hline 16 & 29 & 35 & 42 & 16 & 107 & 101 & 94 \\
\hline 17 & 34 & 41 & 48 & 17 & 119 & 112 & 105 \\
\hline 18 & 40 & 47 & 55 & 18 & 131 & 124 & 116 \\
\hline 19 & 46 & 53 & 62 & 19 & 144 & 137 & 128 \\
\hline 20 & 52 & 60 & 69 & 20 & 158 & 150 & 141 \\
\hline
\end{tabular}


WSRC-TR-2003-00331

December 31, 2004

the solute plume that reflect the efficacy of natural attenuation processes. An important note is that none of the statistical tests described previously are tests for solute plume stability; none presently exist. In evaluating solute plume stability, it is important to combine statistical results with observations of the solute plume boundaries. The presence or absence of statistically significant trends in concentration over time at monitoring points does not necessarily translate into spatial changes in solute plume configuration. The lack of statistically significant trends in concentration over time can generally be taken to represent a steady-state condition at a given monitoring point, but this implies nothing about solute plume behavior. Consideration of results at all the monitoring points is necessary.

In evaluating statistical results for concentration data, it is necessary to consider all of the monitoring points in the solute plume. Depending on the dynamics of mass transfer from the source and the specific natural attenuation processes involved, different portions of a solute plume may exhibit different types of behaviors (Figure 2.4). No single monitoring point can provide statistical results that are definitive since different monitoring points will be located in different geochemical environments which impact the ambient degradation and transformation processes.

A general consideration for the use of statistical methods in identifying trends and evaluating solute plume behavior is that statistical significance does not necessarily imply real-world significance and statistical test results can provide a false sense of assurance regarding conclusions (Barden, 2003). It is important to always relate statistical results and evaluation back to the physical problem in the field to ensure that the results are meaningful. Changes in concentration and trends in concentration time series should be evaluated in the context of the scientific understanding of the relevant natural attenuation processes. The point is to be able to explain why the observed patterns (Figure 2.4) indicated by the statistical results are occurring. The reason for a "statistically significant" change in concentrations is not provided by the statistics themselves.

As an example, consider the results from tests for step trends. Comparison of concentration data for two successive years does not imply that the result is meaningful. The fact that concentrations in the second year are lower (or higher) than those from the previous year only demonstrates a "statistically significant" difference. This does not imply that data from subsequent years would produce the same result. A fundamental flaw in this sort of analysis is that two years of data in most hydrogeologic settings is not a very large amount and the resulting evaluation may not be substantive in the real world.

A consideration with the seasonal Mann-Kendall test is that trends of opposite sign in different seasons may offset each other, giving the impression that no trends are present. This is typically not a substantive concern since the point of the test is to determine overall trends in the data series that may help to describe solute plume behavior. However, the individual seasonal trends may be of importance for helping to unravel relationships between parameters, in which case they could be examined individually in more detail.

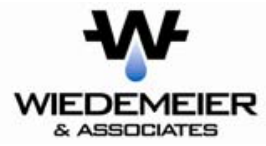



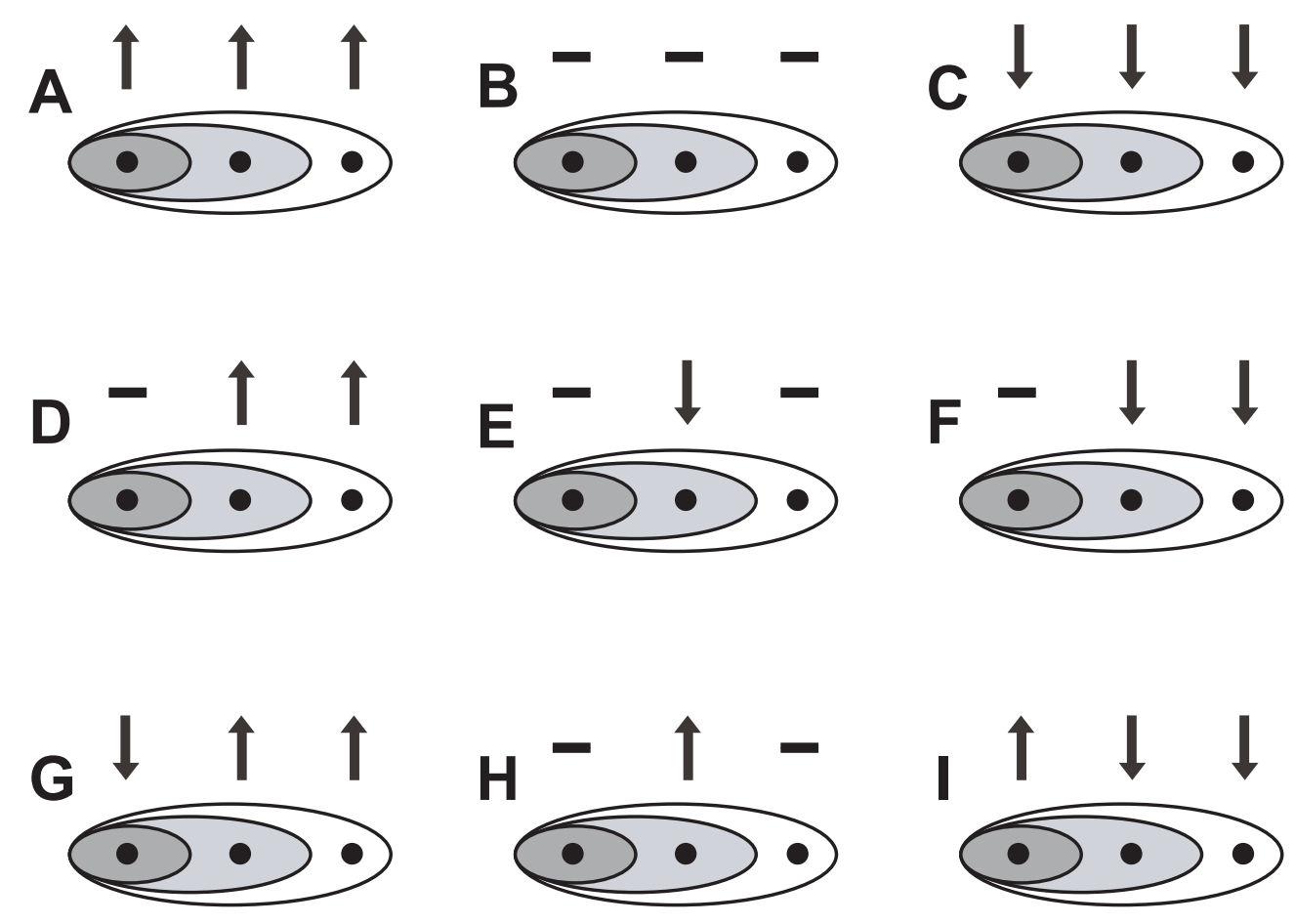

\section{Groundwater flow}

Increasing
trend

Decreasing
trend

- No trend

\section{Figure 2.4}

Solute Plume Behavior Illustrated by Concentration Trends Over Time for Monitoring Points in the Vicinity of the Source, Mid-Plume and the Distal Portion of the Plume

Westinghouse Savannah River MNA/EA Project

\begin{tabular}{|l|l|}
\hline \multicolumn{2}{|c|}{ Westinghouse Savannah River MNA/EA Project } \\
$\begin{array}{l}\text { WIEDEMEIER } 12 / 17 / 04 \\
\text { \& ASSDCIATES }\end{array}$ & $\begin{array}{l}\text { Date: Westinghouse Savannah } \\
\text { River Company } \\
\text { Project Number: 031007 } \\
\text { Revision Number: } 0\end{array}$ \\
\hline
\end{tabular}


WSRC-TR-2003-00331

December 31, 2004

Similarly, it is common for the test for "homogeneity of stations" for monitoring points in the entire solute plume to show no significant overall trend, even though trends are significant within contiguous portions of the solute plume. Careful consideration of how monitoring points should be grouped is necessary to evaluate portions of the solute plume. Graphical evaluation of the data combined with a scientific understanding of the problem should be a good guide on how to group contiguous monitoring points for statistical analysis.

\subsection{CONTAMINANT/DAUGHTER PRODUCT AND GEOCHEMICAL DATA}

Groundwater analytical data used to evaluate degradation products and geochemical parameters are essential parameters for demonstrating that geochemical conditions in the aquifer are appropriate for degradation. When the USEPA published the Technical Protocol for Evaluating Natural Attenuation of Chlorinated Solvents (USEPA, 1998), the prevailing thought was that biodegradation was the dominant mechanism working to remove tetrachloroethene (PCE), trichloroethene (TCE), and carbon tetrachloride (CT) from groundwater. In recent years it has become apparent that there are also several abiotic reductive dechlorination mechanisms that work to remove chlorinated solvents from groundwater. All of these abiotic mechanisms of reductive dechlorination rely on some form of reduced metal, typically iron. The iron can be in the form of $\mathrm{FeS}$ (troilite), marcasite and pyrite $\left(\mathrm{FeS}_{2}\right)$, magnetite, green rust $\left(\mathrm{Fe}^{2+}-\mathrm{Fe}^{3+}\right.$ hydroxy compounds), or other iron-bearing minerals. The formation of these materials in sedimentary environments requires iron- and sulfate-reducing conditions; conditions which are brought about by naturally occurring microorganisms degrading natural or anthropogenic carbon and utilizing $\mathrm{Fe}(\mathrm{III})$ and sulfate as electron acceptors. Iron(II) and $\mathrm{S}^{2-}$ are very reactive and iron-reducing and sulfate-reducing bacteria are ubiquitous in the terrestrial subsurface, so if organic carbon, $\mathrm{Fe}(\mathrm{III})$, and sulfate are present in sufficient quantities FeS will be formed.

In many cases abiotic reductive dechlorination reactions are biologically predicated (i.e., the abiotic reaction will not occur without contemporaneous biologic activity). In these cases, the degradation of PCE and TCE, whether abiotic or biological, and the abiotic degradation of dichloroethene (DCE) appears to require oxidation-reduction potential (ORP) conditions that are at least sulfate reducing. Thus, this line of evidence involves collecting data that helps determine if the system is sufficiently reducing to allow degradation of the chlorinated VOCs listed previously. Visual observations and mineralogical analyses can also be valuable for evaluating the potential for abiotic degradation. In addition, this line of evidence should allow the investigator to determine if the degradation mechanism is biological, abiotic, or a combination of the two. This line of evidence includes the collection of both soil/sediment and groundwater data.

\subsubsection{Soil/Sediment Data}

In addition to the data typically collected to evaluate the hydrogeology of a site which include hydraulic conductivity, hydraulic gradient, and total and effective porosity, two types of

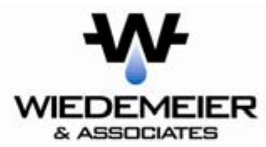


WSRC-TR-2003-00331

December 31, 2004

soil/sediment data are required to help determine the relative importance of natural attenuation mechanisms. These include TOC and field analysis of reduced iron minerals.

\subsubsection{Total Organic Carbon}

Total organic carbon analyses are required to determine the sorptive capacity of an aquifer. Sorption of organic compounds has two ramifications; 1) sorption causes slowing (retardation) of an organic solute plume, and 2) sorption generally is a reversible processes which can cause low concentrations of organic compounds to exist over a long period of time. Sorption is an important component of the natural attenuation capacity of aquifers with high TOC concentrations. Sorption generally is considered important when the TOC concentration is greater that 0.1 percent by weight of the aquifer matrix.

\subsubsection{Field Observation of Iron Minerals}

Qualitative information on the occurrence of reduced Fe(II) and iron sulfide minerals can be obtained by visual observation of samples collected during borehole drilling. Much of the color associated with sediments is provided by the presence of iron-based minerals and their oxidation state. In general there is a correlation between decreasing sediment size and increasing iron concentration (Kennedy et al., 2000). For example, the presence of oxidized iron (Fe[III]) minerals can impart the following colors to sediments (Kennedy et al., 2000):

$\begin{array}{ll}\text { Mineral } & \text { Color } \\ \text { Ferrihydrite }-\mathrm{FeOH} & \text { reddish brown } \\ \text { Göethite }-\mathrm{FeO}(\mathrm{OH}) & \text { yellow to orange } \\ \text { Hematite }-\mathrm{Fe}_{2} \mathrm{O}_{3} & \text { red to maroon } \\ \text { Magnetite }-\mathrm{Fe}_{3} \mathrm{O}_{4} & \text { black }\end{array}$

Conversely, sediments containing reduced iron such as iron sulfide minerals are typically gray to black in color. Figure 2.5 is a photograph of reduced and oxidized iron minerals. Because FeS and $\mathrm{FeS}_{2}$ cannot be differentiated visually in the field a simple field test to differentiate these materials is as follows (from Kennedy et al., 2000):

Place a few grams of sediment into a small mouth bottle such as a 160 milliliter serum bottle and add several milliliters of $6 \mathrm{~N} \mathrm{HCl}$. Cover the mouth of the bottle for 30 seconds or so. If $\mathrm{FeS}$ is present, then the distinctive "rotten egg" odor associated with $\mathrm{H}_{2} \mathrm{~S}$ will be detected. Because the gas being produced by this reaction is toxic, care should be taken to avoid inhaling too much of the gasses produced by this test. Use of such a test must be addressed through a site specific health and safety plan. 


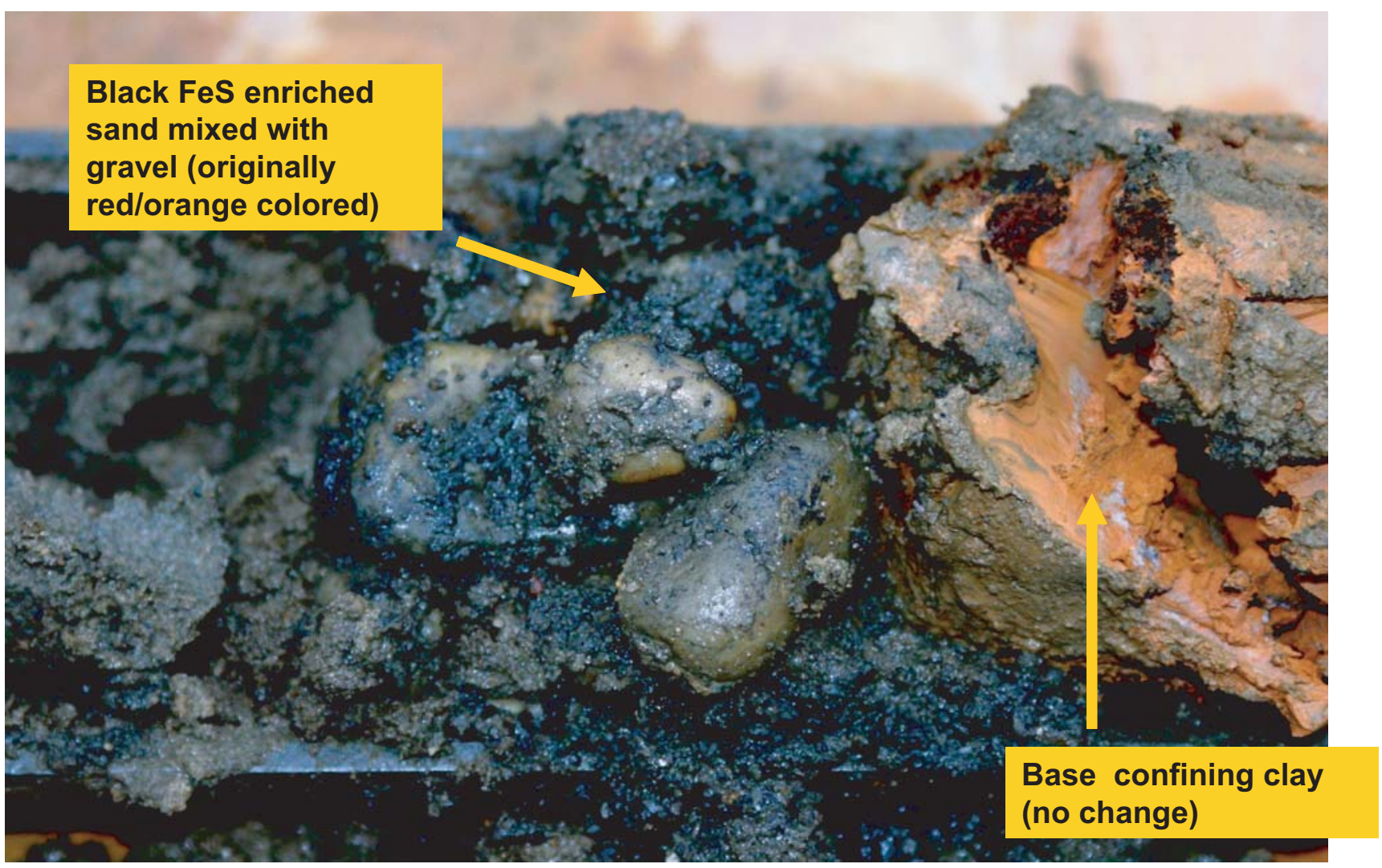

\section{Figure 2.5}

Photograph of Reduced and Oxidized Iron Minerals

Westinghouse Savannah River MNA/EA Project

\begin{tabular}{l|l} 
& Date: $12 / 17 / 04$
\end{tabular}

Client: Westinghouse Savannah River Company

WIEDEMEIER Project Number: 031007 \& ASSDCIATES 
WSRC-TR-2003-00331

December 31, 2004

In addition to these tests, a magnet can be used in the field to determine if magnetic minerals such as magnetite which facilitate abiotic degradation are present.

\subsubsection{NAPL Data}

NAPL analyses can be helpful in establishing which compounds impact a site and the strength of the source. At sites where it can be demonstrated that compounds appearing in groundwater were not present or used at a site these compounds are likely daughter products. It is possible that vinyl chloride (VC) and some of the DCE isomers can be primary contaminants in some groundwater systems. However, $\mathrm{VC}$ is not normally present as a primary contaminant in solvent spills. The reasons for this are; 1) VC was not used as a solvent, and 2) $\mathrm{VC}$ is a gas at temperatures as low as $15^{\circ} \mathrm{C}$. Thus, the presence of $\mathrm{VC}$ in groundwater associated with a chlorinated ethene spill is strong evidence of reductive dechlorination. Also, cis-DCE (rather than trans-DCE or 1,1-DCE) is usually produced from the reductive dechlorination of TCE (both abiotically and biologically). As a rule of thumb, if the ratio of cis-1,2-DCE to trans-1,2-DCE plus 1,1-DCE is greater than about 5:1, then the observed DCE is likely the result of degradation of TCE and/or PCE. When 1,1,1-TCA is present or is suspected to have been present, 1,1-DCE may be present as the result of the abiotic dehydrohalogenation of this compound. This must be taken into account when evaluating the ratio of DCE isomers. Based on these concepts, VC and/or cis-DCE are usually reliable indicators of reductive dechlorination. In addition, the presence of ethene and ethane typically are indicative of reductive dechlorination. However, these products are extremely transitory and low detection limits typically are required to identify and quantify these compounds.

\subsubsection{Groundwater Analytical Data}

There are several groundwater analyses that can be used to evaluate and quantify natural attenuation and enhanced remediation. These analyses are presented in Table 1.3 and discussed in the sections that follow.

\subsubsection{Daughter Products}

Concentrations of chlorinated solvents and their degradation (daughter) products give a direct indication of the presence or absence of degradation (both abiotic and biological) processes. In many cases the production of cis-DCE, $\mathrm{VC}$, and chloride ions along aquifer flowpaths is direct evidence of degradation. For example, if TCE was the only contaminant disposed of at a site, then any cis-DCE or VC present at the site must have come from the degradation of the parent TCE.

\subsubsection{Chloride}

During degradation of chlorinated hydrocarbons dissolved in groundwater, chloride is released into the groundwater, resulting in the accumulation of chloride. This results in chloride 
WSRC-TR-2003-00331

December 31, 2004

concentrations in groundwater in the contaminant plume that are elevated relative to background concentrations. In aquifers with low background concentrations of chloride, the concentration of this material in the solute plume can be seen to increase as chlorinated solvents are degraded.

Elemental chlorine is the most abundant of the halogens. Although chlorine can occur in oxidation states ranging from $\mathrm{Cl}^{-}$to $\mathrm{Cl}^{+7}$, the chloride form $\left(\mathrm{Cl}^{-}\right)$is the only form of major significance in natural waters (Hem, 1985). Chloride forms ion pairs or complex ions with some of the cations present in natural waters, but these complexes are not strong enough to be of significance in the chemistry of fresh water (Hem, 1985). The chemical behavior of chloride is neutral. Chloride ions generally do not enter into oxidation-reduction reactions, form no important soluble complexes with other ions (unless the chloride concentration is extremely high), do not form salts of low solubility, are not significantly adsorbed on mineral surfaces, and play few vital biochemical roles (Hem, 1985). Thus, physical processes control the migration of chloride ions in the subsurface. Kaufman and Orlob (1956) conducted tracer experiments in groundwater, and found that chloride moved through most of the soils/sediments tested more conservatively (i.e., with less retardation and loss) than any of the other tracers tested. Because of the neutral chemical behavior of chloride, it can be used as a conservative tracer to estimate degradation rates.

\subsubsection{Dissolved Oxygen}

The concentration of dissolved oxygen in an aquifer is a very important parameter for determining if the system is capable of supporting the degradation of chlorinated solvents in the terrestrial subsurface. If dissolved oxygen is present at concentrations greater than about 0.5 $\mathrm{mg} / \mathrm{L}$ (assuming accurate measurements) then reductive dechlorination (biological or abiotic) will not occur to any great extent.

Dissolved oxygen is the favored electron acceptor used by microbes for the biodegradation of most forms of organic carbon. Strictly anaerobic bacteria generally cannot function at dissolved oxygen concentrations greater than about $0.5 \mathrm{mg} / \mathrm{L}$ and hence $\mathrm{Fe}(\mathrm{III})$ reduction, sulfate reduction, methanogenesis, and reductive dechlorination (biological or abiotic) cannot occur. This is why it is important to have a source of carbon in the aquifer that can be used by aerobic microorganisms as a primary substrate. During aerobic respiration, dissolved oxygen concentrations decrease. The absence of dissolved oxygen is a prerequisite for iron- and sulfatereduction.

Dissolved oxygen measurements should be taken during well purging and immediately before sample acquisition using a direct-reading meter. Each of these measurements should be recorded during well purging. Because many well purging techniques can allow aeration of groundwater samples, it is important to minimize the potential for aeration during well purging. Because of the difficulty in obtaining accurate dissolved oxygen measurements, especially when the concentration falls below about 1 milligram per liter, these measurements should be used in a qualitative manner. One use of dissolved oxygen measurements is during well purging. Stabilization of dissolved oxygen concentrations, in conjunction with $\mathrm{pH}$, temperature,

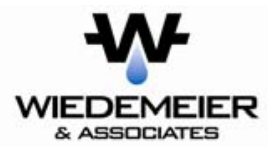


WSRC-TR-2003-00331

December 31, 2004

conductivity, and ORP can be useful during well purging to determine when the well has been purged sufficiently to give representative samples.

If the aquifer is aerobic, then the measurement of reduced dissolved gasses should not be undertaken. The reason for this is that the presence of dissolved oxygen precludes the formation of these gasses which include hydrogen sulfide, methane, ethene, ethane, and hydrogen.

\subsubsection{Nitrate}

After dissolved oxygen has been depleted in the microbiological treatment zone, nitrate is used as an electron acceptor for anaerobic biodegradation of organic carbon via denitrification. During denitrification, nitrate concentrations measured in groundwater decrease. Thus, nitrate concentrations below background in areas with dissolved contamination provide evidence for denitrification. Nitrate is an electron acceptor that competes with dehalorespiration. The absence of nitrate is a prerequisite for iron- and sulfate-reduction so it is important that this compound is absent in groundwater for biological and abiotic reactions to proceed.

\subsubsection{5 $\mathrm{Fe}(\mathrm{II})$}

When $\mathrm{Fe}(\mathrm{III})$ is used as an electron acceptor during anaerobic biodegradation of organic carbon, it is reduced to Fe(II), which is somewhat soluble in water. Fe(II) concentrations are used as an indication that anaerobic degradation of organic carbon has occurred via $\mathrm{Fe}(\mathrm{III})$ reduction. The presence of $\mathrm{Fe}$ (II) (and sulfide) is required in order for many of the abiotic reactions described elsewhere in this document to occur. In addition, Bradley and Chapelle (1996; 1997) have shown that VC and DCE can be biologically oxidized under iron-reducing conditions. Fe(III) is an electron acceptor that competes with dehalorespiration.

\subsubsection{Sulfate and Sulfide}

Sulfate is used as an electron acceptor for anaerobic biodegradation during sulfate reduction wherein sulfate $\left(\mathrm{SO}_{4}{ }^{2-}\right)$ is reduced to sulfide $\left(\mathrm{HS}^{-}\right.$or $\left.\mathrm{H}_{2} \mathrm{~S}\right)$. During this process, sulfate concentrations measured in groundwater decrease and sulfide is produced. The sulfide produced during sulfate reduction is very reactive and in most cases is quickly complexed with Fe(II). From the standpoint of chlorinated solvent degradation, sulfate reduction is important for two reasons; 1) reductive dechlorination caused by biological processes does not become efficient until the dominant terminal-electron accepting process is sulfate reduction or methanogenesis, and 2) sulfate reduction is important for abiotic mechanisms of reductive dechlorination because it results in the production of sulfide. High sulfate concentrations will likely have the following two ramifications:

1) They will reduce the efficiency of biological reductive dechlorination because sulfate is a competing electron acceptor; and 
WSRC-TR-2003-00331

December 31, 2004

2) They will increase the efficiency of abiotic reductive dechlorination, especially if appreciable amounts of $\mathrm{Fe}(\mathrm{II})$ are present.

\subsubsection{Methane}

As implied by the name, methanogenesis results in the production of methane during the biodegradation of organic carbon. The presence of methane in groundwater is indicative of strongly reducing conditions and biologically mediated reductive dechlorination is typically very efficient under these conditions. Analysis of methane concentrations in groundwater should be conducted by a qualified laboratory. It is important that the detection limit for methane be on the order of $1 \mu \mathrm{g} / \mathrm{L}$, especially when evaluating the natural attenuation or enhanced remediation of chlorinated solvents.

The presence of methane generally is indicative of a Type I/Type II Environment where reductive dechlorination to $\mathrm{VC}$ and then to ethene/ethane is likely. If no $\mathrm{VC}$ is present then abiotic reactions should be evaluated. Methane can also be transported by advective groundwater flow. Because of this, its presence in a groundwater does not ensure that the immediate environment is methanogenic; only that methanogenic conditions exist in the vicinity. Evaluating the presence of methane in concert with the other geochemical indicators (e.g., Fe[II] and $\mathrm{SO}_{4}{ }^{2-}$ ) is essential.

\subsubsection{Ethene/Ethane}

Ethene and ethane are the end products of both biological and abiotic reductive dechlorination. Because these compounds are extremely transitory their concentrations typically remain low with concentrations at sites with active reductive dechlorination on the order of hundreds of micrograms per liter.

\subsubsection{Acetylene}

Acetylene is a product of the abiotic dechlorination of chlorinated aliphatic hydrocarbons (e.g., PCE and TCE) by iron sulfides. Although the exact pathway has not been fully determined, it is thought that the pathway for TCE oxidation is via the cis-dichlorovinyl radical directly to acetylene (Butler and Hayes, 1999). Because acetylene is unstable and very transient, it is hard to detect. Researchers are currently working on preservation methods that should allow the detection of acetylene at low concentrations.

\subsubsection{Oxidation-Reduction Potential}

The oxidation-reduction potential (ORP), or "redox" potential, of groundwater is a measure of the electrochemical potential associated with transfer of electrons from one substance to another that indicates the redox condition of the system. Oxidation-reduction reactions involving organic compounds (natural or anthropogenic) in groundwater are usually biologically mediated, and the ORP of a groundwater system depends upon and influences rates of degradation (both biological 
WSRC-TR-2003-00331

December 31, 2004

and abiotic). The ORP of groundwater as measured with field meters generally ranges from -400 millivolts $(\mathrm{mV})$ to $800 \mathrm{mV}$. In general, the lower the ORP of groundwater the more reducing the system is, and the more likely that reductive dechlorination will be efficient.

The measured ORP value depends upon the potential of the reference electrode used in the measurement. The "Eh" is a measure of ORP relative to the "standard hydrogen electrode" that is assigned a potential of $0 \mathrm{mV}$ and is used in theoretical redox calculations. Measured ORP values can be converted to equivalent Eh values by:

$$
\mathrm{Eh}=E_{\text {measured }}+E_{\text {ref.electrode }} .
$$

The silver-silver chloride $(\mathrm{Ag}-\mathrm{AgCl})$ reference electrode used in most field ORP meters has $E=$ $222.3 \mathrm{mV}$ at $25^{\circ} \mathrm{C}$. Another commonly used measure of the redox condition is "pE" which is defined as the negative common logarithm of the "free electron" activity $\left(\mathrm{pE}=-\log _{10}[\mathrm{e}]\right)$. The $\mathrm{pE}$ is a purely theoretical construct that is used to visualize relationships among redox sensitive species. The $\mathrm{pE}$ is related to the Eh by the Nerst factor:

$$
\mathrm{pE}=\frac{[F] \mathrm{Eh}}{2.303 R T}=\frac{\mathrm{Eh}(\mathrm{mV})}{59.157} @ 25^{\circ} \mathrm{C}
$$

where $F$ is the Faraday constant $\left(9.64846 \times 10^{4} \mathrm{C} / \mathrm{mol}.\right), R$ is the Universal Gas Constant $(8.3144$ $\left.\mathrm{J} / \mathrm{mol}-{ }^{\circ} \mathrm{K}\right)$, and $T$ is temperature $\left({ }^{\circ} \mathrm{K}\right)$.

In general, ORP readings should only be used on a qualitative basis in comparing the relative ORP values. ORP measurements assume that the system is at equilibrium, and this is rarely the case in most groundwater systems (Deutsch, 1997; Stumm and Morgan, 1996). Complicating factors include problems with the measurement electrodes, kinetic constraints on redox processes resulting in redox disequilibria, and mixing of waters with different potentials. If the accuracy of ORP measurements are of interest, the measured values should be verified with measured relative concentrations of the members of one or more redox couples (Stumm and Morgan, 1996).

ORP measurements can be used to provide real-time data on the location of the contaminant plume, especially in areas undergoing anaerobic biodegradation. Mapping the ORP of goundwater while in the field helps the field scientist to determine the approximate location of the contaminant plume. To map the ORP of the groundwater while in the field, it is important to have at least one ORP measurement (preferably more) from a well located upgradient from, or peripheral to, the plume. ORP measurements should be taken during well purging and immediately before sample acquisition using a direct-reading meter. Because most well purging techniques can allow aeration of collected groundwater samples (which can affect ORP measurements), it is important to minimize potential aeration by using a flow-through cell as outlined previously. 
WSRC-TR-2003-00331

December 31, 2004

\section{SECTION 3}

\section{SUPPLEMENTAL LINES OF EVIDENCE}

In many cases, evaluation of the primary lines of evidence discussed in the preceeding section will be adequate to evaluate the natural attenuation of a chlorinated solvent solute plume. However, at some sites additional evidence may be useful for deducing the natural attenuation capacity of an aquifer and the effects of enhanced remediation. These lines of evidence can be particularly useful for those portions of the plume where the fate of VOCs is not apparent. For example, in some cases degradation can be enhanced through bioaugmentation or the addition of materials that stimulate the production of iron sulfide minerals to aid abiotic degradation. In many cases recent studies suggest that biologically predicated abiotic degradation may be more efficient than dehalorespiration. According to one researcher, abiotic degradation can occur with half-lives for PCE/TCE as low as 19 days (Dr. Lonnie Kennedy, personal communication).

The supplemental lines of evidence discussed in this section can, in some cases, provide critical information to support monitored natural attenuation and enhanced attenuation approaches. However, evaluation of these supplemental lines of evidence will result in varying amounts of additional effort and cost, both in sampling and analysis and in data interpretation. Therefore, it is important that the investigator consider how the information provided by the supplemental data will contribute to the necessary understanding of natural attenuation processes at a site.

\subsection{SUPPLEMENTAL GROUNDWATER GEOCHEMICAL DATA}

In some cases additional geochemical data can be useful for evaluating the predominant geochemical environment in groundwater. Table 3.1 summarizes some of the supplemental groundwater parameters that may be useful for evaluating natural attenuation and enhanced remediation.

\subsubsection{Mn(II)}

When $\mathrm{Mn}(\mathrm{IV})$ is used as an electron acceptor during anaerobic biodegradation of organic carbon, it is reduced to $\mathrm{Mn}(\mathrm{II})$. $\mathrm{Mn}(\mathrm{II})$ concentrations can thus be used as an indicator that anaerobic degradation of organic carbon has occurred via $\mathrm{Mn}$ (IV) reduction. Changes in $\mathrm{Mn}$ (II) concentrations inside the contaminant plume versus background concentrations can be used to estimate the mass of contaminant that has been biodegraded by $\mathrm{Mn}(\mathrm{IV})$ reduction. $\mathrm{Mn}(\mathrm{IV})$ is an electron acceptor that competes with iron reduction and dehalorespiration. 
Table 3.1

Supplemental Groundwater Data for Evaluating Natural Attenuation and Enhanced Remediation

\begin{tabular}{|c|c|c|c|c|c|}
\hline Analysis & Method/Reference & Comments & Data Use & $\begin{array}{l}\text { Sample Volume, Sample Container, } \\
\text { Sample Preservation }\end{array}$ & $\begin{array}{l}\text { Field or } \\
\text { Fixed-Base } \\
\text { Laboratory }\end{array}$ \\
\hline \multicolumn{6}{|c|}{ Geochemical analyses } \\
\hline Manganese & $\begin{array}{l}\text { Colorimetric Hach } \\
\text { Method }\end{array}$ & $\begin{array}{l}\text { Filter with } 0.45 \\
\text { micron inline } \\
\text { filter. }\end{array}$ & $\begin{array}{l}\text { May indicate an anaerobic degradation } \\
\text { process due to depletion of oxygen, and } \\
\text { nitrate. Interferences can occur if hydrogen } \\
\text { sulfide and high concentrations of calcium } \\
\text { are present. }\end{array}$ & $\begin{array}{l}\text { Collect } 100 \mathrm{~mL} \text { of water in a } \\
\text { headspace-free container to eliminate } \\
\text { introduction of oxygen and analyze as } \\
\text { soon as possible. }\end{array}$ & Field \\
\hline Alkalinity & Hach digital titrate & $\begin{array}{l}\text { Field filter with } \\
0.45 \text { micron inline } \\
\text { filter. Carbonate } \\
\text { alkalinity only } \\
\text { significant at } \mathrm{pH} \\
>8.5 \text {. }\end{array}$ & $\begin{array}{l}\text { General water quality parameter used (1) to } \\
\text { measure the buffering capacity of } \\
\text { groundwater, and (2) as a marker to verify } \\
\text { that all site samples are obtained from the } \\
\text { same groundwater system. }\end{array}$ & $\begin{array}{l}\text { Collect } 100 \mathrm{~mL} \text { of water in glass } \\
\text { container. Analyze as soon as } \\
\text { possible. }\end{array}$ & Field \\
\hline $\begin{array}{l}\text { Dissolved } \\
\text { Inorganic } \\
\text { Carbon } \\
\text { (DIC) }\end{array}$ & E415.1 & $\begin{array}{l}\text { Filter in the field } \\
\text { with } 0.45 \text { micron } \\
\text { inline filter. } \\
\text { Minimize aeration } \\
\text { of sample and fill } \\
\text { sample container } \\
\text { completely to } \\
\text { avoid loss of } \mathrm{CO}_{2} \text {. }\end{array}$ & $\begin{array}{l}\text { An increase of DIC above background } \\
\text { concentrations provides a footprint in } \\
\text { groundwater that has been remediated by } \\
\text { biological processes. Carbon dioxide is the } \\
\text { most universal end product of chlorinated } \\
\text { hydrocarbon biodegradation. DIC is the } \\
\text { sum of dissolved carbon dioxide, carbonic } \\
\text { acid, bicarbonate and carbonate. }\end{array}$ & $\begin{array}{l}\text { Collect } 1 \times 250 \mathrm{~mL} \text { glass amber } \\
\text { container, preserve with } \mathrm{H}_{2} \mathrm{SO}_{4} \text { and } \\
\text { cool to }=4{ }^{\circ} \mathrm{C} \text {. }\end{array}$ & $\begin{array}{l}\text { Fixed-base } \\
\text { laboratory }\end{array}$ \\
\hline $\begin{array}{l}\text { Anions }-\mathrm{Cl}, \\
\mathrm{Fl}, \text { and } \mathrm{SO}_{4}, \\
\mathrm{NO}_{3}, \mathrm{HCO}_{3}, \\
\mathrm{CO}_{3}, \mathrm{Br}\end{array}$ & $\begin{array}{l}\text { Method } \mathrm{E} 300(\mathrm{Cl}, \\
\mathrm{Fl}, \mathrm{SO}_{4}, \mathrm{NO}_{3} \text {, and } \\
\mathrm{Br}) . \text { Method } \\
\mathrm{E} 310.1\left(\mathrm{HCO}_{3} \text { and }\right. \\
\left.\mathrm{CO}_{3}\right)\end{array}$ & $\begin{array}{l}\text { Filter in the field } \\
\text { with } 0.45 \text { micron } \\
\text { inline filter. }\end{array}$ & $\begin{array}{l}\text { Can be used graphically (e.g., Piper and } \\
\text { Stiff diagrams) with cations to identify } \\
\text { different hydrogeologic units and identify } \\
\text { areas impacted by contamination. }\end{array}$ & $\begin{array}{l}\text { Collect } 1 \times 1 \text { Liter poly container and } \\
\text { cool to }=4{ }^{\circ} \mathrm{C} \text {. }\end{array}$ & $\begin{array}{l}\text { Fixed-base } \\
\text { laboratory }\end{array}$ \\
\hline $\begin{array}{l}\text { Cations - } \\
\mathrm{Ca}, \mathrm{Mg}, \mathrm{K}, \\
\text { and } \mathrm{Na}, \mathrm{Mn}, \\
\mathrm{Fe}\end{array}$ & SW6010 & $\begin{array}{l}\text { Filter in the field } \\
\text { with } 0.45 \text { micron } \\
\text { inline filter. }\end{array}$ & $\begin{array}{l}\text { Can be used graphically with anions to } \\
\text { identify different hydrogeologic units and } \\
\text { identify areas impacted by contamination. }\end{array}$ & $\begin{array}{l}\text { Collect } 1 \times 500 \mathrm{~mL} \text { poly container, } \\
\text { preserve with } \mathrm{HNO}_{3} \text { and cool to }=4 \\
{ }^{\circ} \mathrm{C} \text {. }\end{array}$ & $\begin{array}{l}\text { Fixed-base } \\
\text { laboratory }\end{array}$ \\
\hline
\end{tabular}




\section{Table 3.1 (Concluded)}

Supplemental Groundwater Data for Evaluating Natural Attenuation and Enhanced Remediation

\begin{tabular}{|c|c|c|c|c|c|}
\hline Analysis & Method/Reference & Comments & Data Use & $\begin{array}{l}\text { Sample Volume, Sample } \\
\text { Container, Sample Preservation }\end{array}$ & $\begin{array}{l}\text { Field or Fixed-Base } \\
\text { Laboratory }\end{array}$ \\
\hline Hydrogen & $\begin{array}{l}\text { Equilibration with } \\
\text { gas in the field } \\
\text { analyzed with a } \\
\text { reducing gas detector } \\
\text { in the lab. }\end{array}$ & $\begin{array}{l}\text { Supplemental } \\
\text { specialized analysis } \\
\text { to be completed on } \\
\text { select wells. }\end{array}$ & $\begin{array}{l}\text { Determine current terminal electron } \\
\text { accepting process and if sufficient } \\
\text { hydrogen is available for reductive } \\
\text { dechlorination. }\end{array}$ & $\begin{array}{l}\text { Sampled at well head. Requires } \\
\text { the production of } 100 \mathrm{~mL} \text { per } \\
\text { minute of water for } 30 \text { minutes. }\end{array}$ & Fixed-base laboratory \\
\hline $\begin{array}{l}\text { Dissolved Organic } \\
\text { Carbon }\end{array}$ & E415.1 & $\begin{array}{l}\text { Field filter with } 0.45 \\
\text { micron inline filter. } \\
\text { Minimize aeration } \\
\text { and fill sample } \\
\text { container completely. }\end{array}$ & $\begin{array}{l}\text { Used to classify plume and to } \\
\text { evaluate the potential for biologic and } \\
\text { biologically predicated abiotic } \\
\text { degradation. }\end{array}$ & $\begin{array}{l}\text { Collect } 1 \times 250 \mathrm{~mL} \text { glass amber } \\
\text { container, preserve with } \mathrm{H}_{2} \mathrm{SO}_{4} \\
\text { and cool to } 4{ }^{\circ} \mathrm{C} \text {. }\end{array}$ & Fixed-base laboratory \\
\hline VFAs & Ion chromatography. & $\begin{array}{l}\text { Can be a useful } \\
\text { indicator of microbial } \\
\text { metabolism of added } \\
\text { substrate. }\end{array}$ & $\begin{array}{l}\text { Biomarkers of anaerobic metabolism. } \\
\text { Anaerobic bacteria produce these } \\
\text { compounds by fermentation. }\end{array}$ & Contact Laboratory. & Fixed-base laboratory \\
\hline Stable Isotopes & $\begin{array}{l}\text { Sherwood Lollar et } \\
\text { al. Org Geochem. } \\
1999,30,813-820\end{array}$ & $\begin{array}{l}\text { May need more than } \\
\text { one quarter of data } \\
\text { and interpretation } \\
\text { may become } \\
\text { complicated if there } \\
\text { is more than one } \\
\text { source. }\end{array}$ & $\begin{array}{l}\text { Helps elucidate biotic vs. abiotic } \\
\text { dechlorination pathways. }\end{array}$ & $\begin{array}{l}\text { Collect } 1 \times 44 \mathrm{~mL} \text { VOA vial no } \\
\text { headspace and cool to } 4{ }^{\circ} \mathrm{C} .\end{array}$ & Fixed-base laboratory \\
\hline \multicolumn{6}{|c|}{ Microbiological Analyses } \\
\hline PLFAs & White et al. (1997) & $\begin{array}{l}\text { PLFA data can be } \\
\text { readily correlated } \\
\text { with contaminant and } \\
\text { geochemical trends. }\end{array}$ & $\begin{array}{l}\text { Provides microbial biomass, } \\
\text { community structure and } \\
\text { physiological status data. }\end{array}$ & $\begin{array}{l}\text { Collect } 1 \text { to } 2 \text { Liters of } \\
\text { groundwater in a sterile } \\
\text { widemouth poly bottle and cool to } \\
=4{ }^{\circ} \mathrm{C} \text {. }\end{array}$ & Fixed-base laboratory \\
\hline DGGE & $\begin{array}{l}\text { Muyzer } \text { et al. AEM } \\
\text { 1993, 59:695-700. }\end{array}$ & $\begin{array}{l}\text { Mainly for use in } \\
\text { forensic or failure } \\
\text { analyses. }\end{array}$ & $\begin{array}{l}\text { Identifies most dominant } \\
\text { microorganisms in the groundwater. }\end{array}$ & $\begin{array}{l}\text { Collect } 500 \text { to } 1000 \mathrm{~mL} \text { of } \\
\text { groundwater in a sterile } \\
\text { widemouth poly bottle and cool to } \\
4{ }^{\circ} \mathrm{C} \text {. }\end{array}$ & Fixed-base laboratory \\
\hline
\end{tabular}


WSRC-TR-2003-00331

December 31, 2004

\subsubsection{Carbon Dioxide}

Metabolic processes operating during biodegradation of organic compounds lead to the production of carbon dioxide $\left(\mathrm{CO}_{2}\right)$. However, $\mathrm{CO}_{2}$ released into groundwater rapidly reacts to form carbonic acid $\left(\mathrm{H}_{2} \mathrm{CO}_{3}\right)$. Accurate measurement of the amount of carbon dioxide produced during biodegradation is difficult because carbonate in groundwater (measured as alkalinity) serves as both a source and sink for free carbon dioxide. If the carbon dioxide produced during metabolism is not completely removed by the natural carbonate-buffering system of the aquifer, carbon dioxide concentrations higher than background may be observed. Comparison of empirical data to stoichiometric calculations can provide estimates of the degree of microbiological activity and the occurrence of in situ mineralization of contaminants provided the carbonate buffering is accounted for. However $\mathrm{CO}_{2}$ measurements alone typically are uninformative.

\subsubsection{Alkalinity}

Biologically active portions of a solute plume typically can be identified by an increase in alkalinity. This increase in alkalinity is brought about by the production of carbon dioxide during the biodegradation of organic carbon. Alkalinity results from the presence of hydroxides, carbonates, and bicarbonates of cations such as calcium, magnesium, sodium, and potassium. These species result from the dissolution of rock (especially carbonate rocks), the transfer of carbon dioxide from the atmosphere, and respiration of microorganisms. Alkalinity is important in the maintenance of groundwater $\mathrm{pH}$ because it buffers the groundwater system against acids generated during both aerobic and anaerobic biodegradation. In general, areas with organic carbon that has been reduced exhibit a total alkalinity that is higher than that seen in those areas with low organic carbon concentrations. This is expected because the microbially mediated reactions causing biodegradation of organic carbon cause an increase in the total alkalinity in the system. Changes in alkalinity are most pronounced during aerobic respiration, denitrification, $\mathrm{Fe}(\mathrm{III})$ reduction, and sulfate reduction, and less pronounced during methanogenesis (Morel and Hering, 1993).

\subsubsection{Dissolved Inorganic Carbon}

Dissolved inorganic carbon (DIC) is a measure of the inorganic carbon species in solution, including carbon dioxide $\left(\mathrm{CO}_{2}\right)$, carbonic acid $\left(\mathrm{H}_{2} \mathrm{CO}_{3}\right)$, bicarbonate $\left(\mathrm{HCO}_{3}{ }^{-}\right)$, and carbonate $\left(\mathrm{CO}_{3}{ }^{2-}\right)$. Similar to alkalinity, biologically active portions of a solute plume typically exhibit an increase in DIC due to the production of $\mathrm{CO}_{2}$ by microbial metabolism of organic carbon.

In general, alkalinity (as $\mathrm{CaCO}_{3}$ ) measurements are predominantly due to carbonate species in solution. Therefore, the measurement of DIC is typically redundant if alkalinity is measured and if carbonate speciation data is needed, it can be calculated from the alkalinity measurement. 
WSRC-TR-2003-00331

December 31, 2004

\subsubsection{Major and Minor Ions}

In general, data on major and minor ion concentrations in groundwater does not contribute substantively to the evaluation of natural attenuation for chlorinated solvents, with the exception of the geochemical parameters previously discussed (e.g., $\mathrm{Cl}^{-}, \mathrm{NO}_{3}{ }^{-}, \mathrm{Fe}^{2+}, \mathrm{Mn}^{2+}, \mathrm{SO}_{4}{ }^{2-}, \mathrm{HCO}_{3}{ }^{-}$ $\left./ \mathrm{CO}_{3}{ }^{2-}\right)$. However, since chlorinated hydrocarbon solute plumes are superposed on, and interact with, the ambient geochemical system, in some cases knowledge of the major and minor ion chemistry in groundwater can provide useful information for evaluating natural attenuation.

Major ions include constituents that typically are present in groundwater at concentrations greater than $1 \mathrm{mg} / \mathrm{L}$. The major cations include sodium $\left(\mathrm{Na}^{+}\right)$, potassium $\left(\mathrm{K}^{+}\right)$, calcium $\left(\mathrm{Ca}^{2+}\right)$, and magnesium $\left(\mathrm{Mg}^{2+}\right)$ and the major anions include chloride $\left(\mathrm{Cl}^{-}\right)$, suflate $\left(\mathrm{SO}_{4}{ }^{2-}\right)$, the carbonate species $\left(\mathrm{HCO}_{3}{ }^{-}\right.$and $\left.\mathrm{CO}_{3}{ }^{2-}\right)$, and sometimes nitrate $\left(\mathrm{NO}_{3}{ }^{-}\right)$. A major nonionic constituent is silica, that generally is present as the neutral dissolved species $\mathrm{H}_{4} \mathrm{SiO}_{4}{ }^{\circ}$. The minor ions include constituents that typically are present in groundwater at concentrations between 1 and $0.01 \mathrm{mg} / \mathrm{L}$. The minor cations include iron $\left(\mathrm{Fe}^{2+}\right.$ and $\left.\mathrm{Fe}^{3+}\right)$, manganese $\left(\mathrm{Mn}^{2+}\right)$, aluminum $\left(\mathrm{Al}^{3+}\right)$, etc., and the minor anions include fluoride $\left(\mathrm{F}^{-}\right)$, bromide $\left(\mathrm{Br}^{-}\right)$, phosphate $\left(\mathrm{PO}_{4}{ }^{2-}\right)$, etc.

The primary application of data for major and minor ions in the evaluation of natural attenuation of chlorinated solvents is in cases where the bulk groundwater geochemistry is important for characterizing and understanding geochemical processes. Such situations may include evaluation of the formation and stability of mineral phases, detailed examination of the behavior of inorganic constituents, or the design of enhanced remediation systems. Major ions can be plotted on Stiff and Piper diagrams and used to graphically depict different hydrogeologic units and areas impacted by contamination. Geochemical models such as MINTEQ and PHREEQ that require concentrations of major ions as input parameters can be useful for evaluating groundwater geochemistry. In addition, minor ion data may be required for these models if they are important to the reactions in the system. A detailed discussion of the application of major and minor ion chemistry data is complex and beyond the scope of this document, and the interested reader is referred to Deutsch (1997) for a practical overview.

\subsubsection{Dissolved Hydrogen}

Concentrations of dissolved hydrogen can be used to evaluate terminal electron-accepting processes in groundwater systems (Lovley and Goodwin, 1988; Lovley et al., 1994; Chapelle et al., 1995). Because each terminal electron-accepting process (TEAP) has an associated characteristic hydrogen concentration range, hydrogen concentrations can be an indicator of the predominant TEAP. These characteristic ranges are given in Table 3.2.

Oxidation-reduction potential (ORP) measurements are based on the concept of thermodynamic equilibrium and, within the constraints of that assumption, can be used to evaluate TEAPs in groundwater systems. The use of dissolved hydrogen to classify the system is 
WSRC-TR-2003-00331

December 31, 2004

Table 3.2

Range of Hydrogen Concentrations for a Given Terminal Electron-Accepting Process

\begin{tabular}{|l|c|c|c|}
\hline \multirow{2}{*}{$\begin{array}{c}\text { Terminal Electron } \\
\text { Accepting Process }\end{array}$} & \multicolumn{3}{|c|}{ Dissolved Hydrogen $\left(\mathbf{H}_{2}\right)$ Concentration } \\
\cline { 2 - 4 } & $\mathrm{nmol} / \mathrm{L}^{1}$ & $\mathrm{~atm}^{2}$ & $\mu \mathrm{g} / \mathrm{L}$ \\
\hline Denitrification & $<0.1$ & $<1.3 \times 10^{-7}$ & $<0.2 \times 10^{-3}$ \\
\hline Iron (III) Reduction & 0.2 to 0.8 & $0.26-1.0 \times 10^{-6}$ & $0.4-1.6 \times 10^{-3}$ \\
\hline Sulfate Reduction & 1 to 4 & $1.3-5.0 \times 10^{-6}$ & $2.0-8.0 \times 10^{-3}$ \\
\hline Methanogenesis & 5 to 20 & $63-250 \times 10^{-6}$ & $10-40 \times 10^{-3}$ \\
\hline
\end{tabular}

${ }^{1}$ nanomole per liter (nanomolar)

${ }^{2}$ In gas phase in equilibrium with water containing dissolved hydrogen

Source: Adapted from Lovley et al. (1994) and Chapelle et al. (1995) 
WSRC-TR-2003-00331

December 31, 2004

based on the ecological concept of interspecies hydrogen transfer by microorganisms and, within the constraints of that assumption, can also be used to evaluate TEAPs. These methods, therefore, are fundamentally different. A direct comparison of these methods (Chapelle, 1997)

has shown that while oxidation-reduction potential measurements were effective in delineating oxic from anoxic groundwater, they could not reliably distinguish between nitrate-reducing, $\mathrm{Fe}(\mathrm{III})$-reducing, sulfate-reducing, or methanogenic zones in an aquifer. In contrast, the measurement of dissolved hydrogen could readily distinguish between different anaerobic zones. At those sites where distinguishing between different anaerobic processes is important (such as at sites contaminated with chlorinated solvents), hydrogen measurements can be useful for delineating the distribution of terminal electron-accepting processes.

In practice, it is preferable to interpret hydrogen concentrations in the context of electron acceptor (dissolved oxygen, nitrate, $\mathrm{Mn}(\mathrm{IV}), \mathrm{Fe}(\mathrm{III})$, sulfate) availability and the presence of the final products (Mn(II), Fe(II), hydrogen sulfide, methane) of microbial metabolism (Chapelle et al., 1995). For example, if sulfate concentrations in groundwater are less than $0.5 \mathrm{mg} / \mathrm{L}$, methane concentrations are greater than $0.5 \mathrm{mg} / \mathrm{L}$, and hydrogen concentrations are in the 5-20 $\mathrm{nM}$ range, it can be concluded with a high degree of certainty that methanogenesis is the predominant terminal electron-accepting process in the aquifer. Similar logic can be applied to identifying denitrification (presence of nitrate, hydrogen $<0.1 \mathrm{nM}$ ), $\mathrm{Fe}(\mathrm{III})$ reduction (production of $\mathrm{Fe}(\mathrm{II})$, hydrogen 0.2 to $0.8 \mathrm{nM}$ ), and sulfate reduction (presence of sulfate, production of sulfide, hydrogen 1-4 $\mathrm{nM}$ ).

Chapelle et al. (1997) compare three methods for measuring hydrogen concentrations in groundwater; a downhole sampler, a gas stripping method, and a diffusion sampler. The downhole sampler and gas stripping methods gave similar results. The diffusion sampler appeared to overestimate hydrogen concentrations. Of these methods, the gas stripping method is better suited to field conditions because it is faster (approximately 30 minutes for a single analysis as opposed to two hours for the downhole sampler and eight hours for the diffusion sampler), the analysis is easier (less sample manipulation is required), and the data computations are more straightforward (hydrogen concentrations need not be corrected for water sample volume) (Chapelle et al. 1997). At least one commercial laboratory uses the gas stripping method (called the "bubble strip" method) for hydrogen sampling and analysis.

\subsubsection{Dissolved Organic Carbon}

Dissolved organic carbon (DOC) is an operationally defined parameter that measures the organic carbon that passes through a $0.45 \mu \mathrm{m}$ filter. In general, organic carbon dissolved in groundwater is more readily available to microbes and DOC can be used as an indicator of the availability of organic carbon that can maintain reducing conditions and provide fermentable substrates needed to support biological reductive dechlorination.

Naturally occurring DOC consists of humic and fulvic acids, sugars, fatty acids, low molecular weight organic acids, and alkanes. Anthropogenic organic carbon can include organic acids in landfill leachate, fuel hydrocarbons, and other reduced organic compounds.

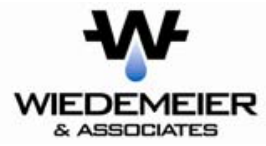


WSRC-TR-2003-00331

December 31, 2004

Measurements of DOC concentrations are more relevant for solute plumes where the reduced organic substrates are not "contaminants" that are otherwise sampled and analyzed. However, even in these cases DOC measurements will include organic compounds that are not chemicals of concern and provide a more representative indication of substrate availability.

Changes in DOC concentrations may be correlated to changes in organic substrate availability. A statistically significant decline over time or space may indicate that readily available organic substrates have become depleated. This could signal a change to conditions that are less conducive to biological or abiotic reductive dechlorination.

\subsubsection{Volatile Fatty Acids (VFAs)}

Short-chain organic acids, or "volatile fatty acids" (VFAs), are end products of the fermentation of organic matter and are important substrates for anaerobic respiration, such as for sulfate-reducing bacteria, in natural settings. Also, the biodegradation of simple hydrocarbons almost always produces organic acid intermediates, particularly under anaerobic conditions. The major volitle fatty acids are acetate, propionate, formate, butyrate, lactate and pyruvate. These are biomarkers of anaerobic bacterial metabolism and accumulation of VFAs is indicative of the availability of fermentable organic matter that also yields hydrogen $\left(\mathrm{H}_{2}\right)$ which is essential for dehalorespiration.

The VFAs are analyzed by ion chromatography methods; generally by ion exclusion chromatography (Bradley et al., 1993; Hansen, 1998). Analysis of VFAs can provide an indication of the availability of fermentation substrates that can support reductive dechlorination (dehalorespiration) and, potentially, information on the stability of redox conditions in a plume (Christensen et al., 2000). The use of VFAs as redox indicators is equivocal, but shifts in the predominant TEAP can yield transient concentration peaks in VFAs that could be used as an indicator of a change in redox conditions (Christensen et al., 2000).

Enhanced attenuation approaches for chlorinated solvents in groundwater that use substrate additions (e.g., vegetable oil or $\mathrm{HRC}^{\circledR}$ ) are intended to augment the substrates available for fermentation to yield hydrogen $\left(\mathrm{H}_{2}\right)$. The presence, or change in concentrations, of various VFAs characteristic of the substrate after substrate addition provides an indication that fermentation in proceeding and the VFAs can also serve as a tracer to monitor where the treated water flows.

Similar to VOCs, VFAs are subject to evaporation losses as well as degradation under both aerobic and anaerobic conditions. Groundwater samples collected for analysis of VFAs must be preserved immediately and handled similar to VOC samples. Preservation of VFA samples by the addition of $0.2 \%$ chloroform and immediate freezing in polypropylene vials has been found to be an appropriate method (Hansen, 1998; Albrechtsen et al., 1999) and also prevents generation of additional VFAs in samples containing dissolved organic matter (e.g., humic and fulvic acids) (Christensen et al., 2000). 
WSRC-TR-2003-00331

December 31, 2004

\subsubsection{Stable Isotopes}

Analysis of stable isotope ratios between parent and daughter compounds can be useful for identifying the biodegradation of chlorinated compounds because isotopic fractionation commonly occurs during biodegradation. This fractionation results in a characteristic pattern of isotope ratios between parent compounds and daughter products. For the chlorinated ethenes, non-degradative subsurface processes such as dissolution, sorption, and volatilization do not involve isotopic fractionation greater than $0.5 \%$, and this is the typical accuracy and reproducibility of continuous flow isotope analysis techniques (Slater et al., 2001).

Hunkeler et al., (1999) studied the occurrence of stable carbon isotope $\left({ }^{13} \mathrm{C} /{ }^{12} \mathrm{C}\right)$ fractionation during the reductive dechlorination of PCE to ethene in the field and in the laboratory using aquifer material from the same site located in Toronto, Ontario, Canada. According to these researchers, all dechlorination steps in the microcosm were accompanied by stable carbon isotope fractionation with similar results for the field study. In the microcosm study the largest fractionation occurred during dechlorination of cis 1,2-DCE and $\mathrm{VC}$, resulting in a large enrichment of ${ }^{13} \mathrm{C}$ in the remaining cis-1,2-DCE and VC. Stable carbon isotope ratios $\left(\delta^{13} \mathrm{C}\right)$ of cis-1,2-DCE and VC increased from -25.7 to $1.5 \%$ and -37 to $-2.5 \%$, respectively. The $\delta^{13} \mathrm{C}$ of ethene was initially $-60.2 \%$ and approached the $\delta^{13} \mathrm{C}$ of the added PCE $(-27.3 \%$ ) as dechlorination came to completion. Based on their work, these researchers conclude that strong enrichment of ${ }^{13} \mathrm{C}$ in cis-1,2-DCE and $\mathrm{VC}$ during microbial dechlorination may serve as a powerful tool to monitor the last two steps of dechlorination. These steps frequently determine the rate of dechlorination of chlorinated ethenes at field sites where degradation is occurring.

\subsection{MINERALOGICAL ANALYSES}

The purpose of mineralogical analysis as a line of evidence for natural attenuation of chlorinated solvents is to evaluate the presence of reduced iron minerals that are known to facilitate abiotic degradation of chlorinated compounds. These include iron sulfides, such as troilite and mackinawite $(\mathrm{FeS})$, marcasite and pyrite $\left(\mathrm{FeS}_{2}\right)$, iron oxides and hydroxides, such as magnetite $\left(\mathrm{Fe}_{3} \mathrm{O}_{4}\right)$ and green rust $\left(\mathrm{Fe}^{2+}-\mathrm{Fe}^{3+}\right.$ hydroxy compounds), and other iron-bearing minerals. Mineralogical analysis can also provide information on the amount of Fe(III) available for reduction to $\mathrm{Fe}(\mathrm{II})$. These analyses can be used to supplement and refine the macroscopic indicators of iron mineralogy described in Section 2.2.1.2.

Characterization of aquifer mineralogy can involve the identification of individual minerals, identification and quantification of the bulk content of minerals or species in aquifer sediment, and identification and quantitation of "reactive" fractions for minerals and species that are available for a given reaction. There are numerous approaches that can be used to determine the mineral composition of soil, sediment, and rock (Amonette and Zelazny, 1994; Amonette, 2002) and approaches specific to iron minerals are discussed in Bigham et al. (2002) and Ribbe (1974). These approaches to mineralogical analysis generally involve standard petrographic methods and bulk elemental and mineral analysis techniques. Some of the most readily applied and useful techniques relavent to evaluation of natural attenuation are summarized in Table 3.3 and briefly discussed below. Other methods, such as ${ }^{57} \mathrm{Fe}$ Mössbauer spectroscopy, may have application in 
WSRC-TR-2003-00331

December 31, 2004

the evaluation of iron-bearing minerals, but are not as readily available as the techniques discussed here. It is best to contact a qualified laboratory for these analyses.

Some iron sulfides, such as troilite and mackinawite $(\mathrm{FeS})$, pyrrhotite $\left(\mathrm{FeS}_{0.9}\right)$ and greigite $\left(\mathrm{Fe}_{3} \mathrm{~S}_{4}\right)$, and the green rusts are highly unstable under oxidizing conditions and care should be exercised in sampling to prevent contact with atmospheric oxygen. Surface oxidation can occur within 30 minutes or less of exposure to aerobic conditions (Fanning et al., 2002). Anaerobic sampling techniques for aquifer sediments are described in Kennedy et al. $(1998,2000)$.

\subsubsection{Petrography}

Petrographic evaluation of aquifer solids using optical methods is a technique that can provide useful information on the mineral composition of the aquifer matrix and the distribution of minerals in the aquifer at the grain scale. Optical petrography is a fairly simple, observational technique that allows the user to see features of the aquifer matrix directly. It can involve the use of thin sections and/or grain separates, and can involve the use of either a petrographic microscope using transmitted and reflected light or with a simple binocular microscope using reflected light. Minerals are identified by their optical characteristics. Good overviews of the methods and application of optical petrography can be found in Cady et al. (1986) and Drees and Ransom (1994), as well as texts on optical mineralogy (e.g., Kerr, 1977).

Transmitted light microscopy with a petrographic microscope is used to examine non-opaque minerals, microcrystalline aggregates, and "amorphous" materials with plane-polarized and cross-polarized light. Reflected-light microscopy is used to examine opaque minerals. The methodology is similar to that used in ore petrography and identification is based on reflectance properties under plane-polarized light (Spry and Gedlinske, 1987). Often, the same specimen that is viewed using the light microscope can be analyzed using the advanced $\mathrm{x}$-ray and ion microprobe techniques discussed below.

Petrographic evaluation of thin sections is useful for determining both the identity and distribution of iron minerals in the aquifer matrix. This is particularly useful in providing a visual representation that retains the original spatial relationships of the minerals. Thin-section petrography also is applicable to both poorly crystallized and "amorphous" components, such as some iron oxides, hydroxides and sulfides, and can be complemented with selective extraction techniques. Quantification can be achieved through standard point-counting techniques or through image analysis (Drees and Ransom, 1994). The construction of thin-sections from unconsolidated aquifer material requires that an intact sample be impregnated with an epoxy or acrylic resin, such as described by Buol and Faddness (1961), Innes and Pluth (1970), and Ashley (1973), to fill the pore space and stabilize the specimen. 
WSRC-TR-2003-00331

December 31, 2004

Table 3.3

\section{Mineralogical Analysis Methods for Evaluating Aquifer Solids for Natural Attenuation and Enhanced Remediation}

\begin{tabular}{|c|c|c|c|}
\hline Analysis & Comments & Data Use & $\begin{array}{l}\text { Field or } \\
\text { Fixed-Base } \\
\text { Laboratory } \\
\end{array}$ \\
\hline Petrography & $\begin{array}{l}\text { Either a petrographic } \\
\text { microscope or a simple } \\
\text { reflecting microscope with a } \\
\text { polarized light source can be } \\
\text { used. }\end{array}$ & Mineral identification and distribution. & Field or Fixed Base \\
\hline Wet Chemistry & $\begin{array}{l}\text { Useful for determining the } \\
\text { amount of "reactive" species } \\
\text { and extimating the amount of } \\
\text { other iron \& sulfur minerals. }\end{array}$ & $\begin{array}{l}\text { Determining amount of } \mathrm{Fe}(\mathrm{III}) \text { available for } \\
\text { reduction to } \mathrm{Fe}(\mathrm{II}) \text {. } \\
\text { Characterization of iron and sulfur mineral } \\
\text { species. }\end{array}$ & Field or Fixed Base \\
\hline X-Ray Diffraction & $\begin{array}{l}\text { Useful for identifying } \\
\text { crystalline minerals; cannot be } \\
\text { used to identify "amorphous" } \\
\text { materials. }\end{array}$ & Mineral Identification and concentration & Fixed Base \\
\hline X-Ray Fluorescence & $\begin{array}{l}\text { Elemental analysis method } \\
\text { useful for determining bulk } \\
\text { element composition. }\end{array}$ & $\begin{array}{l}\text { Bulk element composition used to characterize } \\
\text { potential minerals present. }\end{array}$ & Fixed Base \\
\hline Electron Microprobe & $\begin{array}{l}\text { Elemental analysis method } \\
\text { useful for identifying } \\
\text { microcrystalline and } \\
\text { amorphous iron-bearing } \\
\text { mineral phases. }\end{array}$ & $\begin{array}{l}\text { Identification of iron-bearing mineral phases } \\
\text { from cemical composition in textural context. }\end{array}$ & Fixed Base \\
\hline $\begin{array}{l}\text { Mass Magnetic } \\
\text { Susceptibility Analysis }\end{array}$ & Method under development & $\begin{array}{l}\text { Useful for determining the presence and } \\
\text { concentration of magnetic minerals (e.g., } \\
\text { magnetite) and changes in iron mineral } \\
\text { compostition. }\end{array}$ & Fixed Base \\
\hline
\end{tabular}


WSRC-TR-2003-00331

December 31, 2004

Information on the distribution of iron minerals in the aquifer matrix is of particular interest since the abiotic dechlorination reactions with iron minerals are surface controlled, making an understanding of the distribution and potential contact areas of these minerals useful. This is an advantage of thin-section petrography, since bulk composition analysis methods, such as x-ray diffraction (XRD), do not yield this information.

While petrography can provide definitive identification of individual mineral components, the processes involved in preparing a sample for examination are time consuming and cumbersome and a number of samples will be needed. Specialized equipment (i.e., petrographic and/or binocular microscopes) is required and individuals with specific training and experience in petrographic examination and mineral identification techniques should perform the examination, particularly for iron minerals. Due to this complexity, professional petrographic examination can be expensive and, therefore, only samples deemed to adequately represent aquifer materials should be considered for such evaluation.

\subsubsection{Wet Chemistry Techniques}

Wet chemistry methods for evaluation of iron minerals rely on selective extraction approaches that are based on differential reactivity and dissolution of the various iron-bearing constituents. These approaches have a long history of use in soil science studies and, over time, numerous methods have been developed or refined, particularly for the iron oxides and hydroxides (Loeppert and Inskeep, 1996). Several wet chemical methods have been developed and refined in recent years for speciation of iron and sulphur minerals (e.g., Heron et al., 1994a; 1994b; Kennedy et al., 1998; 2000). These chemical extraction techniques involve measuring operationally defined quantities of extracted or reacted species and are simple and easy to use. They yield a bulk composition analysis of the minerals in the aquifer matrix based on the composition of the extracted phase.

The wet chemistry methods involve the mixing of the sediment with an extractant followed by determination of the extractant composition. Analysis of extracts and evolved gases is used for determining the composition of the reacted mineral phases. Due to the variable composition, degree of crystallinity, and reactivity of the various iron-bearing minerals, specific identification by selective extraction methods is equivocal. However, the wet chemistry methods provide a useful indication of the "reactive fraction" of iron-bering minerals in the aquifer matrix. A standard reaction time is selected for each extraction method, but a given method does not necessarily extract the same "reactive fraction" from different sediments due to differences in specific mineral composition.

Several speciation techniques for iron and sulfur species and a protocol for their use is presented in Kennedy et al. (2000). However, this protocol focuses on capacity determination for fuel hydrocarbon biodegradation; for chlorinated solvents a more detailed speciation may be needed to address the constituents important for abiotic dechlorination. Heron et al. (1994a) describes several iron speciation techniques and determined that the "traditional" soil science extractions for $\mathrm{Fe}(\mathrm{III})$ (dithionate and ammonium oxalate) were inappropriate in reduced aquifer sediments due to interference from Fe(II). Techniques for sulfur species that separate acid- 
WSRC-TR-2003-00331

December 31, 2004

volatile sulphides (AVS), pyrite, chromium-reducible sulphur, elemental sulphur, and solid sulphates are described in Heron et al. (1994b). All these methods involve $\mathrm{HCl}$ extractions that are inappropriate in sediments with high background content of carbonates due to neutralization of the acid during extraction (Amirbahman et al., 1998). In systems supersaturated with respect to ferrous carbonate, precipitation of siderite and ferroan calcite can occur (Tuccillo et al., 1999). This can result in interferences for Fe(II) quantification and a milder extraction using ascorbic acid may be appropriate (Amirbahman et al., 1998).

The techniques using "mild" extractants (e.g., weak $\mathrm{HCl}$ solutions) preferentially dissolve surface-related, very reactive, or "amorphous" minerals, such as ferrihydrite $\left[\mathrm{Fe}(\mathrm{OH})_{3}\right]$ and ferrous monosulphides (FeS), while leaving most of the bulk iron and sulfur species behind and intact. Hydrochloric acid and ascorbic acid extractions are the most promising approaches for reactive fraction measurements (Christensen et al., 2000).

\subsubsection{X-Ray Diffraction}

$\mathrm{X}$-ray diffraction (XRD) is a technique that allows the determination of minerals based on measuring the diffraction pattern of X-rays reflected off of mineral crystal surfaces. It is one of the primary techniques used to examine the physico-chemical composition of unknown solids and can provide unambiguous determination of mineralogical composition of a sample. However, the major limitation on the application of XRD is that it typically will not resolve poorly crystallized or "amorphous" (noncrystalline) materials.

X-Ray diffraction can be a useful method for identifying crystalline iron-bearing minerals, such as magnetite and pyrite, and can therefore be useful for determining the potential for abiotic reductive dechlorination. However, poorly crystallized or "amorphous" monosulfides (FeS), perhaps one of the most important minerals contributing to abiotic reductive dechlorination, will not be detected with this technique.

$\mathrm{XRD}$ uses a powdered sample of the material placed in a holder and illuminated with $\mathrm{x}$-rays of a fixed wavelength. The reflection angles and intensity of the reflected radiation are recorded using a goniometer. This data is then analyzed for the reflection angle to calculate the interatomic spacing (D). The intensity (I) is measured to discriminate the various D spacings using relative intensities. The results are compared to single-phase XRD patterns of known minerals to identify possible matches.

When minerals can be obtained in adequate quantity and purity, their identification by XRD powder methods is likely the simplest and most reliable approach. The technique can also be applied to bulk (mixed mineral) samples, but the number of intensity peaks from the various minerals that are present complicates the evaluation of results. Various sample pre-treatment techniques, such as discussed in Laird and Dowdy (1994) Jones and Malik (1994), may be useful, depending upon the information needed from the XRD results. Differential XRD (DXRD) is widely used for determination of iron-oxide minerals. DXRD involves comparing XRD patterns of samples before and after selective dissolution treatment for one or more

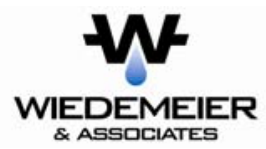


WSRC-TR-2003-00331

December 31, 2004

constituents. This allows discerning the components of a bulk analysis. An overview of DXRD approaches is provided in Schulze (1994).

\subsubsection{X-Ray Fluorescence}

$\mathrm{X}$-Ray fluorescence (XRF) is a non-destructive, bulk elemental analysis technique that can be useful for characterizing both crystalline and amorphous iron-bearing solids, such as magnetite, pyrite, and FeS. Therefore, it can be useful for determining the potential for abiotic reductive dechlorination.

XRF spectrometry is based on measuring the emitted radiation (fluorescence) of element atoms generated by exposure to an X-ray source. Primary x-rays from the source that are absorbed by atoms in the target sample displace electrons from the inner shell of the atoms. Electrons from the outer shell of the atoms transfer to the inner shell to fill the vacancies and the energy change yields secondary $\mathrm{x}$-rays with energies equivalent to the difference in the binding energies of the two electron shells. Each element produces characteristic secondary $\mathrm{x}$-ray energies and measurement of these allows quantitation of the elemental composition of the sample.

$\mathrm{XRF}$ is capable of detecting elements with atomic number $\geq 8$ (oxygen) and can commonly resolve concentrations of a few parts per million. It is commonly used in the laboratory and in the field to determine concentrations of metals in soils. Reviews of the technique are presented in Amonette and Sanders (1994) and Karathanasis and Hajek (1996).

Bulk elemental analysis by XRF yields information on the total elemental content of the sample; it does not distinguish individual mineral phases. While information on the amounts of each element present in a sample can be useful in constraining the mineral phases that may be present, in itself this information on a bulk sample of aquifer material does not necessarily aid in mineralogical characterization. Selection of sample material that represents the specific minerals of interest can, to some extent, alleviate this issue. XRF cannot distinguish between oxidation states [e.g., $\mathrm{Fe}(\mathrm{II})$ and $\mathrm{Fe}(\mathrm{III})$ ], among mineral polymorphs (minerals with different structures, but the same elemental stoichiometry), or between species (e.g., $\mathrm{S}^{2-}$ and $\mathrm{SO}_{4}{ }^{2-}$ ). Thus, it does not lead to the quantitation of minerals directly and must be supplemented by other types of analysis. However, it can aid in determining what additional analyses are appropriate.

\subsubsection{Electron Microprobe Analysis}

Electron microprobe analysis is a non-destructive technique that provides for an in situ determination of chemical composition on specimen surfaces. It is applicable to all iron-bearing mineral phases, regardless of their degree of crystallinity. While the technique is typically limited to concentrations of 50-100 parts per million, the ability to resolve very small volumes (e.g., $1 \mu \mathrm{m}^{3}$ ) compensates for this limitation (Sawhney, 1986). Electron microprobe analysis is a combination of the techniques of scanning electron microscopy and x-ray spectroscopy. An overview of aspects of the basic methodology is provided in Sawhney (1986) and Reed (1996).

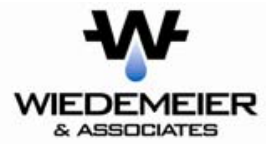


WSRC-TR-2003-00331

December 31, 2004

An electron microprobe uses a high-energy focused beam of electrons to generate $\mathrm{x}$-rays characteristic of the elements within a sample. It can typically resolve volumes as small as $3 \mu \mathrm{m}$ across. Analysis locations are selected using a transmitted-light optical microscope, which allows positioning accurate to about $1 \mu \mathrm{m}$. The resulting data yield quantitative chemical information in a textural context and variations in chemical composition within a material, such as a mineral grain, can be readily determined. Chemical composition is determined by comparing the intensity of x-rays from standards with those from unknown materials and correcting for the effects of absorption and fluorescence in the sample. The electron microprobe allows quantitative determination of elements with atomic numbers $>3$ (beryllium) to $>8$ (oxygen), depending on the specific instrument, at routine levels as low as $100 \mathrm{ppm}$.

Electron microprobe analysis is a specialized technique that is not inexpensive, making it inappropriate for routine use in evaluating mineral composition. Samples prepared for routine optical petrographic evaluation can typically also be used for electron microprobe analysis and this technique can help resolve ambiguities from optical petrographic evaluations.

\subsubsection{Mass Magnetic Susceptibility Analysis}

Magnetic susceptibility is essentially a measure of how liable a mineral is to magnetization when subjected to a magnetic field. The mass specific magnetic susceptibility, $\chi$, is the magnetization induced by an applied field with units of $\mathrm{m}^{3} / \mathrm{kg}$. Whole cores, or individual sediment samples, are exposed to an external magnetic field that causes the sediments to become magnetized according to the amount of various magnetizable, predominantly iron-bearing, minerals present in the samples. Mc Bride (1986) provides a discussion of this type of analysis.

Magnetizable minerals include the ferri- and ferro-magnetic minerals (strongly magnetizable) and any of the paramagnetic (moderately magnetizable) minerals and other substances. The former include magnetite, hematite, iron titanium oxides, pyrrhotite, maghemite, greigite and goethite. The paramagnetic minerals include a broad array of substances all of which contain $\mathrm{Fe}^{2+}, \mathrm{Fe}^{3+}$, or $\mathrm{Mn}^{2+}$ ions, such as clay minerals (chlorite, smectite and glauconite), iron and manganese carbonates (siderite, rhodochrosite), as well as a variety of ferric-oxyhydroxide mineraloids. The ferri-magnetic iron oxides (e.g., magnetite, maghemite) typically dominate the magnetic signature of soil, sediment and rock and have strong, positive mass magnetic susceptibility values that are two to three orders of magnitude greater than those of the other iron oxides (Bigham et al., 2002). For a mixed-mineral sample, the magnetic susceptibility is primarily determined by the concentration of the ferri-magnetic iron oxides and related samples will commonly show a positive, linear relationship with the magnetite and maghemite content (Bigham et al., 2002). The magnetic susceptibility of a sample is ultimately related to the concentration and composition (size, shape and mineralogy) of magnetizable material present within the sample.

If the composition and structure of iron-bearing minerals changes as ferrous iron and sulfide are incorporated into the aquifer matrix, there should be a variation in the magnetic susceptibility. Evaluation of changes in the magnetic susceptibility signature may be useful for determining the presence of these iron-bearing minerals. Although still under development for 
WSRC-TR-2003-00331

December 31, 2004

application to natural attenuation evaluation, this analysis is rapid, inexpensive, and easy to use in both the field and laboratory. It could prove useful in the future to help differentiate between areas where abiotic dehalogenation is active or not.

\subsection{MICROBIOLOGICAL METHODS}

Several microbiological methods can yield useful information that provides more detailed information on natural degradation mechanisms. These methods include microcosm studies and molecular biology tools, such as phospholipid fatty acids (PLFA) and denaturing gradient gel electrophoresis (DGGE). These methods are discussed briefly below. For more detailed discussion and description of these, and other, molecular biology methods, see White and Ringelberg (1998), Burlage (1998), Liu and Stahl (2002), and Pinkart et al. (2002).

\subsubsection{Microcosm Studies}

The most common type of data collected for evaluating the degradation of organic contaminants in aquifer material is the laboratory microcosm study. If properly designed, implemented, and interpreted, microcosm studies can provide very convincing documentation of the potential for intrinsic bioremediation and/or abiotic reductive dechlorination. Microcosm studies are the only "line of evidence" that allows an unequivocal mass balance on the biodegradation of environmental contaminants. If the microcosm study is properly designed, it will be easy for decision-makers with non-technical backgrounds to interpret. The results of a microcosm study are strongly influenced by the nature of the geological material submitted for study, by the physical properties of the microcosm, by the sampling strategy, and by the duration of the study. Therefore, relating laboratory microcosm results back to in situ field conditions can be difficult. Additionally, microcosm studies are time consuming and expensive to conduct. For these reasons, microcosm studies should be used very selectively in assessing the efficiency of natural attenuation and enhanced remediation.

There are some circumstances, however, when laboratory studies are useful. When specific questions are raised concerning conditions under which degradation processes occur or do not occur, controlled laboratory studies can be helpful. For example, if concentrations of a particular compound are observed to decrease in the field, it is often not clear whether this decrease is due to sorption, dilution, or biological or abiotic degradation. Laboratory studies in which the effects of each process can be isolated and controlled (they usually cannot be controlled in the field) are the only available method of answering these questions.

\subsubsection{Phospholipid Fatty Acids (PLFA)}

Examining the phospholipid fatty acids (PLFA) in environmental samples is an effective tool for monitoring microbial responses to their environment. They are essential components of the membranes of all cells (except for the Archea), so their sum includes most of the important actors in microbial communities. Methanogens are members of the Archea and are not included in this analysis. There are four different types of information in PLFA profiles - biomass, community structure, diversity, and physiological status.

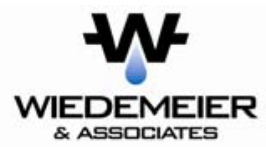


WSRC-TR-2003-00331

December 31, 2004

\subsubsection{Biomass}

PLFA analysis is the most reliable and accurate method available for the determination of viable microbial biomass. Since phospholipids break down rapidly upon cell death (White et al., 1979; White and Ringelberg, 1995), the PLFA biomass does not contain 'fossil' lipids of dead cells. The sum of the PLFA, expressed as picomoles ( 1 picomole $=1 \times 10^{-12}$ mole), is proportional to the number of cells. The proportions used typically are taken from cells grown in laboratory media, and vary somewhat with the type of organism and environmental conditions. Starving bacterial cells have the lowest cells/pmol, and healthy eukaryotic cells have the highest.

\subsubsection{Community Structure}

The PLFA in an environmental sample is the sum of the microbial community's PLFA, and reflects the proportions of different organisms in the sample. PLFA profiles are routinely used to classify bacteria and fungi (Tighe et al., 2000) and are one of the characteristics used to describe new bacterial species (Vandamme et al., 1996). Broad phylogenic groups of microbes have different fatty acid profiles, making it possible to distinguish among them (Dowling et al., 1986; Edlund et al., 1985; White et al., 1997; White et al., 1996). Table 3.4 describes the six major structural groups employed in a typical analysis of groundwater.

\subsubsection{Diversity}

The diversity of a microbial community is a measure of the number of different organisms and the evenness of their distribution. Natural communities in an undisturbed environment tend to have high diversity. Contamination with toxic compounds will reduce the diversity by killing all but the resistant organisms. The addition of a large amount of a food source will initially reduce the diversity as the opportunists (usually Proteobacteria) over-grow organisms less able to reproduce rapidly. The formulas used to calculate microbial community diversity from PLFA profiles have been adapted from those applied to communities of macro-organisms (Hedrick et al., 2000).

\subsubsection{Physiological Status}

The membrane of a microbe must adapt to the changing conditions of its environment, and these changes are reflected in the PLFA. Toxic compounds or environmental conditions that disrupt the membrane cause some bacteria to make trans fatty acids from the usual cis fatty acids (Guckert et al., 1986). Many Proteobacteria and others respond to starvation or highly toxic conditions by making cyclopropyl (Guckert et al., 1986) or mid-chain branched fatty acids (Tsitko et al., 1999). The physiological status biomarkers for toxic stress and starvation/toxicity are formed by dividing the amount of the stress-induced fatty acid by the amount of its biosynthetic precursor. 
WSRC-TR-2003-00331

December 31, 2004

\section{Table 3.4}

\section{Description of PLFA Structural Groups}

\begin{tabular}{ll}
\hline PLFA Structural Group & General classification \\
\hline Monoenoic (Monos) & $\begin{array}{l}\text { Abundant in Proteobacteria (Gram negative bacteria), typically fast } \\
\text { growing, utilize many carbon sources, and adapt quickly to a variety of } \\
\text { environments. }\end{array}$ \\
\hline Terminally Branched Saturated (TerBrSats) & $\begin{array}{l}\text { Characteristic of Firmicutes (Low G+C Gram-positive bacteria), and } \\
\text { also found in Bacteriodes, and some Gram-negative bacteria } \\
\text { (especially anaerobes). }\end{array}$ \\
\hline Branched Monoenoic (BrMonos) & $\begin{array}{l}\text { Found in the cell membranes of micro-aerophiles and anaerobes, such } \\
\text { as sulfate- or iron-reducing bacteria . }\end{array}$ \\
\hline Mid-Chain Branched Saturated (MidBrSats) & $\begin{array}{l}\text { Common in Actinobacteria (High G+C Gram-positive bacteria), and } \\
\text { some metal-reducing bacteria. }\end{array}$ \\
\hline Normal Saturated (Nsats) & Found in all organisms. \\
\hline Polyenoic & $\begin{array}{l}\text { Found in eukaryotes such as fungi, protozoa, algae, higher plants, and } \\
\text { animals. }\end{array}$ \\
\hline
\end{tabular}


WSRC-TR-2003-00331

December 31, 2004

\subsubsection{Example PLFA Analysis}

Two groundwater samples were collected from downgradient of a landfill for analysis of PLFAs. Over the course of operation the landfill accepted municipal solid waste and spent chlorinated solvents. PLFAs were analyzed by extraction of the total lipid (White et al., 1979) and then separation of the polar lipids by column chromatography (Guckert et al., 1985). The polar lipid fatty acids were derivatized to fatty acid methyl esters, which were quantified using gas chromatography (Ringelberg et al., 1994). Fatty acid structures were verified by chromatography/mass spectrometry and equivalent chain length analysis. Results from the analysis of these two samples revealed the following information.

Biomass content (as determined by the total PLFA concentration) was fairly similar in both samples (Figure 3.1). The total biomass calculated based upon PLFA attributed to bacterial and eukaryotic biomass is $\sim 10^{5}$ cells $/ \mathrm{mL}$ using the proportion 20,000 cells/pmole taken from cells grown in laboratory media.

Both samples had relatively diverse community structures that differed between the two sampling points based on the relative proportions of PLFA structural groups (Figure 3.2). Structural groups are assigned according to PLFA chemical structure, which is related to fatty acid biosynthesis, as described in Table 3.4. The results for the two samples indicate (Table 3.5):

- Sample MNA-10 was primarily composed of Gram-negative proteobacteria (as indicated by the percentage of monoenoic PLFA). High proportions of proteobacteria are of particular interest at contaminated sites due to their ability to utilize a wide range of carbon sources and adapt quickly to environmental conditions.

- Sample MNA-05 differed from MNA-10 in that proportions of Proteobacteria were lower whereas proportions of biomarkers associated with Firmicutes (as indicated by terminally branched PLFA) and anaerobic metal reducing bacteria (branched monoenoic and mid chain branched PLFA) were noticeably higher. Terminally branched PLFA are common in Firmicutes (Clostridia-like Gram-positive bacteria). An increase in terminally branched PLFA is often seen in environmental transects from more aerobic to more anaerobic conditions.

Physiological status ratios for starvation were highest in sample MNA-05, whereas both samples were indicating a response to environmentally induced stress (Figure 3.3). The starvation biomarker for the gram-negative bacterial community is assessed by the ratios of cyclopropyl fatty acids to their metabolic precursors. An adaptation of the Gram-negative community to toxic stress is determined by the ratio of trans to cis omega-7 fatty acids $(\omega 7 \mathrm{t} / \omega 7 \mathrm{c})$. Gram-negative bacteria generate trans fatty acids to minimize the permeability of their cellular membranes as an adaptation to a less favorable environment. Ratios greater than 0.1 have been shown to indicate an adaptation to a toxic or stressful environment, resulting in decreased membrane permeability. Of course, one must be cautious when interpreting bacterial response to an environment using data from only one sampling event.

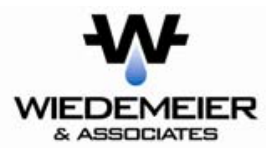




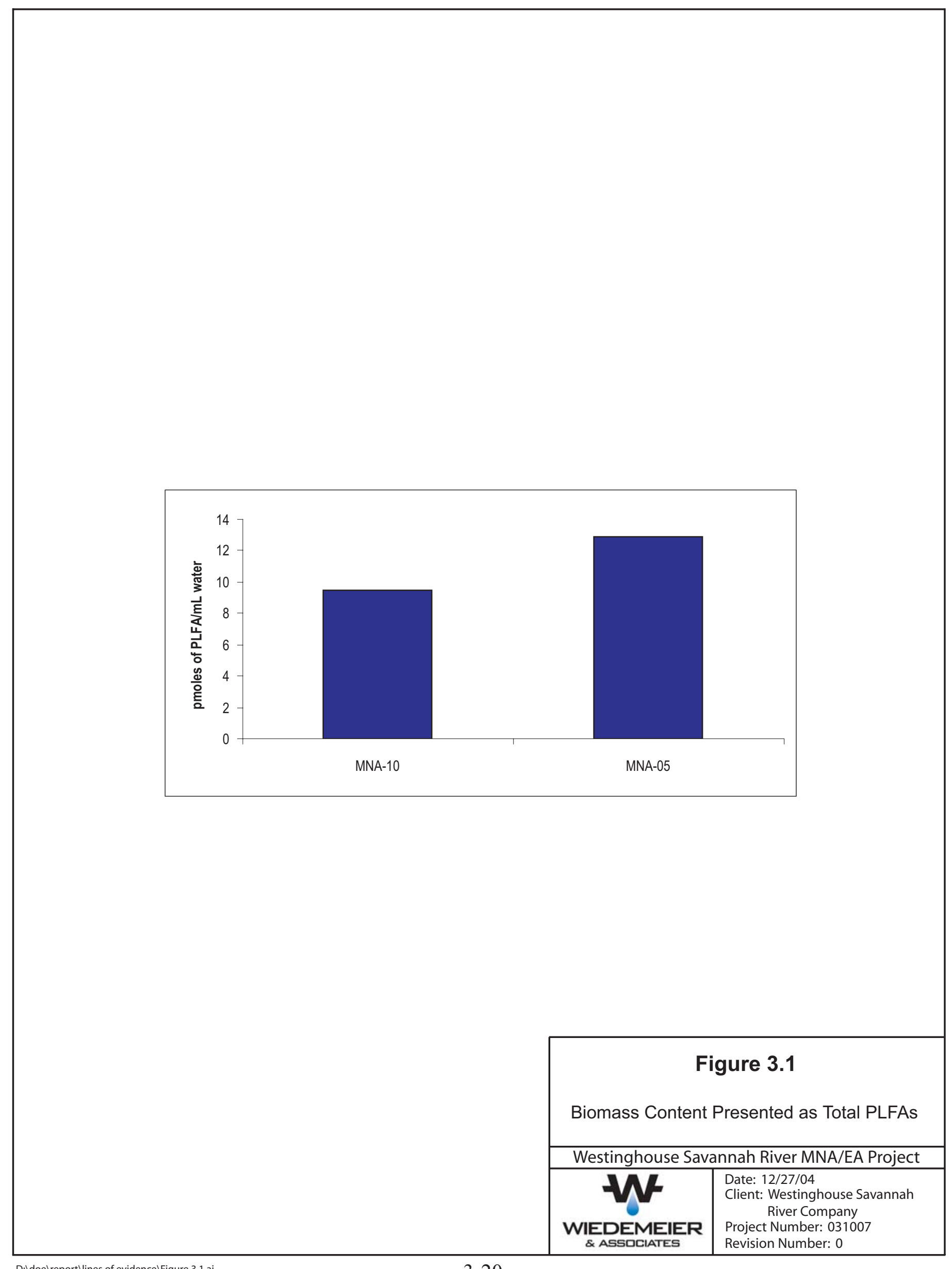




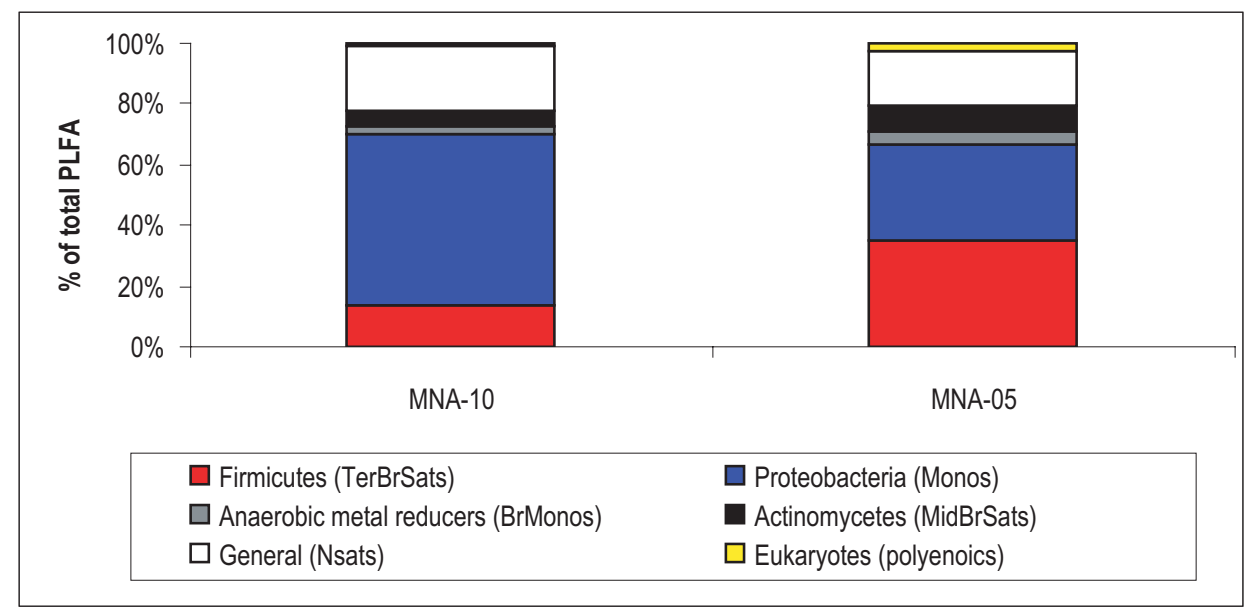

Figure 3.2

Relative Percentages of PLFA Structual Groups. Table 3.4 Describes the Various Structural Groups.

\begin{tabular}{|c|c|}
\hline \multicolumn{2}{|c|}{ Westinghouse Savannah River MNA/EA Project } \\
\hline NIEL & $\begin{array}{l}\text { Date: } 12 / 27 / 04 \\
\text { Client: Westinghouse Savannah } \\
\quad \text { River Company } \\
\text { Project Number: } 031007\end{array}$ \\
\hline & Revision Number: 0 \\
\hline
\end{tabular}


Table 3.5

Viable Microbial Biomass Expressed as picomoles of PLFA per mL of Sample and as Cells per mL of Sample, Fatty Acid

Structural Groups as Percent of Total PLFA, and Physiological Status Biomarkers as Mole Ratio

\begin{tabular}{|c|c|c|c|c|c|c|c|c|c|c|c|}
\hline \multicolumn{2}{|c|}{ Samples } & \multicolumn{2}{|c|}{ Biomass } & \multicolumn{6}{|c|}{ Community Structure (Percent of Total PLFA) } & \multicolumn{2}{|c|}{ Physiological Status } \\
\hline $\begin{array}{l}\text { Sample } \\
\text { Name }\end{array}$ & $\begin{array}{c}\text { Sample } \\
\text { Date }\end{array}$ & $\mathrm{pmol} / \mathrm{mL}$ & cells $/ \mathbf{m L}$ & $\begin{array}{c}\text { Anaerobic } \\
\text { Gram Neg./ } \\
\text { Firmicutes } \\
\text { (TerBrSats) }\end{array}$ & $\begin{array}{c}\text { Proteobacteria } \\
\text { (Monos) }\end{array}$ & $\begin{array}{c}\text { Anaerobic } \\
\text { metal } \\
\text { reducers } \\
\text { (BrMonos) }\end{array}$ & $\begin{array}{c}\text { Actinomycetes/SRB } \\
\text { (MidBrSats) }\end{array}$ & $\begin{array}{c}\text { General } \\
\text { (Nsats) }\end{array}$ & $\begin{array}{l}\text { Eukaryotes } \\
\text { (polyenoics) }\end{array}$ & Starved cy/cis & $\begin{array}{c}\text { Membrane } \\
\text { Stress, } \\
\text { trans/cis }\end{array}$ \\
\hline MNA-10 & $6 / 5 / 2003$ & 9 & $1.89 \mathrm{E}+05$ & 13.7 & 56.5 & 2.8 & 4.7 & 21.3 & 1.0 & 0.39 & 0.17 \\
\hline MNA-05 & $6 / 5 / 2003$ & 13 & $2.58 \mathrm{E}+05$ & 35.2 & 31.8 & 4.1 & 8.6 & 17.7 & 2.6 & 0.65 & 0.15 \\
\hline
\end{tabular}


WSRC-TR-2003-00331

December 31, 2004

\subsubsection{Denaturing Gradient Gel Electrophoresis}

The recovery of DNA and RNA and its subsequent analysis after amplification by polymerase chain reaction (PCR) provides a powerful tool for characterizing microbial community structure that complements the PLFA analysis. As with PLFA analysis, numerous studies have used PCR amplification of ribosomal RNA genes (rDNA) to characterize microbial populations in a number of different environments and have demonstrated that the dominant microorganisms isolated by culture frequently do not match those identified by molecular techniques (Amann, et al., 1995). Given that often only $0.1-10 \%$ of visually countable bacteria in samples are cultured and previous studies have demonstrated that organisms obtained from culturing are not necessarily the numerically dominant organisms in situ, it is apparent that the results from culture-based community structure assessments can be noticeably incomplete.

Denaturing gradient gel electrophoresis (DGGE) analysis can be used to detect and identify organisms from a whole community of organisms. The DGGE approach directly determines the species composition of complex microbial assemblages based on the amplification of conserved gene sequences (16S rDNA fragments for prokaryotes, $18 \mathrm{~S}$ or $28 \mathrm{~S}$ rDNA for eukaryotes). In DGGE analysis, differences in gene sequences among organisms allow DNA from various organisms to be physically separated in a denaturing gradient gel, thereby allowing one to generate profiles of numerically dominant bacterial community members for a sample. The profiles are visible as bands (or lines) in a gel. The banding patterns and relative intensities of the bands provide a measure of difference among the communities. Gel bands from dominant species, which constitute at least $1 \%$ of the total bacterial community, can be excised and sequenced. Sequence analysis of individual bands is used to infer the identity of the source organism based on database searches and phylogenetic methods. Phylogenetic affiliations are determined by comparing the rDNA sequences retrieved from samples to rDNA sequences of known bacterial sequences in national databases, such as the Ribosomal Database Project (RDP) or GenBank). 


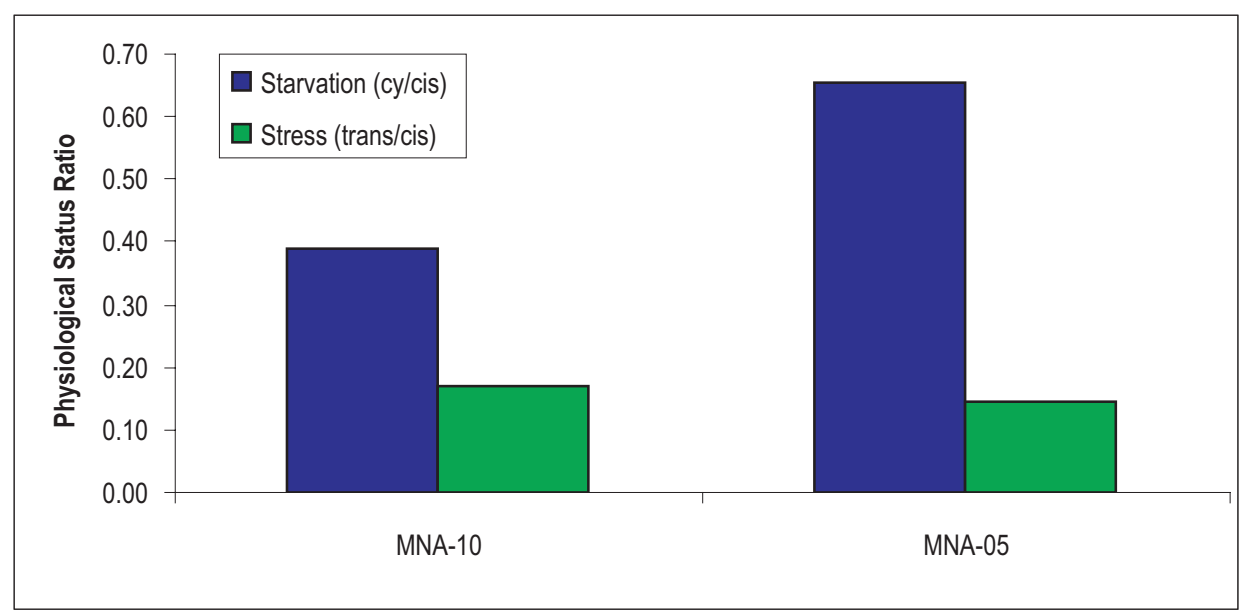

Figure 3.3

Microbial Physiological Stress Markers.

Westinghouse Savannah River MNA/EA Project \begin{tabular}{l|l}
\hline & $\begin{array}{l}\text { Date: 12/27/04 } \\
\text { Client: Westinghouse Savannah }\end{array}$
\end{tabular} Project Number: 031007 \& ASSDCIATES Revision Number: 0 
WSRC-TR-2003-00331

December 31, 2004

\section{SECTION 4}

\section{DEDUCING GEOCHEMICAL ENVIRONMENTS AND DEGRADATION PATHWAYS}

Solute plumes formed by petroleum hydrocarbons and most other sources of reduced organic carbon behave in a very predictable manner in the terrestrial subsurface. This consistent behavior results from these compounds being used as electron donors that are oxidized by bacteria utilizing the naturally-occurring electron acceptors that are ubiquitous in groundwater. Conversely, the reductive dechlorination of the common chlorinated solvents (i.e., PCE, TCE, $\mathrm{CT}$, and TCA) is much more dependent upon the prevailing groundwater geochemistry because these compounds are highly oxidized and are used as electron acceptors. In addition, the lesser chlorinated compounds (e.g., DCE and VC) can be used as electron donors or electron acceptors; that is they can either be oxidized or reduced depending upon the prevailing terminal electronaccepting process. For these reasons an accurate assessment of groundwater geochemistry is required to determine if biological or abiotic degradation is occurring, to determine degradation pathways, and to determine the sustainability of the reactions. As stated by Dr. John T. Wilson of the USEPA (per comm.) chlorinated solvent plumes are like children, each one is different.

The main factor affecting the degradation of chlorinated compounds is the prevailing geochemical environment. Thus, an understanding of the groundwater geochemistry, principally the distribution of aerobic versus anaerobic environs, is essential for deducing degradation pathways, and interpreting chlorinated solvent behavior. Once degradation pathways are elucidated it is possible to determine if natural attenuation will be sufficient as a remedial action. In addition, if natural attenuation is shown not to be protective, an understanding of the ambient groundwater geochemistry and degradation pathways is essential for determining the most appropriate remedial enhancement. In many cases, portions of the plume with differing geochemistry will require different remediation approaches.

To help understand the degradation pathways of chlorinated compounds in different environments, Wiedemeier et al. (1998) proposed a classification system for chlorinated solvent plumes which was adopted by the USEPA (1998). This classification system presented "Type" geochemical environments that result in specific chlorinated solvent behavior. In essence, this classification system groups the groundwater system into either anaerobic and strongly reducing (Type 1 and Type 2) or aerobic and oxidizing (Type 3) end-member environments. In most solvent plumes where reductive dechlorination is occurring, some mixture of environments will be observed, and thus degradation pathways will be different in different portions of the plume. 
WSRC-TR-2003-00331

December 31, 2004

Once the geochemistry of the groundwater has been characterized it is possible to deduce degradation pathways and interpret solute plume behavior. This is essential and required for evaluating the efficacy of natural attenuation and selecting enhanced remedial alternatives should they be necessary.

As mentioned previously, Wiedemeier et al. (1998) proposed a classification system for chlorinated solvent plumes which was adopted by the USEPA (1998). Because the predominant thinking at the time was that the reductive dechlorination of chlorinated solvents was strictly a biological process, this classification system was based on the amount and origin of fermentation substrates that produce the hydrogen that drives dehalorespiration. Three types of groundwater environments and associated plume behavior (Type 1, Type 2, and Type 3) are described in USEPA (1998). Type 1 and Type 2 environments were those environments where the groundwater was very strongly reducing (i.e., sulfate reducing or methanogenic) because of the presence of anthropogenic or naturally-occurring organic carbon, respectively. In the Type 1 and Type 2 environments chlorinated solvents can be completely biodegraded to ethane and ethane. The Type 3 environment was characterized by oxidizing or only very slightly reducing groundwater. In this environment the more highly chlorinated compounds (e.g., PCE, TCE, CT, and TCA) are not biodegraded but VC and DCE can be biologically oxidized. Recent advances in the understanding of chlorinated solvent degradation shows that abiotic reductive dechlorination reactions can be important in some systems. Because this type of reaction typically requires the availability of $\mathrm{Fe}(\mathrm{II})$ and sulfide to generate iron sulfides, the system must be at least sulfate-reducing. Thus, when a site has a Type 1 or Type 2 environment, an assessment of the relative importance of biological versus abiotic degradation mechanisms must be made.

Table 4.1 summarizes the characteristics of the different "Type" geochemical environments with subsets for biological (possibly combined with abiotic) versus exclusively abiotic reactions. Table 4.2 is a matrix showing some of the potential geochemical environments encountered in the terrestrial subsurface and the impact of these environments on the fate of chlorinated ethenes. The potential variability in chlorinated solvent plume behavior is almost infinite and most plumes exhibit mixed behavior in different portions of the plume. Thus, the attenuation capacity will be different in different portions of the plume. This has a direct and profound impact on the remedial approach selected for different portions of the plume.

\subsection{TYPE 1 ENVIRONMENT: SYSTEMS THAT ARE ANAEROBIC DUE TO ANTHROPOGENIC CARBON}

For highly chlorinated solvents to be reductively dechlorinated via dehalorespiration or biologically predicated abiotic processes, anaerobic, strongly reducing conditions must prevail within the contaminant plume. Anaerobic conditions are typical at sites contaminated with fuel hydrocarbons, landfill leachate, or other anthropogenic carbon because these organics exert a tremendous electron-acceptor demand on the system, driving it to a strongly reducing condition. 
Table 4.1

General Characteristics of the "Type" Geochemical Environments

\begin{tabular}{|c|c|c|c|c|}
\hline Environment & $\begin{array}{l}\text { Reductive } \\
\text { Dechlorination? }\end{array}$ & General Characteristics & Comments & Natural Attenuation Capacity \\
\hline Type 1 & $\begin{array}{l}\text { Yes; biological } \\
\text { (dehalorespiration) } \\
\text { and possibly } \\
\text { abiotic }\end{array}$ & $\begin{array}{l}\text { Depleted: } \\
\text { Dissolved Oxygen } \\
\text { Nitrate } \\
\text { Sulfate } \\
\text { Elevated: } \\
\text { Fe(II) [if biologically available Fe(III) is present] } \\
\mathrm{H}_{2} \mathrm{~S} \text { (if sulfate is available) } \\
\text { Methane/ethene/ethane } \\
\text { Hydrogen } \\
\text { Daughter Product Concentrations } \\
\quad \text { (If chlorinated ethenes are present then VC } \\
\quad \text { will likely be present) } \\
\text { Acetylene (+/-) } \\
\quad \text { (results from abiotic reductive dechlorination) } \\
\text { Microbiology: } \\
\text { Dehalococcoides or other dehalorespirators present }\end{array}$ & $\begin{array}{l}\text { Strongly reducing environment } \\
\text { due to the presence of } \\
\text { anthropogenic organic carbon } \\
\text { where biologically-mediated } \\
\text { dehalorespiration is an important } \\
\text { reaction. } \\
\text { Abiotic reactions may or may not } \\
\text { occur. Degradation of chlorinated } \\
\text { ethenes to VC and ethene/ethane } \\
\text { common. } \\
\text { All of the chlorinated ethenes, } \\
\text { ethanes, and methanes will } \\
\text { degrade in this environment. }\end{array}$ & $\begin{array}{l}\text { PCE, TCE = High } \\
\text { DCE = Moderate } \\
\text { VC = Low (may accumulate) } \\
\text { TCA = High (biodegradation/hydrolysis) } \\
\text { DCA = Moderate } \\
\text { Chloroethane = Very High (Hydrolysis) } \\
\text { Cabon Tetrachloride }(\mathrm{CT})=\text { High } \\
\text { Chloroform }(\mathrm{TCM})=\mathrm{High} \\
\text { Methylene Chloride }(\mathrm{DCM})=\text { Moderate } \\
\text { Chloromethane = Very High } \\
\text { (Hydrolysis) }\end{array}$ \\
\hline
\end{tabular}


Table 4.1 - Continued

General Characteristics of the "Type" Geochemical Environments

\begin{tabular}{|c|c|c|c|c|}
\hline Environment & $\begin{array}{l}\text { Reductive } \\
\text { Dechlorination? }\end{array}$ & General Characteristics & Comments & Natural Attenuation Capacity \\
\hline Type 2 & $\begin{array}{l}\text { Yes; biological } \\
\text { (dehalorespiration) } \\
\text { and possibly } \\
\text { abiotic }\end{array}$ & $\begin{array}{l}\text { Depleted: } \\
\text { Dissolved Oxygen } \\
\text { Nitrate } \\
\text { Sulfate } \\
\text { Elevated: } \\
\text { Fe(II) [if biologically available Fe(III) is present] } \\
\mathrm{H}_{2} \mathrm{~S} \\
\text { Methane/ethane/ethene } \\
\text { Hydrogen } \\
\text { Daughter Product Concentrations } \\
\quad \text { (If chlorinated ethenes are present then VC } \\
\quad \text { will likely be present) } \\
\text { Acetylene (+/-) } \\
\quad \text { (results from abiotic reductive dechlorination) } \\
\text { Microbiology: } \\
\text { Dehalococcoides or other dehalorespirators present }\end{array}$ & $\begin{array}{l}\text { Strongly reducing environment due } \\
\text { to the presence of natural organic } \\
\text { carbon where biologically-mediated } \\
\text { dehalorespiration is an important } \\
\text { reaction. } \\
\text { Abiotic reactions may or may not } \\
\text { occur. Degradation of chlorinated } \\
\text { ethenes to VC and ethene/ethane } \\
\text { common. } \\
\text { All of the chlorinated ethenes, } \\
\text { ethanes, and methanes will degrade } \\
\text { in this environment. }\end{array}$ & $\begin{array}{l}\text { PCE, TCE = High } \\
\text { DCE = Moderate } \\
\text { VC = Low (may accumulate) } \\
\text { TCA = High (biodegradation and } \\
\text { hydrolysis) } \\
\text { DCA = Moderate } \\
\text { Chloroethane = Very High (Hydrolysis) } \\
\text { Cabon Tetrachloride }(\mathrm{CT})=\text { High } \\
\text { Chloroform }(\mathrm{TCM})=\mathrm{High} \\
\text { Methylene Chloride }(\mathrm{DCM})=\text { Moderate } \\
\text { Chloromethane = Very High } \\
\text { (Hydrolysis) }\end{array}$ \\
\hline
\end{tabular}


Table 4.1 - Concluded

General Characteristics of the "Type" Biogeochemical Environments

\begin{tabular}{|c|c|c|c|c|}
\hline Environment & $\begin{array}{l}\text { Reductive } \\
\text { Dechlorination? }\end{array}$ & General Characteristics & Comments & Natural Attenuation Capacity \\
\hline Type 3 & $\begin{array}{l}\text { Insignificant to } \\
\text { Nonexistant }\end{array}$ & $\begin{array}{l}\text { Dissolved Oxygen Elevated } \\
\text { Nitrate }+/- \\
\text { Fe(II) absent or }+/- \\
\text { Sulfate }+/- \\
\mathrm{H}_{2} \mathrm{~S} \text { absent } \\
\mathrm{FeS} \text { absent } \\
\text { Methane absent } \\
\text { Acetylene absent }\end{array}$ & $\begin{array}{l}\text { Essentially an aerobic or only } \\
\text { slightly reducing environment. } \\
\text { PCE, TCE, and CT will not } \\
\text { degrade in this environment. } \\
\text { VC is biologically oxidized } \\
\text { very rapidly. } \\
\text { TCA hydrolyzes and } \\
\text { dehydrochlorinates in this } \\
\text { environment. }\end{array}$ & $\begin{array}{l}\text { PCE, TCE = Very Low } \\
\text { DCE = Moderate } \\
\text { VC = High to Very High } \\
\text { TCA = High (Hydrolysis) } \\
\text { DCA = Moderate } \\
\text { Chloroethane = Very High (Hydrolysis) } \\
\text { Cabon Tetrachloride (CT) = Very Low } \\
\text { Chloroform (TCM) = Very Low } \\
\text { Methylene Chloride (DCM) = Moderate } \\
\text { Chloromethane = Very High (Hydrolysis) }\end{array}$ \\
\hline
\end{tabular}


Table 4.2

Matrix Showing Some of the Potential Geochemical Environments Encountered in the Terrestrial Subsurface and Impact on the Fate of Chlorinated Ethenes

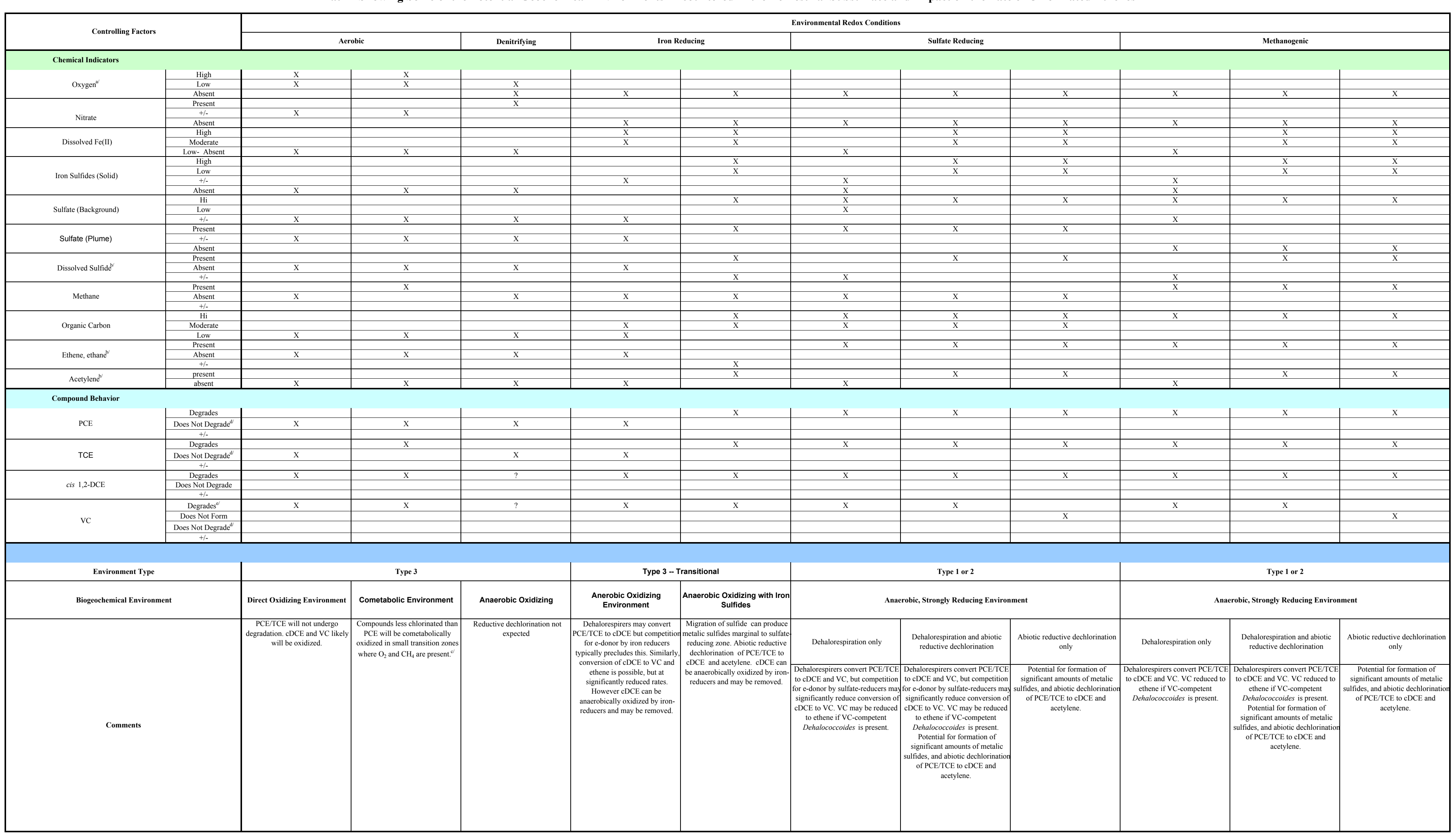

Disclaimer: This table i i intended to present some representative combinations of analytical parameters that are reflective of the various environments for example purposes. NO representation is made that these encompass all possible combinations of parameters and appication to chlorinated compounds other than chlorinated ethenes (PCETCE) Iikely will be differer

al Athough dissolved oxygen may be detected in groundwater samples from ron reducing, suffate reducing, and methanogenic zones this is inevitiably due to poor sampling technique that allows contamination of a sample by atmospheric oxygen

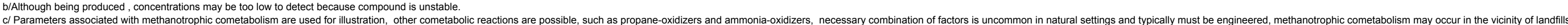

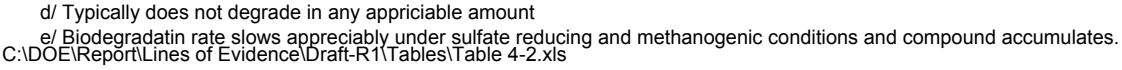


WSRC-TR-2003-00331

December 31, 2004

This condition is referred to as a Type 1 environment. In a Type 1 environment, anthropogenic carbon is fermented to produce hydrogen that drives dehalorespiration. In many cases this environment also produces $\mathrm{FeS}$ or other reduced iron minerals which can cause biologically predicated abiotic reductive dechlorination.

The geochemistry of groundwater in a Type 1 environment is typified by strongly reducing conditions. This environment is characterized by the absence of dissolved oxygen and nitrate, elevated $\mathrm{Fe}$ (II) and sulfide concentrations, sulfate concentrations that typically are lower than those found in uncontaminated groundwater in the vicinity of the solute plume, and the presence of methane. In addition, minerals containing reduced iron (e.g., FeS) also can be produced. Unless background sulfate concentrations are very high, methane is almost always observed and confirms that fermentation has occurred or is occurring at the site, generating hydrogen. If measured, hydrogen concentrations are typically greater than 1 nanomolar.

A Type 1 environment results in the rapid and extensive degradation of the more highlychlorinated solvents such as PCE, TCE, CT, and TCA. A conceptual model of the Type 1 environment for a chlorinated ethene plume is shown in Figure 4.1, where map views and centerline concentration profiles of PCE, TCE, cis-1,2-DCE, VC, inorganic electron acceptors (dissolved oxygen, nitrate, sulfate, and carbon dioxide), metabolic by-products (methane and dissolved iron), fermentation substrates (biochemical oxygen demand or BOD), and fermentation products (acetate) are shown. If the reductive dechlorination is due to dehalorespiration alone, the following sequence of reactions occurs:

$$
\mathrm{PCE} \rightarrow \mathrm{TCE} \rightarrow \mathrm{DCE} \rightarrow \mathrm{VC} \rightarrow \text { Ethene } \rightarrow \text { Ethane }
$$

In this type of plume where degradation results from dehalorespiration only, cis-1,2-DCE and VC degrade more slowly than TCE; thus, they tend to accumulate and form longer plumes (Figure 4.1a). In Figure 4.1b, the PCE declines to zero and is replaced, in sequence, by a peak in TCE concentrations, followed by a peak in cis-1,2-DCE, VC, and ethene. The oxidationreduction potential is depressed in the source zone by the anthropogenic carbon source and stays depressed throughout the entire plume. Fermentation constituents (BOD and acetate) and inorganics are shown in Figure 4.1c and 4.1d. Figure 4.1d illustrates how the fermentation substrate (represented by BOD) extends beyond the source before being consumed. Both panels show long chloride and methane plumes extending far downgradient from the plume area, because chloride is conservative and methane is not biodegraded in an anaerobic environment. The acetate curve indicates where active primary fermentation is occurring; declining acetate concentrations are due to consumption by methanogens in the plume area. 


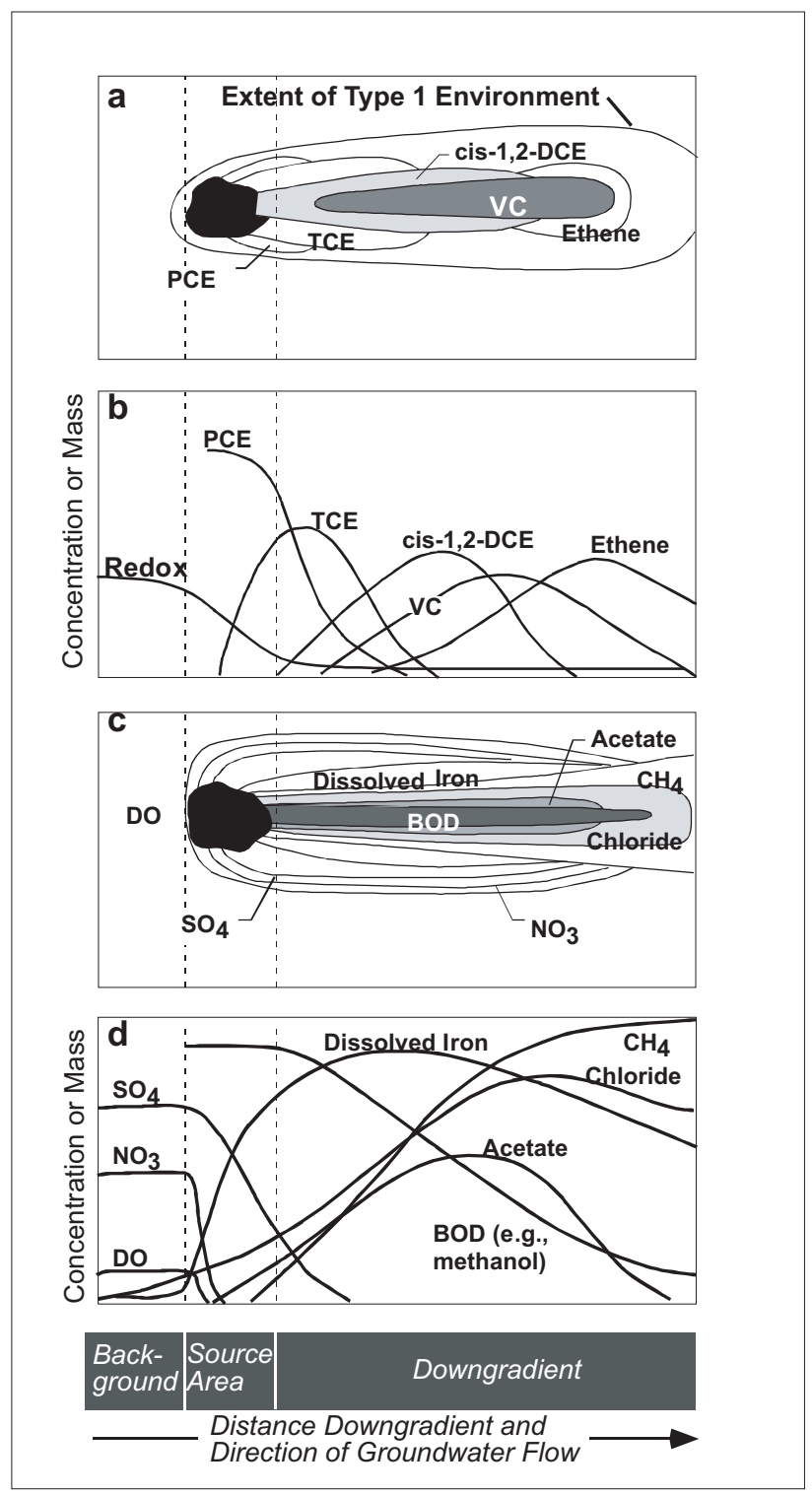

(After RTDF, 1997)

Figure 4.1

Conceptual Model of Type 1 Environment for Chlorinated Solvent Plume Due to a PCE and TCE Release

\begin{tabular}{|l|l}
\hline \multicolumn{2}{|c|}{ Westinghouse Savannah River MNA/EA Project } \\
$\begin{array}{c}\text { WIEDEMEIER } \\
\text { \& ASSDCIATES }\end{array}$ & $\begin{array}{l}\text { Date: 12/27/04 } \\
\text { Client: Westinghouse Savannah } \\
\text { River Company } \\
\text { Project Number: 031007 } \\
\text { Revision Number: 0 }\end{array}$ \\
\hline
\end{tabular}


WSRC-TR-2003-00331

December 31, 2004

In addition to biologically-mediated reductive dechlorination, abiotic reductive dechlorination also may be important in a Type 1 environment. The Fe(II) and sulfide generated by microbial $\mathrm{Fe}(\mathrm{III})$-reduction and sulfate-reduction will react readily to produce iron sulfide minerals that can reductively dechlorinate the chlorinated aliphatic hydrocarbons. If chlorinated ethenes are present in such a system, the degradation may appear to stall at DCE because no VC is produced. In fact, in many cases the reaction has not stalled; instead the DCE is being abiotically degraded to acetylene by iron sulfides. It appears that the acetylene then degrades to ethene and ethane.

Some important questions regarding the long-term behavior of plumes in a Type 1 environment are:

1) Is the supply of the anthropogenic carbon adequate to allow complete reductive dechlorination?

2) Will the production of hydrogen from fermentation be sufficient to drive dechlorination to completion if dehalorespiration is the dominant degradation mechanism?

3) What is the role of alternate electron acceptors (e.g., dissolved oxygen, nitrate, Fe(III) and sulfate) in the competition for the hydrogen? In a Type I environment, there is usually sufficient anthropogenic carbon delivered to the source zone (typically from dissolution of residual NAPLs or from landfill leachate) to remove all the competing electron acceptors and make dehalorespiration more efficient. If the supply of anthropogenic carbon declines (such as through the dissolution of NAPL, removal of a floating product layer, or removal of the landfill leachate), then the competing electron acceptors may no longer be depleted. This would result in cessation of biologic, and possibly abiotic, reductive dechlorination. In addition, the chlorinated solvent plume may migrate out of the area influenced by the biodegradation of reduced organic carbon into a Type 3 environment where, again, there would be a cessation of biologic and abiotic reductive dechlorination.

4) If produced, is vinyl chloride attenuated at rates sufficient to be protective of human health and the environment? Vinyl chloride biodegrades the slowest of the chlorinated ethene compounds in anaerobic environments and may accumulate, forming a longer vinyl chloride plume relative to other chlorinated ethenes (PCE, TCE, or DCE). Based on carcinogen slope factors, vinyl chloride poses a higher potential health risk than the other chlorinated ethenes.

5) Are sufficent ferric iron $\left(\mathrm{Fe}^{3+}\right)$ and sulfate available to yield the production of significant FeS that can result in abiotic reductive dechlorination. The amount of FeS generated from biogenically produced $\mathrm{Fe}(\mathrm{II})$ and sulfide will determine the potential for abiotic reductive dechlorination and its importance relative to dehalorespiration. 
WSRC-TR-2003-00331

December 31, 2004

\subsection{TYPE 2 ENVIRONMENT: SYSTEMS THAT ARE ANAEROBIC DUE TO NATURALLY-OCCURRING CARBON}

The classification system of Wiedemeier et al. (1996a) recognized that anaerobic conditions may also result from the biodegradation of naturally-occurring organic material in the groundwater that flows through chlorinated solvent source zones. The Type 2 environment occurs in hydrogeologic settings that have inherently high organic carbon concentrations, such as coastal or stream/river deposits with high concentrations of organics, shallow aquifers associated with organic-rich environments (such as swamps), or zones impacted by natural oil seeps. When evaluating natural attenuation of a chlorinated solvent plume in a Type 2 environment, the same questions as for a Type 1 environment apply. In addition, the same general conceptual model applies (See Figure 4.1). A Type 2 environment typically will not occur in crystalline igneous and metamorphic rock (see discussion of likely hydrogeologic settings for Type 3 environments).

As with the Type 1 environment, abiotic reductive dechlorination processes may be important. The importance of abiotic reductive dechlorination relative to dehalorespiration is dependant upon the amount of biologically available Fe(III) and sulfate in the system. A potentially important consideration for Type 2 environments is that the ambient redox conditions are well established and iron sulfide minerals are already precipitated prior to a chlorinated solvent release occurring. The iron sulfides are aged over time to produce different mineral species with varying oxidation states. Recent work suggests that aged iron sulfides may show reduced reactivity to some chlorinated organic compounds (e.g., TCE) and that the oxidation state of iron sulfide minerals likely will strongly influence the potential for abiotic reductive dechlorination (Butler and Hayes, 2001).

\subsection{TYPE 3 ENVIRONMENT: AEROBIC SYSTEMS DUE TO LACK OF FERMENTATION SUBSTRATES}

A Type 3 environment is characterized by a well-oxygenated groundwater system with little or no organic matter. Concentrations of dissolved oxygen typically are greater than $1.0 \mathrm{mg} / \mathrm{L}$. In such an environment, dehalorespiration will not occur and chlorinated solvents such as PCE, TCE, TCA, and CT will not be reductively dechlorinated. In this environment, very long aqueous-phase solvent plumes can form. The most significant natural attenuation mechanisms for PCE and TCE will likely be dispersion and sorption. However, VC and DCE can be rapidly oxidized under these conditions. A Type 3 environment is often found in crystalline igneous and metamorphic rock (fractured or unfractured) such as basalt, granite, schist, phyllite and also in glacial outwash deposits, eolian deposits, thick deposits of well-sorted, clean, beach sand with no associated peat or other organic carbon deposits, or any other type of deposit with inherently low organic carbon content if no anthropogenic carbon has been released. 
WSRC-TR-2003-00331

December 31, 2004

Two conceptual models are provided for environments in which Type 3 behavior occurs. For sources with PCE and TCE, the major natural attenuation processes are dilution and dispersion alone (no biodegradation). As shown in Figure 4.2, the PCE and TCE plumes extend from the source zone and concentrations are slowly reduced by dilution, dispersion, and sorption processes. Chloride concentrations and oxidation-reduction potential will not change as groundwater passes through the source zone and forms the chlorinated ethene plume. If TCA is the solvent of interest, significant abiotic hydrolysis and dehydrohalogenation may occur, resulting in a more rapid decrease in TCA concentrations and an increase in chloride concentrations with production of 1,1-DCE.

In Figure 4.3, a source releases $\mathrm{VC}$ and 1,2-DCA into the groundwater at a Type 3 site (an unlikely occurrence as more highly chlorinated solvents are typically released at sites). Because the VC and 1,2-DCA can be degraded aerobically, these constituents decline in concentration at a significant rate. Chloride is produced, and a depression in dissolved oxygen concentration similar to that occurring at fuel sites, is observed.

\subsection{MIXED ENVIRONMENTS}

Most chlorinated solvent plumes exhibit different types of behavior in different portions of the plume. This generally is the result of the distribution of different geochemical environments along the flow path. Figures 4.4 through 4.7 show several conceptual models for mixed environments.

Mixed geochemical environments can be beneficial for natural biodegradation of chlorinated solvent plumes. For example, Wiedemeier et al. (1996b) describe a plume at Plattsburgh AFB, New York that exhibits Type 1 behavior in the source area and Type 3 behavior downgradient from the source. For natural attenuation, this may be an efficient remediation scenario. PCE, TCE, and DCE are reductively dechlorinated with accumulation of VC near the source area (Type 1); then, VC is oxidized (Type 3) to carbon dioxide, either aerobically or via $\mathrm{Fe}(\mathrm{III})$ reduction further downgradient and does not accumulate. Vinyl chloride is removed from the system much faster under these conditions than under reducing conditions.

A less ideal variation of the mixed Type 1 and Type 3 environments is shown in the conceptual model in Figure 4.4. An extended TCE and cis-1,2-DCE plume results because insufficient fermentable carbon results in an anaerobic zone which is too short for complete biodegradation. Therefore, TCE extends well into the aerobic zone where no biodegradation occurs. A long DCE plume also extends into the aerobic zone, indicating insignificant direct aerobic oxidation has occurred. While a long chloride plume will be observed, the short anaerobic zone means much less methane is produced, allowing dilution/dispersion to limit the extent of the methane plume. 


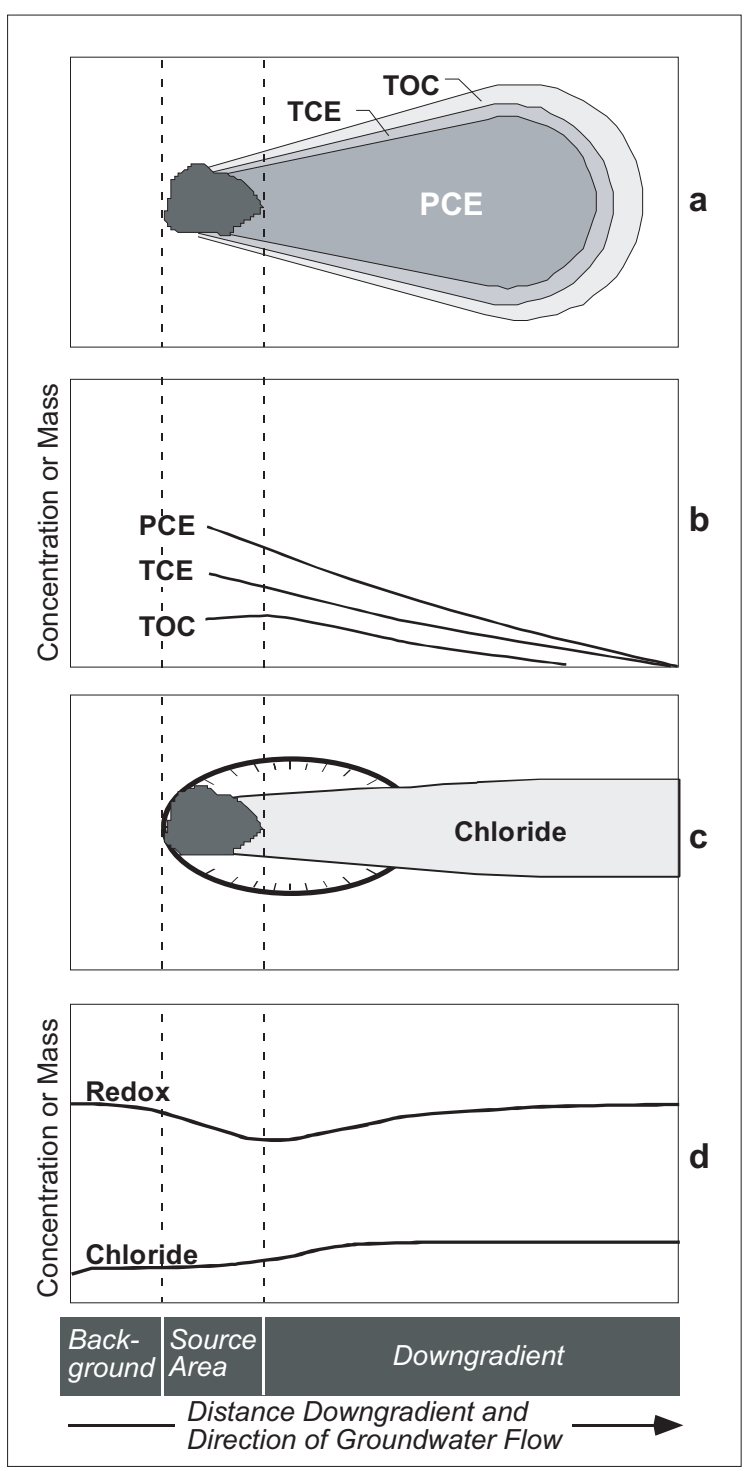

Figure 4.2

Conceptual Model of Type 3 Environment for Chlorinated Solvent Plume due to a PCE and TCE Release

\begin{tabular}{|l|l}
\hline \multicolumn{2}{|c|}{ Westinghouse Savannah River MNA/EA Project } \\
$\begin{array}{c}\text { WIEDEMEIER } \\
\text { \& ASSDCIATES }\end{array}$ & $\begin{array}{l}\text { Date: } 12 / 27 / 04 \\
\text { Client: Westinghouse Savannah } \\
\text { River Company } \\
\text { Project Number: 031007 } \\
\text { Revision Number: 0 }\end{array}$ \\
\hline
\end{tabular}




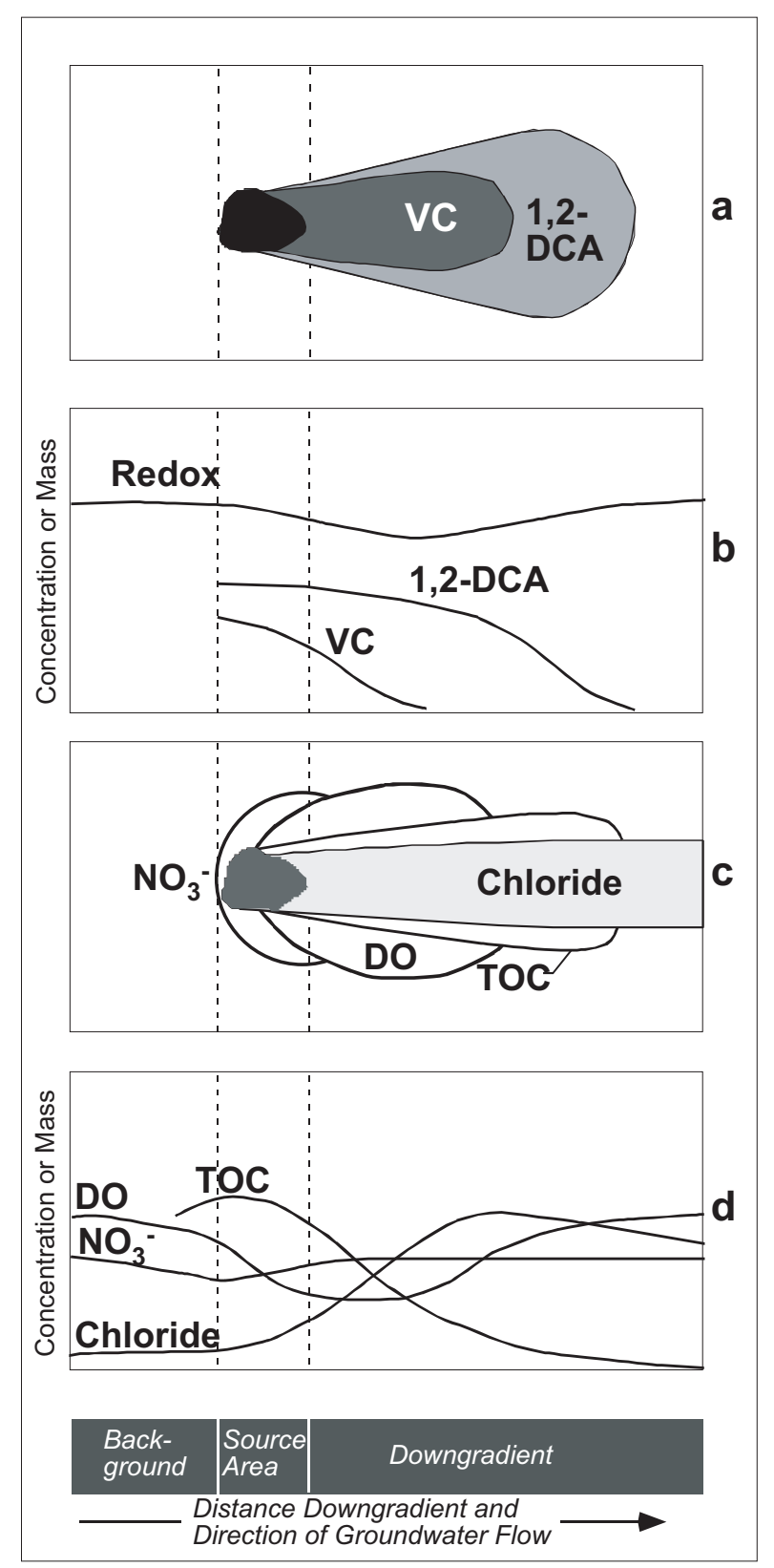

Figure 4.3

Conceptual Model of Type 3 Environment for Chlorinated Solvent Plume with VC and 1,2-DCA 


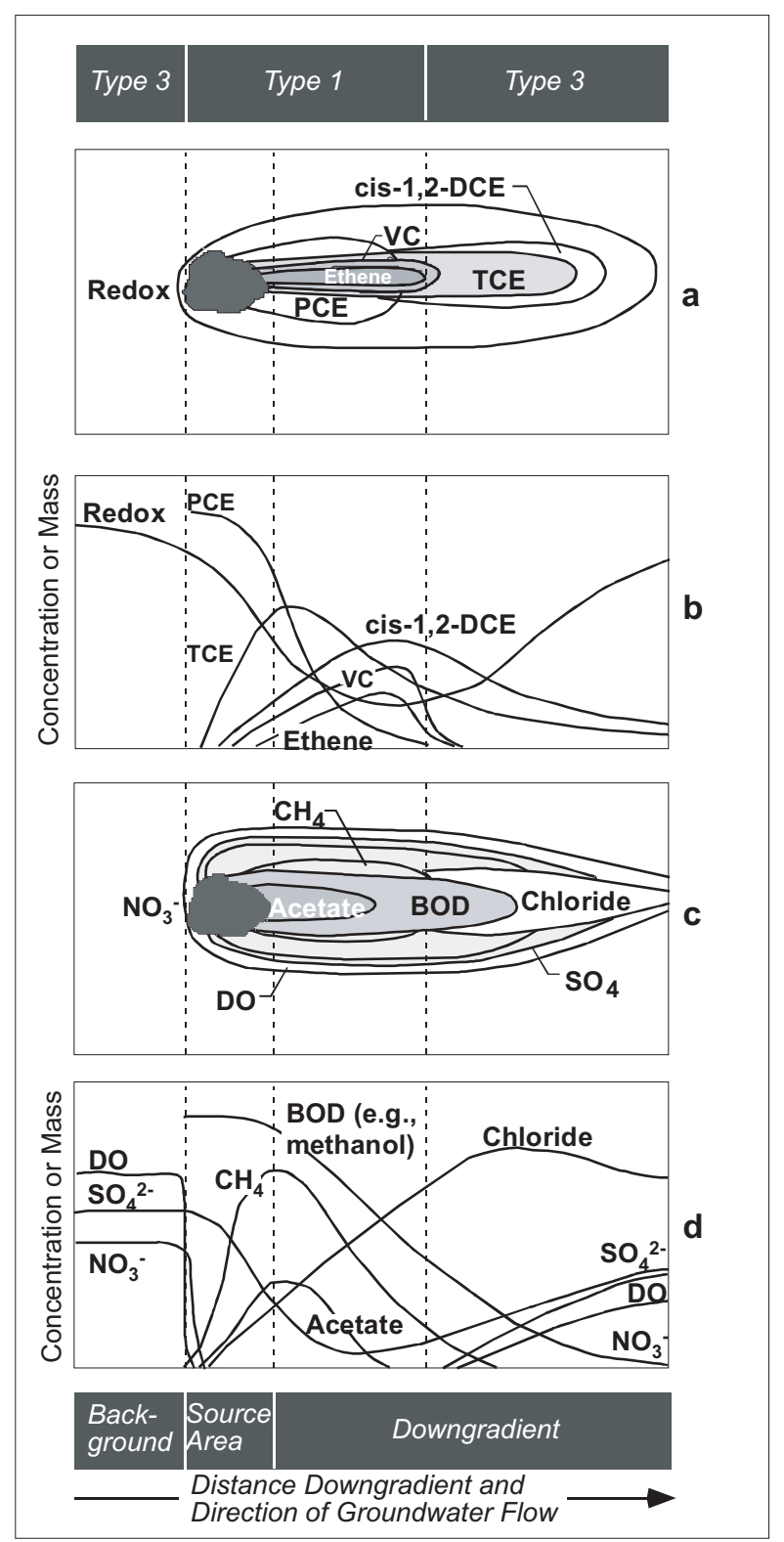

Figure 4.4

Conceptual Model of Mixed Environments with Type 1 Environment in the Source Zone and

Type 3 Environment in the Downgradient Portion of the Plume 


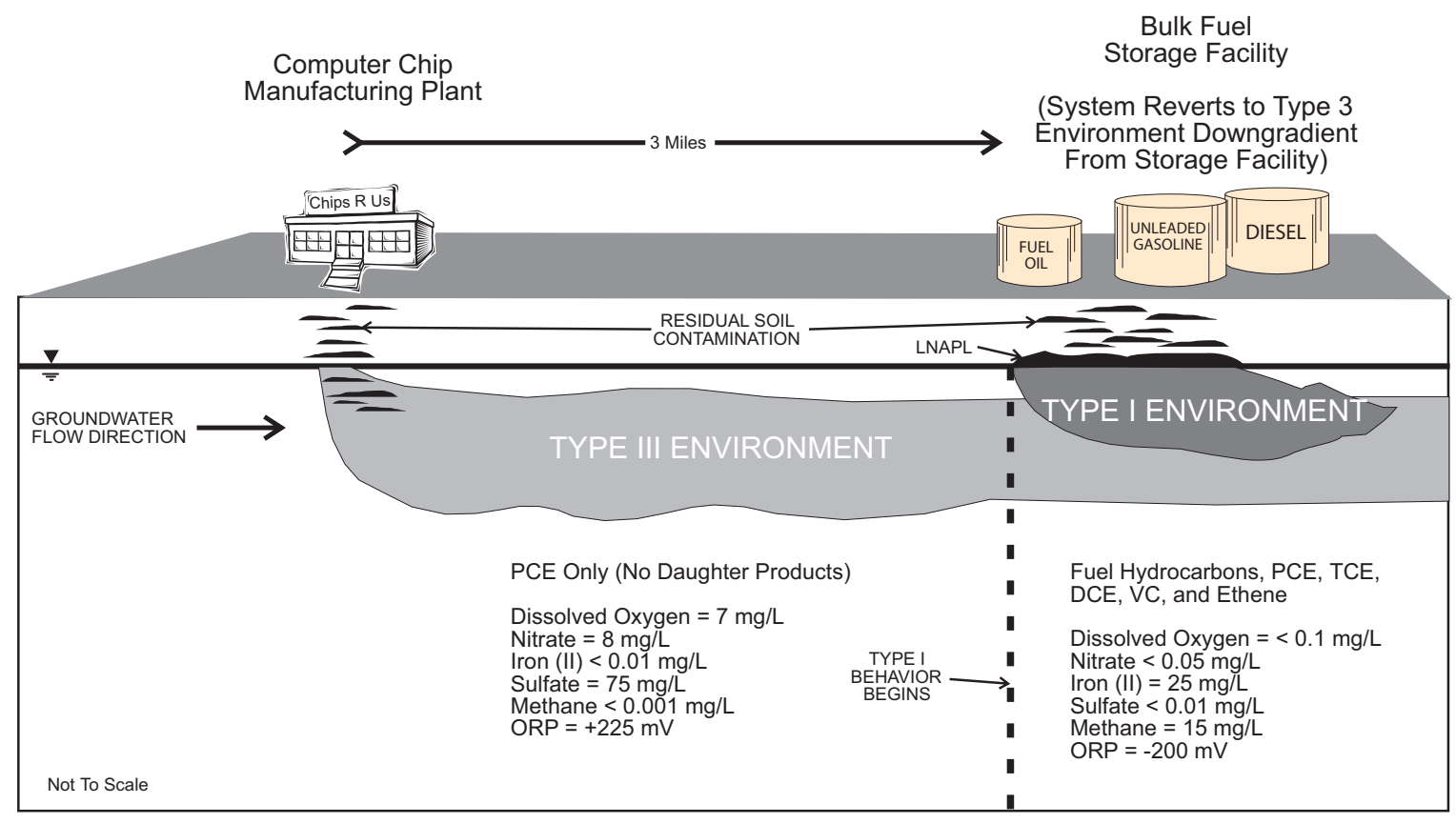

Figure 4.5

Conceptual Site Model of Mixed Type 3/Type 1/ Type 3 Environments

\begin{tabular}{|l|l|}
\hline \multicolumn{2}{|c|}{ Westinghouse Savannah River MNA/EA Project } \\
$\begin{array}{c}\text { WIEDEMEIER } \\
\text { \& ASSDCIATES }\end{array}$ & $\begin{array}{l}\text { Date: } 12 / 27 / 04 \\
\text { Client: Westinghouse Savannah } \\
\text { River Company } \\
\text { Project Number: 031007 } \\
\text { Revision Number: 0 }\end{array}$ \\
\hline
\end{tabular}




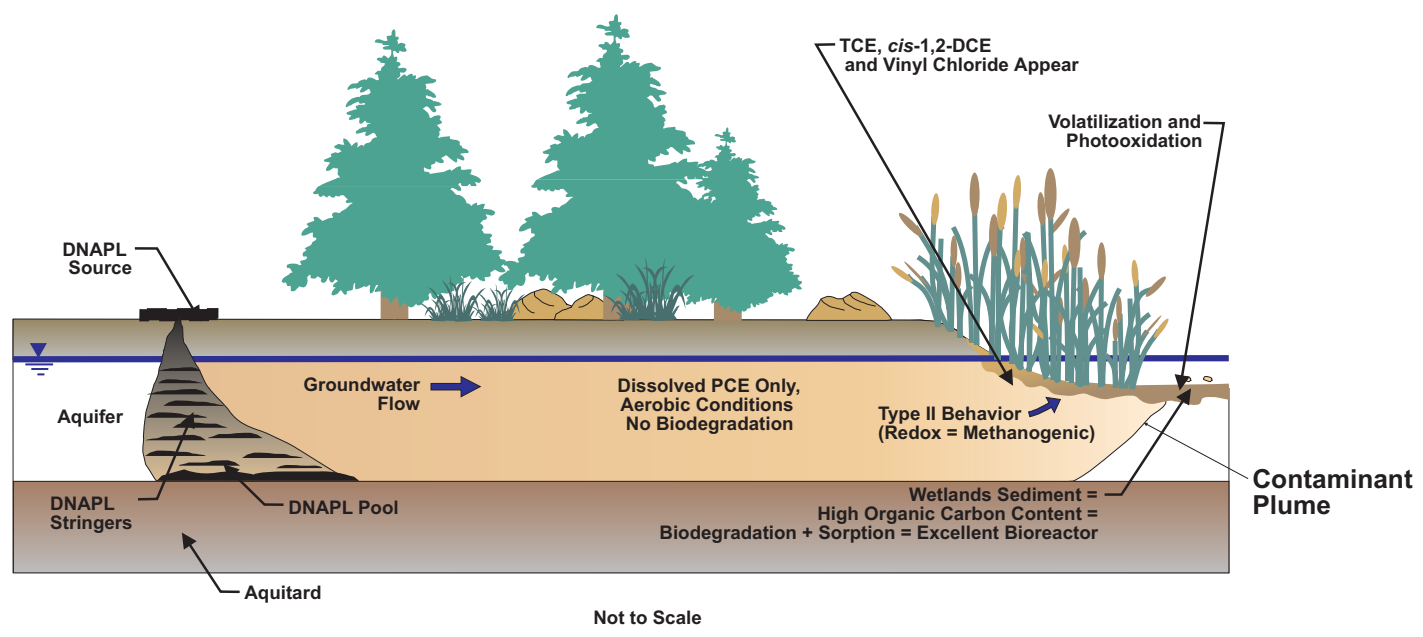

Figure 4.6

Conceptual Model of a Plume Discharging to Surface Water

Westinghouse Savannah River MNA/EA Project

IN

Client: Westinghouse Savannah

River Company

WIEDEMEIER

Project Number: 031007

\& ASSDCIATES

Revision Number: 0 


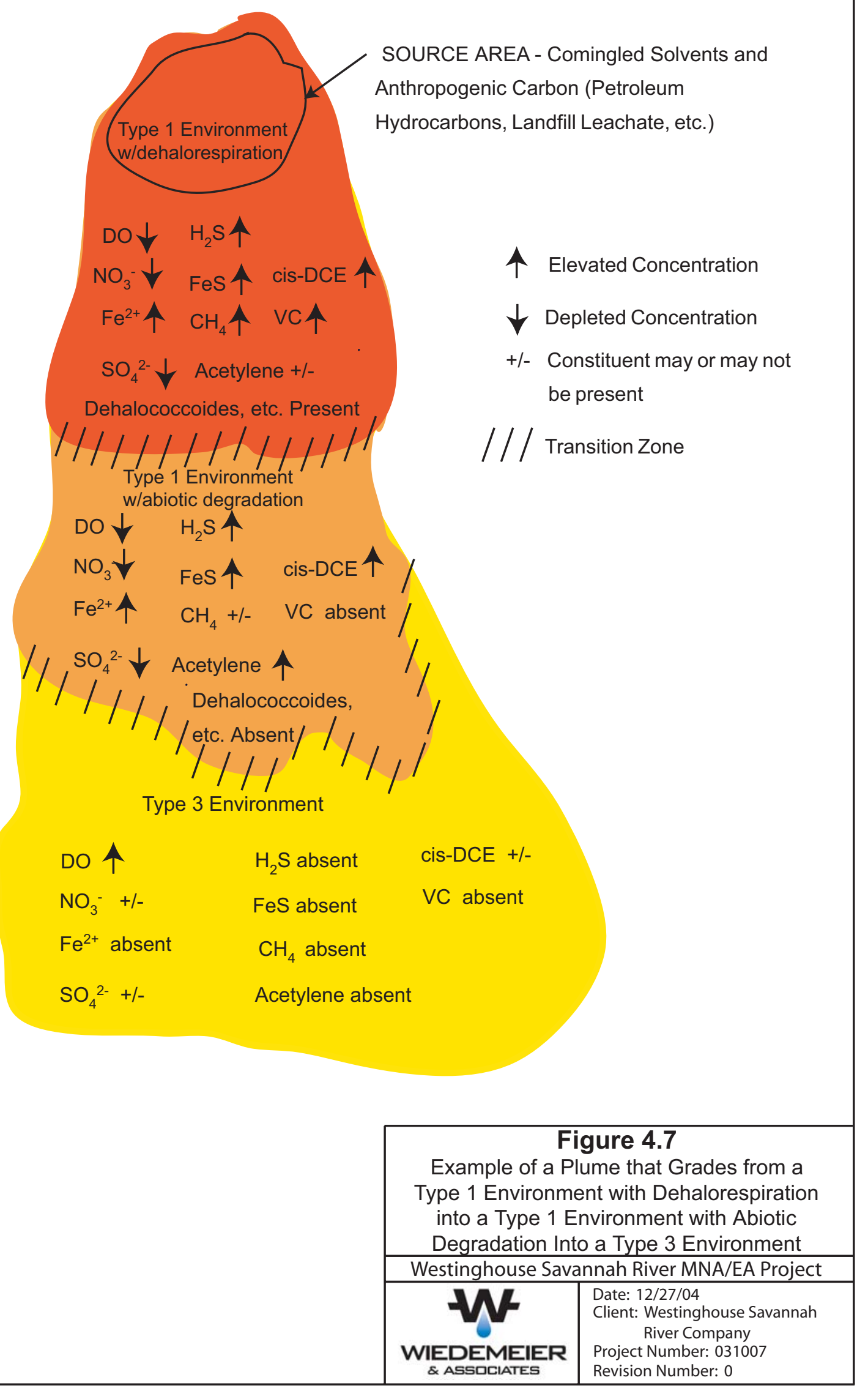


WSRC-TR-2003-00331

December 31, 2004

A less common type of mixed environment occurs where a chlorinated solvent source zone in a Type 3 environment produces a plume that extends downgradient to a zone in the aquifer where fermentation substrates are supplied (Figure 4.5). For example, a downgradient leaking underground storage tank could introduce benzene, toluene, ethylbenzene, and the xylenes (BTEX) compounds into the chlorinated solvent plume, changing the environment to Type 1. Because petroleum hydrocarbons tend not to migrate a significant distance, the environment would likely revert to a Type 3 environment and the solvent plume will likely continue migrating.

Another possibility is an upland plume discharging into a wetland. In this case a Type 3 environment would be converted to a Type 2 environment if a downgradient recharge zone introduced naturally-occurring fermentation substrates to the subsurface (Figure 4.6).

Figure 4.7 shows a conceptual site model where the plume grades from a Type 1 environment with both biological and abiotic reductive dechlorination into a Type 1 environment where abiotic reductive dechlorination dominates into a Type 3 environment. 
WSRC-TR-2003-00331

December 31, 2004

\section{SECTION 5}

\section{REFERENCES}

Albrechtsen, H.-J., Bjerg, P.L., Ludvigsen, L., Rugge, K., Christensen, T.H., 1999. An anaerobic field injection experiment in a landfill leachate plume Grindsted, Denmark: 2. Deduction of anaerobic methanogenic, sulfate- and Fe(III)-reducing redox conditions. Water Resour. Res. 35:1247-1256.

Amann, R. I., W. Ludwig, and K.-H. Schleifer, 1995, Phylogenetic identification and in situ detection of individual microbial cells without cultivation. Microbiological Reviews 59:143-169.

Amirbahman, A., Schoenenberger, R., Johnson, C.A., Sigg, L., 1998. Aqueous- and solid-phase biogeochemistry of a calcareous aquifer system downgradient from a municipal solid waste landfill Winterthur, Switzerland . Environ. Sci. Technol. 32:1933-1940.

Amonette, J.E., 2002, Methods for determination of mineralogy and environmental availability, p. 153-197: In J.B. Dixon and D.G. Schulze (eds.), Soil Mineralogy with Environmental Applications. SSSA Book Series No. 7. Soil Science Society of America, Madison, WI.

Amonette, J.E., and Sanders, R.W., 1994, Nondestructive techniques for bulk elemental analysis, p. 1-48: In J.E. Amonette and L.W. Zelazny (eds). Quantitative Methods in Soil Mineralogy, SSSA Miscellaneous Publication. Soil Science Society of America, Madison, WI.

Amonette, J.E., and Zelazny, L.W. (eds), 1994. Quantitative Methods in Soil Mineralogy, SSSA Miscellaneous Publication. Soil Science Society of America, Madison, WI.

Ashley, G.M., 1973, Impregnation of fine-grained sediments with a polyester resin: A modification of Altemuller's method: Journal of Sedimentary Petrology 43:298-301.

ASTM, 1998, E1943-98 Standard and Guide for Remediation by Natural Attenuation at Petroleum Release Sites: American Society for Testing and Materials, Philadelphia, PA.

Barden, M.J., 2003, Practical Use of Statistics for Natural Attenuation Trend Analysis. Environmental Institute for Continuing Education Online Seminar EST-0101. June, 2003.

Bigham, J.M., Fitzpatrick, R.W., and Schulze, D.G., 2002, Iron oxides, p. 323-366: In J.B. Dixon and D.G. Schulze (eds.), Soil Mineralogy with Environmental Applications. SSSA Book Series No. 7. Soil Science Society of America, Madison, WI. 
WSRC-TR-2003-00331

December 31, 2004

Bradley, P.M., and Chapelle, F.H., 1996, Anaerobic mineralization of vinyl chloride in Fe(III)reducing aquifer sediments: Environmental Science and Technology, v. 30, p. 2084 2086.

Bradley, P.M., and Chapelle, F.H., 1997, Kinetics of DCE and VC mineralization under methanogenic and Fe(III)-reducing conditions: Environmental Science and Technology, v. 31, p. 2692 - 2696.

Bradley, P.M., Chapelle, F.H., and Vroblesky, D.A., 1993. Does lead affect microbialmetabolism in aquifer sediments under different terminal electron-accepting conditions. Geomicrobiol. J. 11: 85-94.

Buol, S.W., and Faddness, D.M., 1961, A new method of impregnating fragile material for thin sectioning. Soil Sci. Soc. Amer. Proc., v. 25, p. 253.

Burlage, R.S., 1998, Molecular techniques, p. 289-334: In R.S. Burlage, R. Atlas, D. Stahl, G. Geesey and G. Sayler (eds.), Techniques in Microbial Ecology. Oxford University Press, New York.

Butler, E. C., and K. F. Hayes, 1999, Kinetics of the transformation of trichloroethylene and tetrachloroethylene by iron sulfide: Environmental Science and Technology, 33:20212027.

Butler, E. C., and K. F. Hayes, 2001, Factors influencing rates and products in the transformation of trichloroethylene by iron sulfide and iron metal: Environmental Science and Technology, 35:3884-3891.

Cady, J.G., Wilding, L.P., and Drees, L.R., 1986, Petrographic microscope techniques, p. 185218: In A. Klute (ed.), Methods of Soil Analysis: Part 1, Physical and Mineralogical Methods (Second Edition). SSSA Book Series No. 5 (Part 1). American Societry of Agronomy and Soil Science Society of America, Madison, WI.

Chapelle, F.H., McMahon, P.B., Dubrovsky, N.M., Fujii, R.F., Oaksford, E.T., and Vroblesky, D.A., 1995, Deducing the distribution of terminal electron-accepting processes in hydrologically diverse groundwater systems: Water Resources Research, v. 31, p. 359371.

Chapelle, F.H., 1997, Identifying redox conditions that favor the natural attenuation of chlorinated ethenes in contaminated groundwater systems, In Proceedings of the Symposium on Natural Attenuation of Chlorinated Organics in Groundwater, Dallas, TX: EPA/540/R-97/504, May 1997.

Chapelle, F.H., Vroblesky, D.A., Woodward, J.C., and Lovley, D.R., 1997, Practical considerations for measuring hydrogen concentrations in groundwater: Environmental Science and Technology, v. 31:2873-2877.

Christensen, T.H., Bjerg, P.L., Banwart, S.A., Jakobsen, R., Heron, G., and Albrechtsen, H-.J., 2000. Characterization of redox conditions in groundwater contaminant plumes. Journal of Contaminant Hydrology 45: 165-241. 
WSRC-TR-2003-00331

December 31, 2004

Conover, W.J., 1999, Practical Nonparametric Statistics ( $3^{\text {rd }}$ Edition): John Wiley \& Sons, Inc., New York, 584 p.

Dawson K.J. and Istok, J.D., 1991, Aquifer Testing - Design and analysis of pumping and slug tests: Lewis Publishers, Chelsea, Michigan, 344 p.

Deutsch, W.J., 1997, Groundwater Geochemistry: Fundamentals and Applications to Contamination: Lewis Publishers, Boca Raton, FL. 221 p.

Dowling, N. J. E., F. Widdel, and D. C. White, 1986, Phospholipid ester-linked fatty acid biomarkers of acetate-oxidizing sulfate reducers and other sulfide forming bacteria. Journal of General Microbiology 132:1815-1825.

Drees, L.R., and Ransom, M.D., 1994, Light microscopic techniques in quantitative soil mineralogy, p. 137-176: In J.E. Amonette and L.W. Zelazny (eds). Quantitative Methods in Soil Mineralogy, SSSA Miscellaneous Publication. Soil Science Society of America, Madison, WI.

Edlund, A., P. D. Nichols, R. Roffey, and D. C. White, 1985, Extractable and lipopolysaccharide fatty acid and hydroxy acid profiles from Desulfovibrio species: Journal of Lipid Research 26:982-988.

Fanning, D.S., Rabenhorst, M.C., Burch, S.N., Islam, K.R., and Tangren, S.A., 2002, Sulfides and sulfates, p. 229-260: In J.B. Dixon and D.G. Schulze (eds.), Soil Mineralogy with Environmental Applications. SSSA Book Series No. 7. Soil Science Society of America, Madison, WI.

Gibbons, R.D., 1994, Statistical Methods for Groundwater Monitoring: John Wiley \& Sons, Inc., New York, 286 p.

Gilbert, R.O., 1987, "Statistical Methods for Environmental Pollution Monitoring," Van Nostrand Reinhold, New York.

GSI, 1998, Remediation by Natural Attenuation (RNA) ToolKit Users Manual: Groundwater Services, Inc., Houston, Texas.

Guckert, J. B., C. P. Antworth, P. D. Nichols, and D. C. White, 1985, Phospholipid ester-linked fatty acid profiles as reproducible assays for changes in prokaryotic community structure of estuarine sediments: FEMS Microbiol. Ecol. 31:147-158.

Guckert, J. B., M. A. Hood, and D. C. White, 1986, Phospholipid ester-linked fatty acid profile changes during nutrient deprivation of Vibrio cholerae: increases in the trans/cis ratio and proportions of cyclopropyl fatty acids: Appl. Environ. Microbiol. 52:794-801.

Hansen, L.K., 1998. Biogeochemistry of Methane In A Shallow Sandy Aquifer. PhD Dissertation, Technical University of Denmark, Lyngby, Denmark.

Hedrick, D.B., A Peacock, J.R. Stephen, S.J. Macnaughton, Julia Brüggemann, and David C. White, 2000, Measuring soil microbial community diversity using polar lipid fatty acid and denatured gradient gel electrophoresis data: J. Microbiol. Methods, 41, 235-248. 
WSRC-TR-2003-00331

December 31, 2004

Helsel, D.R., and Hirsch, R.M., 2002, Statistical methods in water resources: U.S. Geological Survey - Techniques of Water-Resources Investigations, Book 4, Ch. A3, 510 p. [Available online only at http://water.usgs.gov/twri/twri4a3/]

Hem, J.D., 1985, Study and Interpretation of the Chemical Characteristics of Natural Water: United States Geological Survey Water-Supply Paper 2254, 264 p.

Heron, G., Christensen, T.H., Tjell, J.C., 1994a. Oxidation capacity of aquifer sediments. Environ. Sci. Technol. 28:153-158.

Heron, G., Crouzet, C., Bourg, A.C.M., Christensen, T.H., 1994b. Speciation of Fe(II) and $\mathrm{Fe}(\mathrm{III})$ in contaminated aquifer sediments using chemical extraction techniques. Environ. Sci. Technol. 28:1698-1705.

Hirsch, R.M., and Slack, J.R., 1984, A nonparameteric trend test for seasonal data with serial dependence. Water Resources Research, vol. 20, p. 727-732.

Hirsch, R.M., Slack, J.R., and Smith, R.A., 1982, Techniques of trend analysis for monthly quality data: Water Resources Research, vol. 18, p. 107-121.

Hollander, M., and Wolfe, D.A., 1999, Nonparametric Statistical Methods (2 ${ }^{\text {nd }}$ Edition): John Wiley \& Sons, Inc., New York, 787 p.

Hunkeler, D., Aravena, R., and Butler, B.J., 1999, Monitoring microbial dechlorination of tetrachloroethene (PCE) in groundwater using compound-specific stable carbon isotope ratios - microcosm and field studies: Environmental Science and Technology, v. 33, p. 2733-2738.

Innes, R.P., and Pluth, D.J., 1970, Thin section preparation using epoxy impregnation for petrographic and electron microprobe analysis: Soil Sci. Soc. Amer. Proc. 34:483-485.

Johnson, A.I., 1967, Specific Yield - Compilation of Specific Yields for Various Materials. United States Geological Survey Water-Supply Paper 1662-D, p. D1-D74.

Jones, R.C., and Malik, H.U., 1994, Analysis of minerals in oxide-rich soils by x-ray diffraction, p. 296-329: In J.E. Amonette and L.W. Zelazny (eds). Quantitative Methods in Soil Mineralogy, SSSA Miscellaneous Publication. Soil Science Society of America, Madison, WI.

Karathanasis, A.D., and Hajek, B.F., 1996, Elemental analysis by x-ray fluorescence spectroscopy, p. 161-223: In D.L. Sparks (ed.), Methods of Soil Analysis: Part 3, Chemical Methods. SSSA Book Series No. 5 (Part 3). American Societry of Agronomy and Soil Science Society of America, Madison, WI.

Kaufman, W.J. and Orlob, G.T., 1956, Measuring groundwater movement with radioactive and chemical tracers: American Water Works Association Journal, v. 48, p. 559-572.

Kendall, M.G., 1975, Rank Correlation Methods, 4th ed. Charles Griffith, London. 
WSRC-TR-2003-00331

December 31, 2004

Kennedy, L., and Everett, J, 2004, Draft Final Report, Field Test of Biogeochemical Reductive Dechlorination at Dover Air Force Base, Dover Delaware: Air Force Center for Environmental Excellence, San Antonio, Texas, December 2004.

Kennedy, L., Everett, J., and J. Gonzales, 2000, Aqueous and Mineral Intrinsic Bioremediation Assessment (AMIBA) Protocol. U.S. Air Force Center for Environmental Excellence, San Antonio, Texas.

Kennedy, L.G., Everett, J.W., Ware, K.J., Parsons, R., Green, V., 1998. Iron and sulfur mineral analysis methods for natural attenuation assessments. Biorem. Jour. 2:259-276.

Kerr, P.F., 1977. Optical Mineralogy (4 ${ }^{\text {th }}$ edition). McGraw Hill, New York. 492 p.

Kruseman, G.P. and de Ridder N.A., 1991, Analysis and Evaluation of Pumping Test Data: International Institute for Land Reclamation and Improvement, The Nederlands, 377 p.

Laird, D.A., and Dowdy, R.H., 1994, Preconcentration techniques in soil mineralogical analysis, p. 236-266: In J.E. Amonette and L.W. Zelazny (eds). Quantitative Methods in Soil Mineralogy, SSSA Miscellaneous Publication. Soil Science Society of America, Madison, WI.

Ling, M., Rifai, H.S., Newell, C.J., Aziz, J.J., and Gonzales, J.R., 2003, Groundwater monitoring plans at small-scale sites: An innovative spatial and temporal methodology: Journal of Environmental Monitoring, vol. 5, p. 126-134.

Liu, W-.T., and Stahl, D., 2002, Molecular approaches for the measurement of density, diversity, and phylogeny, p. 114-134: In C. J. Hurst, R.L. Crawford, G. R. Knudsen, M. J. McInerney, and L. D. Stetzenbach (eds.), Manual of Environmental Microbiology, Second Edition. ASM Press, Washington, DC.

Loeppert, R.H., and Inskeep, W.P., 1996, Iron, p. 639-664: In D.L. Sparks (ed.), Methods of Soil Analysis: Part 3, Chemical Methods. SSSA Book Series No. 5 (Part 3). American Societry of Agronomy and Soil Science Society of America, Madison, WI.

Lovley, D.R., and Goodwin, S., 1988, Hydrogen concentrations as an indicator of the predominant terminal electron-accepting reaction in aquatic sediments: Geochimica et Cosmochimica Acta, v. 52, p. 2993-3003.

Lovley, D.R., F.H. Chapelle, and J.C. Woodward, 1994, Use of dissolved $\mathrm{H}_{2}$ concentrations to determine distribution of microbially catalyzed redox reactions in anoxic groundwater. Environmental Science and Technology, v. 28, no. 7, p. 1205-1210.

Mann, H.B., 1945, Nonparametric tests against trend: Econometrica, vol. 13, p. 245-259.

Mann, H.B. and Whitney, D.R., 1947, "On a test of whether one or more random variables is stochastically larger than in the other," Ann. Math. Sciences, 18, pp. 52-54.

Mc Bride, M.B., 1986, Magnetic methods, p. 219-270: In A. Klute (ed.), Methods of Soil Analysis: Part 1, Physical and Mineralogical Methods (Second Edition). SSSA Book Series No. 5 (Part 1). American Societry of Agronomy and Soil Science Society of America, Madison, WI. 
WSRC-TR-2003-00331

December 31, 2004

Morel, F.M.M. and Hering, J.G., 1993, Principles and Applications of Aquatic Chemistry: John Wiley \& Sons, Inc., New York

National Research Council, 1993, In Situ Bioremediation, When Does it Work?: National Academy Press, Washington, D.C., 207 p.

Pinkart, H.C., Ringelberg, D.B., Piceno, Y.M., MacNaughton, S.J., and White, D.C., 2002, Biochemical approaches to biomass measurements and community structure analysis, $\mathrm{p}$. 101-113: In C. J. Hurst, R.L. Crawford, G. R. Knudsen, M. J. McInerney, and L. D. Stetzenbach (eds.), Manual of Environmental Microbiology, Second Edition. ASM Press, Washington, DC.

Reed, S. J. B., 1996. Electron Microprobe Analysis and Scanning Electron Microscopy in Geology. Cambridge University Press. 215 p.

Ribbe, P.H. (ed.), 1974, Sulfide Mineralogy. Mineralogical Society of America Short Course Notes, v. 1. Southern Printing Company, Blacksburg, VA.

Ringelberg, D. B., G. T. Townsend, K. A. DeWeerd, J. M. Sulita, and D. C. White, 1994, Detection of the anaerobic dechlorinating microorganism Desulfomonile tiedjei in environmental matrices by its signature lipopolysaccharide branch-long-chain hydroxy fatty acids. FEMS Microbiol. Ecol. 14:9-18.

RTDF, 1997, Natural Attenuaton of Chlorinated Solvents in Groundwater Seminar, Class Notes, Remediation Technologies Development Forum

Sawhney, B.L., 1986, Electron Microprobe analysis, p. 271-290: In A. Klute (ed.), Methods of Soil Analysis: Part 1, Physical and Mineralogical Methods (Second Edition). SSSA Book Series No. 5 (Part 1). American Societry of Agronomy and Soil Science Society of America, Madison, WI.

Schulze, D.G., 1994, Differential x-ray diffraction analysis of soil minerals, p. 412-429: In J.E. Amonette and L.W. Zelazny (eds). Quantitative Methods in Soil Mineralogy, SSSA Miscellaneous Publication. Soil Science Society of America, Madison, WI.

Slater, G.F., Lollar, B.S., Sleep, B.E., Edwards, E.A., 2001, Variability in carbon isotopic fractionation during biodegradation of chlorinated ethenes - implications for field applications: Environmental Science and Technology, v. 35, p. 901-907.

Spry, P.G. and Gedlinske, B.L., 1987. Tables for the determination of common opaque minerals: Economic Geology, 52 p.

Stumm, W. and Morgan, J.J., 1996, Aquatic Chemistry, Chemical Equilibria and Rates in Natural Waters: Wiley-Interscience, New York, New York, 1022 p.

Tighe, S.W., de Lajudie, P., Dipietro, K., Lindström, K., Nick, G. \& Jarvis, B.D.W., 2000, Analysis of cellular fatty acids and phenotypic relationships of Agrobacterium, Bradyrhizobium, Mesorhizobium, Rhizobium and Sinorhizobium species using the Sherlock Microbial Identification System: Int J Syst Evol Microbiol 50, 787-801. 
WSRC-TR-2003-00331

December 31, 2004

Tuccillo, M.E., Cozzarelli, I.M., and Herman, J.S., 1999. Iron reduction in the sediments of a hydrocarbon-contaminated aquifer. Appl. Geochem. 14:655-667.

Tsitko, I.V. Zaitsev, G.M., Lobanok, A.G., and Salkinoja-Salonen, M.S., 1999, Applied and Environmental Microbiology 65(2):853-855.

USEPA, 1992, Methods for evaluating attainment of cleanup standards, volume 2, Groundwater: EPA/230-R-92-014.

USEPA, 1998, Technical Protocol for Evaluating Natural of Chlorinated Solvents in Groundwater: EPA/600/R-98/128, September, 1998.

US Environmental Protection Agency (USEPA), 1999, Use of Monitored Natural Attenuation at Superfund, RCRA Corrective Action, and Underground Storage Tank Sites, Final: Office of Solid Waste and Emergency Response. April 21. Directive Number 9200.

USEPA, 2000. Guidance for Data Quality Assessment, Practical Methods for Data Analysis. U.S. Environmental Protection Agency, Office of Environmental Information, Washington, DC. EPA QA/G-9 (QA00 Update).

Vandamme P, Pot B, Gillis M, de Vos P, Kersters K, Swings J., 1996, Polyphasic taxonomy, a consensus approach to bacterial systematics: Microbiol Rev 1996 Jun;60(2):407-38.

White, D. C., W. M. Davis, J. S. Nickels, J. D. King, and R. J. Bobbie, 1979, Determination of the sedimentary microbial biomass by extractable lipid phosphate: Oecologia 40:51-62.

White, D. C., H. C. Pinkart, and D. B. Ringelberg, 1997, Biomass measurements: Biochemical approaches, p. 91-101: In C. J. Hurst, G. R. Knudsen, M. J. McInerney, L. D. Stetzenbach, and M. V. Walter (eds.), Manual of Environmental Microbiology. ASM Press, Washington, DC.

White, D. C., and D. B. Ringelberg, 1995, Utility of signature lipid biomarker analysis in determining in situ viable biomass, community structure, and nutritional / physiological status of the deep subsurface microbiota: In P. S. Amy and D. L. Halderman (ed.), The microbiology of the terrestrial subsurface. CRC Press, Boca Raton.

White, D. C., and Ringelberg, D. B., 1998, Signature lipid biomarker analysis, p. 255-272: In R.S. Burlage, R. Atlas, D. Stahl, G. Geesey and G. Sayler (eds.), Techniques in Microbial Ecology. Oxford University Press, New York.

White, D. C., J. O. Stair, and D. B. Ringelberg, 1996, Quantitative comparisons of in situ microbial biodiversity by signature biomarker analysis: Journal of Industrial Microbiology 17:185-196.

Wiedemeier, T.H., Wilson, J.T., Kampbell, D.H., Miller, R.N., and Hansen, J.E., 1995, Technical protocol for implementing intrinsic remediation with long-term monitoring for natural attenuation of fuel contamination dissolved in groundwater: US Air Force Center for Environmental Excellence, San Antonio, Texas.

Wiedemeier, T.H., Swanson, M.A., Moutoux, D.E., Wilson, J.T., Kampbell, D.H., Hansen, J.E., and Haas, P., 1996a, Overview of the Technical Protocol for Natural Attenuation of 
WSRC-TR-2003-00331

December 31, 2004

Chlorinated Aliphatic Hydrocarbons under Development for the U.S. Air Force Center for Environmental Excellence: EPA/540/R-96/509, p. 35-59.

Wiedemeier, T.H., Swanson, M.A., Wilson, J.T., Kampbell, D.H., Miller, R.N., and Hansen, J.E., 1996b, Approximation of biodegradation rate constants for monoaromatic hydrocarbons (BTEX) in groundwater: Groundwater Monitoring and Remediation, v. 16, no. 3, Summer 1996, p. 186-194.

Wiedemeier, T.H., Swanson, M.A., Moutoux, D.E., Gordon, E.K., Wilson, J.T., Wilson, B.H., Kampbell, D.H., Hansen, J.E., Haas, P., and Chapelle, F.H., 1998, Technical Protocol for Evaluating the Natural Attenuation of Chlorinated Solvents Dissolved in Groundwater, Air Force Center for Environmental Excellence, San Antonio, Texas.

Wiedemeier, T.H., Rifai, H.S., Newell, C.J., and Wilson, J.T., 1999, Natural Attenuation of Fuels and Chlorinated Solvents in the Subsurface: John Wiley \& Sons, New York, New York, $617 \mathrm{p}$.

Wiedemeier, T.H., and Haas, P.E., 2002, Designing Monitoring Programs to Evaluate the Performance of Natural Attenuation: Ground Water Monitoring and Remediation, Summer 2002. 